Florida International University FIU Digital Commons

FIU Electronic Theses and Dissertations

University Graduate School

5-30-2018

\title{
Structure and Mechanism of Mycobacterial Topoisomerase I
}

nan cao

Florida International University, ncao001@fiu.edu

DOI: 10.25148 /etd.FIDC006890

Follow this and additional works at: https:// digitalcommons.fiu.edu/etd

Part of the Biochemistry Commons, Molecular Biology Commons, and the Other Biochemistry, Biophysics, and Structural Biology Commons

\section{Recommended Citation}

cao, nan, "Structure and Mechanism of Mycobacterial Topoisomerase I" (2018). FIU Electronic Theses and Dissertations. 3747. https://digitalcommons.fiu.edu/etd/3747

This work is brought to you for free and open access by the University Graduate School at FIU Digital Commons. It has been accepted for inclusion in FIU Electronic Theses and Dissertations by an authorized administrator of FIU Digital Commons. For more information, please contact dcc@fiu.edu. 


\title{
FLORIDA INTERNATIONAL UNIVERSITY
}

Miami, Florida

\section{STRUCTURE AND MECHANISM OF MYCOBACTERIAL TOPOISOMERASE I}

\author{
A dissertation submitted in partial fulfillment of \\ the requirements for the degree of \\ DOCTOR OF PHILOSOPHY \\ in \\ BIOCHEMISTRY \\ by \\ Nan Cao
}

2018 
To: Dean Michael R. Heithaus

College of Arts, Sciences and Education

This dissertation, written by Nan Cao, and entitled Structure and Mechanism of Mycobacterial Topoisomerase I, having been approved in respect to style and intellectual content, is referred to you for judgment.

We have read this dissertation and recommend that it be approved.

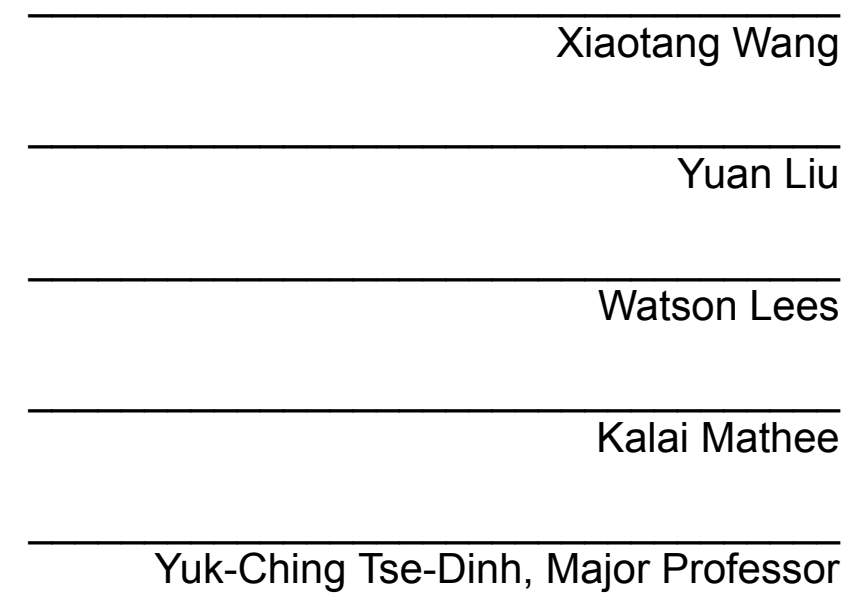

Date of Defense: May 30, 2018

The dissertation of Nan Cao is approved.

Dean Michael R. Heithaus College of Arts, Sciences and Education

Andrés G. Gil Vice President for Research and Economic Development and Dean of the University Graduate School

Florida International University, 2018 
(C) Copyright 2018 by Nan Cao

All rights reserved. 


\section{DEDICATION}

I dedicate this dissertation to all my family members for their support and encouragement. 


\section{ACKNOWLEDGMENTS}

I would like to thank all the people who helped and supported me during my Ph.D. study period. First of all, I express my thanks to my advisor, Dr. YukChing Tse-Dinh, for her advice, patience and support. With her excellent and experienced mentorship, I gathered valuable experience for scientific research, presentation and writing.

I would like to thank our collaborator Dr. Kemin Tan for his work on the crystal structures, which supported my dissertation a lot.

I would like to thank my committee members, Dr. Wang, Dr. Liu, Dr. Lees and Dr. Mathee for their assistance, advice and support throughout my Ph.D. study.

I would like to thank all my lab members, Dr. Thirunavukkarasu Annamalai, Dr. Qingxuan Zhou, Dr. Srikanth Banda, Dr. Shayna Sandhaus, Pamela Garcia and Wenjie Wang for their help. 


\section{ABSTRACT OF THE DISSERTATION \\ STRUCTURE AND MECHANISM OF MYCOBACTERIAL TOPOISOMERASE I}

by

Nan Cao

Florida International University, 2018

Miami, Florida

Professor Yuk-Ching Tse-Dinh, Major Professor

The enzyme DNA topoisomerase I is an essential enzyme that plays an important role in eukaryotic and prokaryotic cellular processes such as DNA replication, transcription, recombination and repair. Mycobacterium tuberculosis topoisomerase I (MtTOP1) is a validated drug target for antituberculosis treatment. Mycobacterial topoisomerase I regulates the topological constraints in chromosomes and helps in maintaining the growth of mycobacteria. The $\mathrm{N}$ terminal domain (NTD) of mycobacterial topoisomerase I contains conserved catalytic domains that along with the active site Tyrosine are involved in cleaving and rejoining a single strand of DNA. Magnesium is required in DNA cleavage activity of type IA topoisomerases. The C-terminal domain (CTD) of mycobacterial topoisomerase $\mathrm{I}$ is divided into four subdomains (D5-D8) and a positively charged tail. Each subdomain has a GxxGPY sequence motif. The DNA binding, relaxation, cleavage, religation, catenation and decatenation ability of each subdomains of CTD were studied. The present study shows that each 
subdomain has its own characteristics. Subdomain D8 and D7 are responsible for maintaining the relaxation activity of mycobacterial topoisomerase I. Subdomain D5 is essential to maintain the DNA cleavage, religation, catenation and decatenation activity. A new crystal structure of MtTOP1-704t (amino acids A2-T704 containing NTD+D5 domains) was obtained. Structures with ssDNA substrate bound to the active site (Y342) in the presence and absence of $\mathrm{Mg}^{2+}$ were also investigated. Significant enzyme conformational changes upon DNA binding place the catalytic tyrosine in a pre-transition position for cleavage of a specific phosphodiester linkage to form a covalent intermediate. Meanwhile, the enzyme/DNA complex with $\mathrm{Mg}^{2+}$ bound at active site may present the posttransition state for religation in the enzyme's multiple-state DNA relaxation activity. The critical function of a strictly conserved glutamic acid in acid-base catalysis of the DNA cleavage step was also demonstrated by site-directed mutagenesis. The present work provides new functional insights into the more stringent requirement for DNA rejoining versus cleavage by type IA topoisomerase, and further establishes the potential for select interference of DNA rejoining via specific inhibitors. 


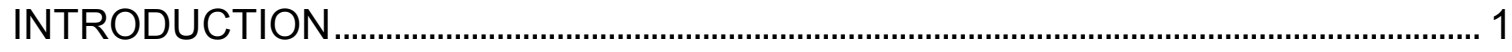

I.1 Tuberculosis ......................................................................................................................

I.2 The prevention and treatment of tuberculosis .........................................................

I.3 DNA topology ...........................................................................................................6

I.4 DNA topoisomerases................................................................................................9

I.4.1 Classification of DNA topoisomerases ...............................................................

I.4.2 Type II topoisomerases ........................................................................................

I.4.3 Type I topoisomerases .................................................................................. 15

I.4.4 The cellular function of DNA topoisomerases ..............................................2

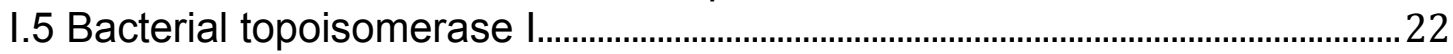

I.5.1 E. coli type IA topoisomerases .......................................................................22

I.5.2 Mycobacterial topoisomerase I........................................................................25

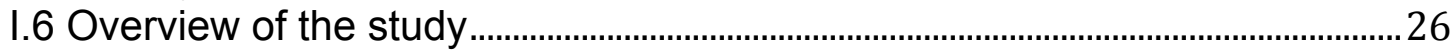

CHAPTER 1: MECHANISM AND FUNCTION OF SUBDOMAINS IN MYCOBACTERIAL TOPOISOMERASE I C-TERMINAL DOMAIN............................28

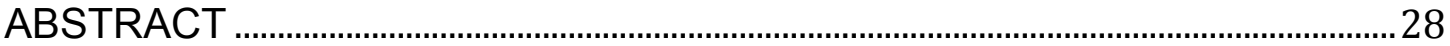

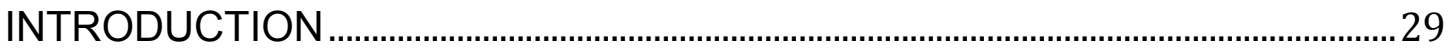

MATRIALS AND METHOD ............................................................................................. 34

Construction of plasmids and clones ....................................................................34

Protein expression and purification........................................................................39

Complementation of topA temperature sensitive mutation in E. coli AS17

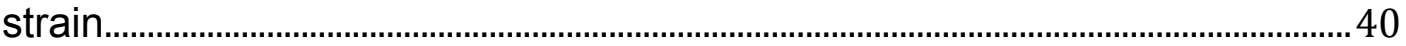

Electrophoretic mobility shift assay (EMSA) ………………………………….....4

Cleavage assay ............................................................................................................. 43

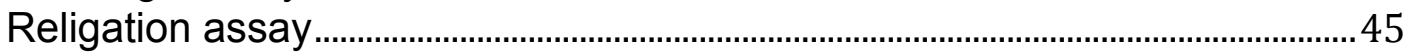

Catenation assay .........................................................................................................4

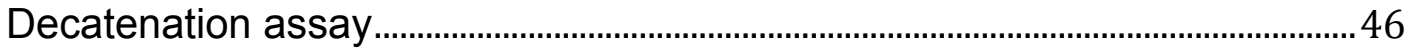

RESULTS ........................................................................................................... 47

Complementation of topA temperature sensitive mutation in E. coli AS17 by recombinant mycobacterial topoisomerase I...................................................4

Relaxation assay of mycobacterial topoisomerase I with negatively

supercoiled DNA.

Mycobacterial topoisomerase I truncated mutant proteins with C-terminal subdomain D5 only have reduced binding to oligonucleotide STS32 and MT3

Cleavage activity of mycobacterial topoisomerase I with 32 nucleotide long STS32 and 25 nucleotide long MT2 substrate. 
Cleavage assay of mycobacterial topoisomerase I with short

oligonucleotides

Cleavage oligonucleotide MT3 in the presence of Mg (II)

Religaton assay of mycobacterial topoisomerase I with oligonucleotide

STS32

Catenation assay and decatenation assay

DISCUSSION

\section{CHAPTER 2: TYPE IA TOPOISOMERASE MECHANISM-ACTIVE SITE} STRUCTURE AND INTERACTIONS ...............................................................................78

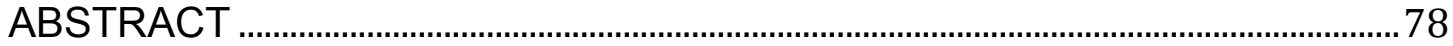

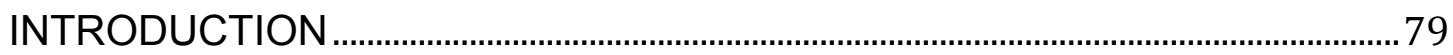

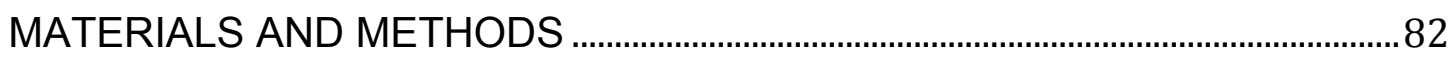

Cloning, expression and purification .......................................................................... 82

Cleavage assay ..................................................................................................... 84

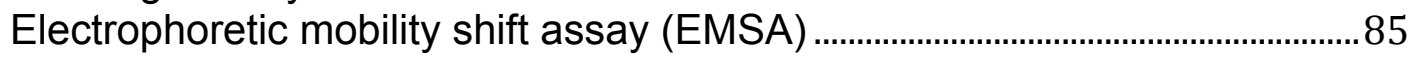

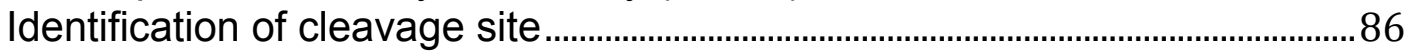

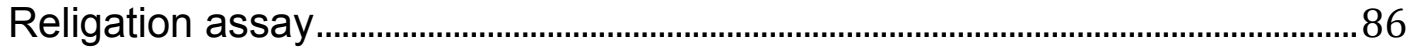

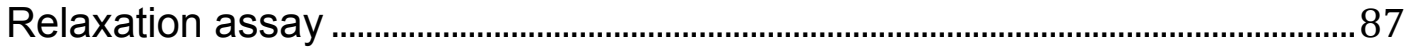

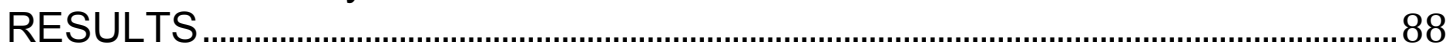

Cleavage and religation activity assay of MtTOP1-704t with

oligonucleotide MTS2-13......................................................................................... 88

The crystal structure of MtTOP1-704t .................................................................. 91

Co-crystals of MtTOP1-704t with short ssDNA substrates .................................93

Conformation of ssDNA substrate and its kink ...................................................95

Active-site conformation in the absence of $\mathrm{Mg}^{2+}$-binding.................................... 97

Structure of active site with bound $\mathrm{Mg}^{2+}$ ions........................................................99

Mapping of exact cleavage site on single-stranded oligonucleotide

substrates

Requirement of the strictly conserved Glu24 carboxyl side chain for DNA

cleavage

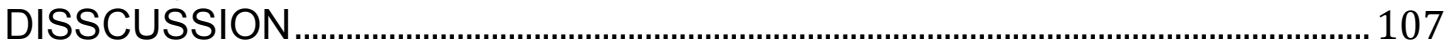

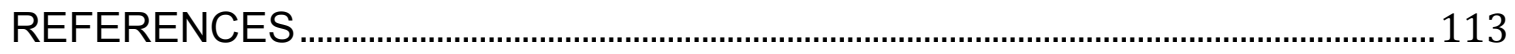

VITA 


\section{LIST OF TABLES}

TABLE

PAGE

Table I.1 Basic structure, mechanism and properties of different DNA

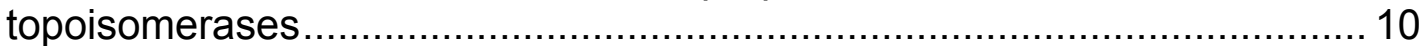

Table I.2 Subfamilies of DNA topoisomerases (Wang, 2002) .......................... 11

Table 1.1 The construction of wild-type and mutant recombinant mycobacterial topoisomerase I clones that include the residues shown in the brackets. .......... 33

Table 1.2 Primer sequences used for clone construction

Table 1.3 Methods and materials used for site directed mutagenesis of

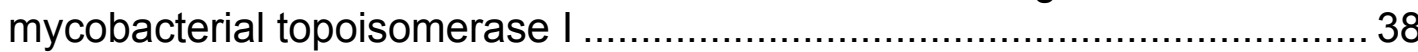

Table 1.4 Oligos used in cleavage assay. Arrows indicate the cleavage site ..... 44 Table 1.5 Product analysis of religation activity of wild-type and mutant mycobacterial topoisomerase I with oligonucleotide STS32 substrate ........ 72

Table 2.1 Primers used for site-directed mutagenesis. 84

Table 2.2 Oligonucleotides used for mycobacterial activity assay 85 


\section{LIST OF FIGURES}

FIGURE

PAGE

Figure I.2 Drugs and vaccine development history of TB treatment ................... 4

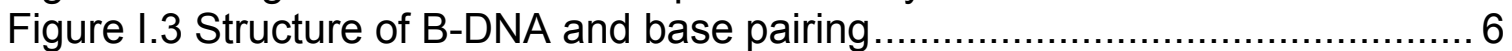

Figure I.4 The simple knots and catenanes. ............................................ 7

Figure I.5 The generation of supercoiling during transcription and replication...... 8

Figure I.6 Catalysis of transient breakage of DNA by type IA DNA

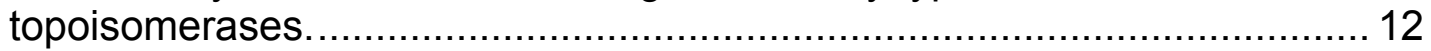

Figure I.7 Catalytic reactions of type II topoisomerases ................................ 13

Figure I.8 Crystal structure of S. cerevisiae type II topoisomerase ................... 15

Figure I.9 Catalytic reactions of type I topoisomerases ............................... 16

Figure I.10 Proposed mechanism of type IA topoisomerase ......................... 18

Figure I.11 Comparison of topoisomerase I sequences from various bacterial

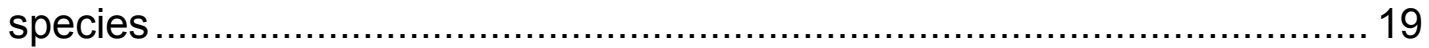

Figure I.12 Topoisomerase function in replication elongation ........................ 22

Figure I.13 Structures of EcTOP I and EcTOP III. ..................................... 24

Figure 1.1 The subdomain organization of mycobacterial topoisomerase I........32

Figure 1.2 Division of the C-terminal domain of M. tuberculosis topoisomerase I in four subdomains and a flexible tail ............................. 32

Figure 1.3 Growth of $E$. coli AS17 complemented by recombinant mycobacterial topoisomerase $\mathrm{I}$ at $30^{\circ} \mathrm{C}$ and $42^{\circ} \mathrm{C}$ in LB agar plates. ........ 48

Figure 1.4 Relaxation assays of serially diluted wild-type and mutant MsTOP1 with negatively supercoiled pBAD/Thio DNA. .....................................5 51

Figure 1.5 Relaxation assays of serially diluted wild-type and mutant MtTOP1 with negatively supercoiled $\mathrm{pBAD} / \mathrm{Thio}$ DNA

poisomerase I with negatively supercoiled pBAD/Thio DNA ...........................53

Figure 1.7 Relaxation time course for wild-type MsTOP1 and MsTOP1-839t with negatively supercoiled pBAD/Thio DNA. .....................................5 54

Figure 1.8 Electrophoretic mobility shift assay for formation of non-covalent complex between labeled STS32 oligonucleotide and mycobacterial

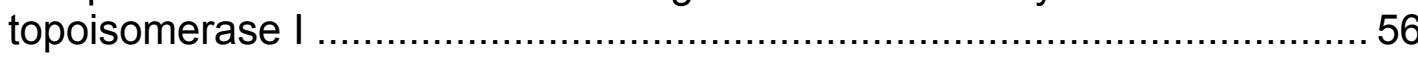

Figure 1.9 Electrophoretic mobility shift assay of MtTOP1, MtTOP1-704t, MsTOP1 and MsTOP1-701t with labeled MT3 oligonucleotide. ................. 57

Figure 1.10 Cleavage activity assay wild-type MtTOP1, MtTOP1-910t, MtTOP1-840t, MtTOP1-786t and MtTOP1-704t with STS32 substrate. ...... 60

Figure 1.11 Cleavage activity assay of wild-type MsTOP1, MsTOP1-909t, MsTOP1-839t, MsTOP1-785t and MsTOP1-701t with STS32 substrate..... 61

Figure 1.12 Cleavage activity assay of wild-type MsTOP1, MsTOP1-909t, MsTOP1-839t, MsTOP1-785t and MsTOP1-701t with MT2 substrate. 62

Figure 1.13 Cleavage of MT2 substrate by MtTOP1-704t is more robust than wild-type MtTOP1.

Figure 1.14, Cleavage of short 13-14 base long oligo by MtTOP1-704t but 
not wild-type MtTOP1

Figure 1.15 Cleavage activity assay of wild-type MsTOP1, MsTOP1-909t, MsTOP1-839t, MsTOP1-785t and MsTOP1-701t with MT3 oligonucleotide substrate.

Figure 1.16 Cleavage activity assay of wild-type MtTOP1, MtTOP1-840t, MtTOP1-786t and MtTOP1-704t with MT3 oligonucleotide substrate. ........67 67

Figure 1.17 Cleavage of short oligonucleotide MT3 in the presence of Mg (II)...69

Figure 1.18 Comparison of religation activity of wild-type and mutant mycobacterial topoisomerase I with oligonucleotide STS32 substrate........ 71

Figure 1.19 Catenation of single-stranded M13mp18DNA by MsTOP1, MtTOP1 and MtTOP1-704t ........................................................... 74

Figure 1.20 Decatenation of kDNA network by MtTOP1 and MtTOP1 704t ....... 74

Figure 2.1 Assay of MTS2-13 cleavage by wild-type MtTOP1 and

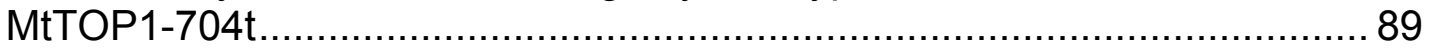

Figure 2.2 Religaton assay of MtTOP1-704t with MTS2-13 .......................... 90

Figure 2.3 The crystal structure of MtTOP1-704t ........................................ 92

Figure 2.4 Structure of MtTOP1-704t/ssDNA complex ................................... 94

Figure 2.5 Conformation of ssDNA substrate and its interaction to

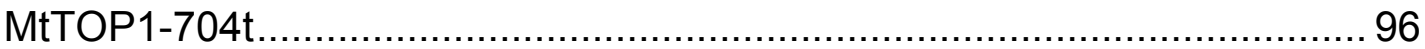

Figure 2.6 Active sites in the absence and in the presence of Mg2+ .............. 100

Figure 2.7 Identification of cleavage site with MTS2-11, MTS2-13 and STS32 oligonucleotide substrate.

Figure 2.8 Substitutions in MtTOP1 E24 prevent relaxation of supercoiled DNA and ssDNA cleavage by the enzyme without affecting non-covalent DNA binding 105

Figure 2.9 Substitutions in MsTOP1-E21 prevent ssDNA cleavage by the enzyme 106

Figure 2.10 Proposed schemes for DNA cleavage and religation 108 


\section{ABBREVIATIONS AND ACRONYMS}

$\begin{array}{ll}\text { ATP } & \text { Adenosine triphosphate } \\ \text { BCG } & \text { Bacille Calmette-Guérin } \\ \text { BSA } & \text { Bovine serum albumin } \\ \text { CsCl } & \text { Caesium chloride } \\ \text { CTD } & \text { C-terminal domain } \\ \text { dsDNA } & \text { Double-stranded DNA } \\ \text { DTT } & \text { Dithiothreitol } \\ \text { E. coli } & \text { Escherichia coli } \\ \text { EcTOP I } & \text { E. coli topoisomerase I } \\ \text { EcTOP III } & \text { E. coli topoisomerase III } \\ \text { EDTA } & \text { Ethylenediaminetetraacetic acid } \\ \text { EMSA } & \text { Electrophoretic mobility shift assay } \\ \text { HCI IPTG } & \text { Hydrochloric Acid } \\ \text { KCl } & \text { Isopropyl } \beta \text {-D-1-thiogalactopyranoside } \\ \text { kDa } & \text { Potassium chloride } \\ \text { KDNA } & \text { kilo Dalton } \\ \text { KH }{ }_{2} \text { PO } & \text { kinetoplast DNA } \\ \text { LB } & \text { Potassium phosphate monobasic } \\ \text { M. smegmatis } & \text { Mycobacterium smegmatis } \\ & \end{array}$




\begin{tabular}{|c|c|}
\hline M. tuberculosis & Mycobacterium tuberculosis \\
\hline MDR-TB & Multidrug resistant tuberculosis \\
\hline $\mathrm{MgCl}_{2}$ & Magnesium chloride \\
\hline MsTOP1 & Mycobacterium smegmatis topoisomerase I \\
\hline MTS & Mycobacterial Topoisomerase Substrate \\
\hline MtTOP1 & Mycobacterium tuberculosis topoisomerase I \\
\hline $\mathrm{NaCl}$ & Sodium chloride \\
\hline $\mathrm{NaH}_{2} \mathrm{PO}_{4}$ & Sodium phosphate monobasic \\
\hline NTD & $\mathrm{N}$-terminal domain \\
\hline OD & Optical density \\
\hline PCR & Polymerase chain reaction \\
\hline SDS-PAGE & $\begin{array}{l}\text { Sodium dodecyl sulfate polyacrylamide gel } \\
\text { electrophoresis }\end{array}$ \\
\hline ssDNA & Single-stranded DNA \\
\hline TAE & Tris-acetate-EDTA \\
\hline TB & Tuberculosis \\
\hline TBE & Tris-Borate- EDTA \\
\hline TEV & Tobacco etch virus protease \\
\hline TopA & Topoisomerase I \\
\hline TOPIla & Topoisomerase Ila \\
\hline TOPIß & Topoisomerase II $\beta$ \\
\hline Topo I & Type I topoisomerase \\
\hline Topo II & Type II topoisomerase \\
\hline
\end{tabular}


TOPRIM

UV

XDR-TB
Topoisomerase-primase domain

Ultraviolet

Extensively resistant tuberculosis 


\section{INTRODUCTION}

\section{I.1 Tuberculosis}

Tuberculosis (TB) is a fatal airborne disease. It is a global health problem and kills millions of people annually. In 2016, 6.3 million new TB cases were reported, and 1.3 million people died from TB worldwide. The World Health Organization (WHO) estimates that 10.4 million people are currently infected by TB. Most of the new cases are in low-income countries in Asia and African. As TB is one of the top causes of human mortality (Fogel, 2015), much effort has been devoted to diagnosis, prevention and treatment TB. The world health organization's end TB strategy plans to stop TB in 2030 2035 (WHO, 2017).

Mycobacterium tuberculosis (M. tuberculosis) is a pathogenic bacterium and is the cause of TB (Tang et al., 2016). The genome of Mycobacterium tuberculosis H37RV was sequenced, and pathogenic factors were characterized (Glickman and Jr., 2001). Mycobacterium tuberculosis is mainly transmitted in the aerosol droplet and passes through the upper respiratory tract. Mycobacterium tuberculosis infects lungs, but the infection also involves other organs (Piccini et al., 2014). Mycobacterium tuberculosis has the characteristics of both Gram-negative and Gram-positive bacteria (Fu and Fu-Liu, 2002). The cell wall of Mycobacterium tuberculosis is distinctive and impermeable. It is difficult to characterize between Gram-negative and Gram-positive cell wall. The thick outer layer membrane contains mycolic acid and outermost capsule 
composed of polysaccharides (Jankute et al., 2015). The three basic structure component of Mycobacterium tuberculosis cell wall are, long-chain mycolic acids, highly branched arabinogalactan based polysaccharide, and cross-linked network of peptidoglycan (Figure I.1) (Bhat et al., 2017; Jankute et al., 2015; Smith, 2017).

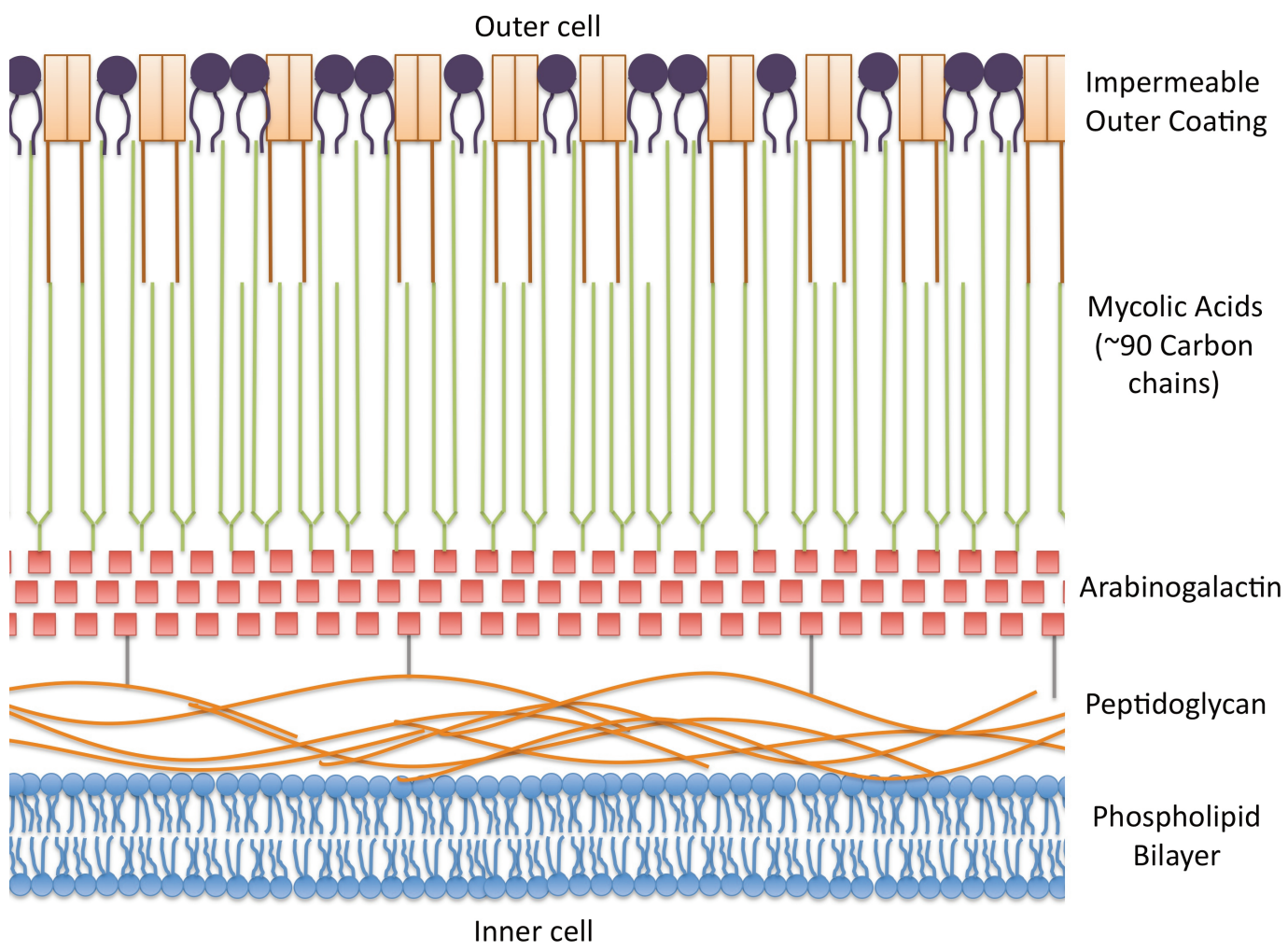

Figure I. 1 The basic structure of Mycobacterium tuberculosis cell wall (Smith, 2017) 
When $M$. tuberculosis initially infects the host, the infection phase is asymptotic, and this is called the latent phase (Lipworth et al., 2016). The innate immune and adaptive immune system of the human body will react to the bacillus invasion (Jacobs et al., 2016), by the development of antibodies and macrophage phagocytosis (Delogu et al., 2013; Jacobs et al., 2016). In the latent phase, the innate and adaptive immune system defenses can control the reproduction of $M$. tuberculosis in the lung by macrophages, neutrophils, monocytes, dendritic cells, and T cells (Fogel, 2015; Pieters, 2008). If the balance of immune system regulation is disturbed, the growth of $M$. tuberculosis in the host out of control, M. tuberculosis develops new ways to survive under immune defense (Pieters, 2008). The reactivation of dormant M. Tuberculosis causes tuberculosis (Venketaraman et al., 2015). The active tuberculosis is also called TB disease (Pai et al., 2016). Patients with TB disease are infectious and spread $M$. tuberculosis through the air. About $15 \%$ of latent tuberculosis cases will develop into active tuberculosis during the total lifetime (Connell et al., 2011). Another issue with TB disease is that $10 \%$ of HIV positive patients are coinfected with TB (Connell et al., 2011; Sulis et al., 2014).

\section{I.2 The prevention and treatment of tuberculosis}

Decades of global efforts are developing and discovering new prevention and treatment method to eliminate TB transmission and activation (Figure I.2). Bacille Calmette-Guérin (BCG) is a vaccine developed from Mycobacterium bovis strain. It was first used in the 1920s (Kaufmann, 2013). Although the 
mechanism of BCG is not well identified, it is the only licensed vaccine to against TB (Kaufmann, 2013). Bacille Calmette-Guérin could prevent TB efficiently when it is given in infancy or childhood (Sridevi et al., 2015; Venturini et al., 2014). The meta-analysis study shows the protection ability declines after 10 year (Abubakar et al., 2013; Alsdurf et al., 2016). Thus the TB disease occurs in adults and adolescents (Tang et al., 2016). Studies reported new TB vaccines, and some TB vaccine candidates are already in clinical tests, such as recombinant BCG and vaccine isolated from M. tuberculosis (Chawla et al., 2014; Pai et al., 2016).
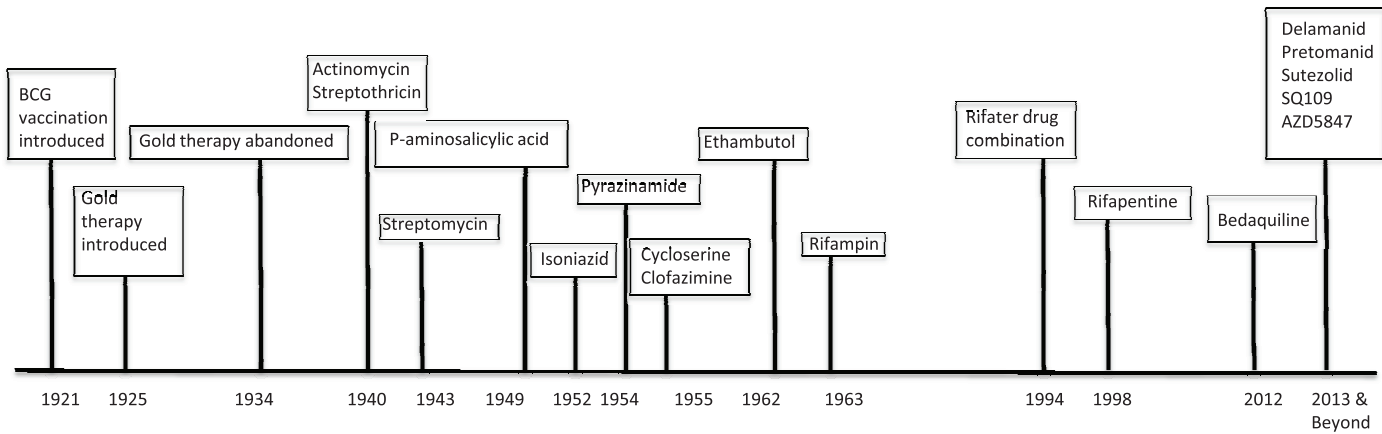

Figure I.2 Drugs and vaccine development history of TB treatment (Podany and Swindells, 2016)

The TB treatment drugs include first-line TB agents and second-line TB agents. The first line antituberculosis reagents include isoniazid, rifampicin, pyrazinamide, and ethambutol (Wilby et al., 2014). The second line antituberculosis reagents include Amikacin capreomycin, ciprofloxacin, cycloserine, ethionamide, kanamycin, ofloxacin, P-aminosalicylic acid and other drugs (Nath and Ryoo, 2013). The cell wall of M. tuberculosis is impermeable to 
noxious compounds and drugs. Many drugs target $M$. tuberculosis cell walls, such as isoniazid, ethambutol, ethionamide and other drugs (Smith, 2017). Fluoroquinolones are being considered as new first-line agents (Takiff and Guerrero, 2011). Fluoroquinolones inhibit the function of DNA gyrase in $M$. tuberculosis. Other drugs inhibit fatty acid biosynthesis, protein biosynthesis, DNA based process and other metabolic processes (Janin, 2007).

The challenge of the treatment of TB is drug-resistant tuberculosis. Under the pressure of drug treatment, $M$. tuberculosis develops mutations to escape death. Drug treatment always fails in these situations. Drug-resistant tuberculosis includes multidrug-resistant tuberculosis (MDR-TB) and extensively drug-resistant tuberculosis (XDR-TB). Multidrug-resistant tuberculosis is identified as being resistant to at least two first-line agents, especially isoniazid and rifampicin (Mishra et al., 2015). Extensively drug-resistant tuberculosis is identified as MDR-TB plus resistance to at least one fluoquinolone, and at least one of the three injectable second-line agents (amikacin, capreomycin, or kanamycin) (Jassal and Bishai, 2009). The mechanisms for drug resistance are complex. Mycobactrium tuberculosis develops mutations that lead to drug resistance during drug treatment. In isoniazid-resistant $M$. tuberculosis, mutations of gene katG, ahpC, and inhA have been identified (Nath and Ryoo, 2013; Wilby et al., 2014). The katG gene is essential for $M$. tuberculosis. It is required for converting isoniazid to its active form (Ameeruddin and Luke Elizabeth, 2014). Activated isoniazid targets at cell wall and inhibits the synthesis of mycolic acids, 
which is essential for the cell wall of $M$. tuberculosis. Other challenges to TB treatment include first-line antituberculosis agents being given to patients for 18 weeks (Pai et al., 2016). The first-line drugs are efficient for overcoming tuberculosis, but MDR-TB and longtime treatments are challenges to treat tuberculosis. There are urgent needs for new therapeutic drugs to shorten the treatment period and kill $M$. tuberculosis with drug-resistant mutations.

\section{I.3 DNA topology}

DNA molecules exist in different forms (Dai and Rothma-Denes, 1999; Kouzine et al., 2014). Among these forms, B-DNA molecule is the most common form. B-DNA is a right-handed double helix with 10 base pairs per complete turn of the helix (Wang, 1979). The two-polynucleotide chains are associated by hydrogen bonding. They are antiparallel. Watson and Crick proposed this DNA double helix model in 1953. The DNA double helix model was found in physiological conditions by X-ray crystallography by Franklin. Complementary base pairing is featured in this model (Adenine-Thymine, Guaninecytosine)(Figure I.3).
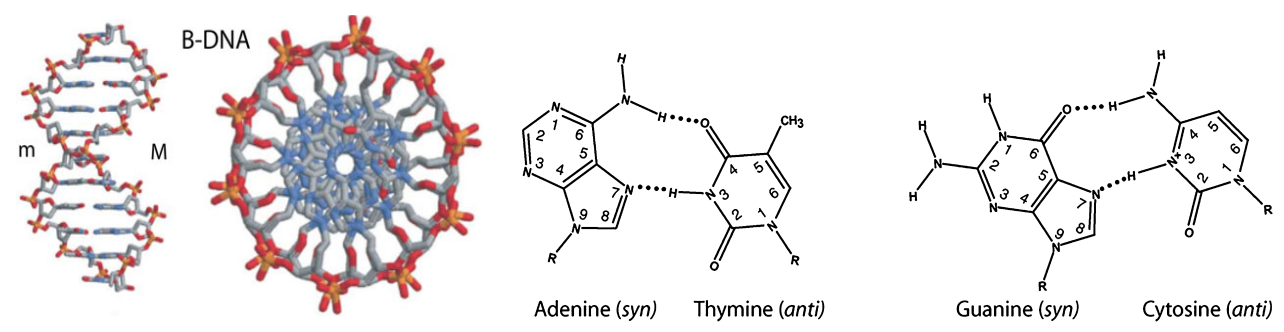

Figure I.3 Structure of B-DNA and base pairing. (Travers and Muskhelishvili, 2015) 
In eukaryotic and prokaryotic organisms, genomic DNA carries coded information. It is crucial for the cellular process to maintain DNA topological structure. The topological structures of DNA molecules change during cellular processes (Vologodskii, 2010). The genomic DNA structures are dynamic and flexible. Some of them link to each other and form different topology states, such as DNA knots, and DNA catenates (Figure I.4) (Higgins and Vologodskii, 2015).

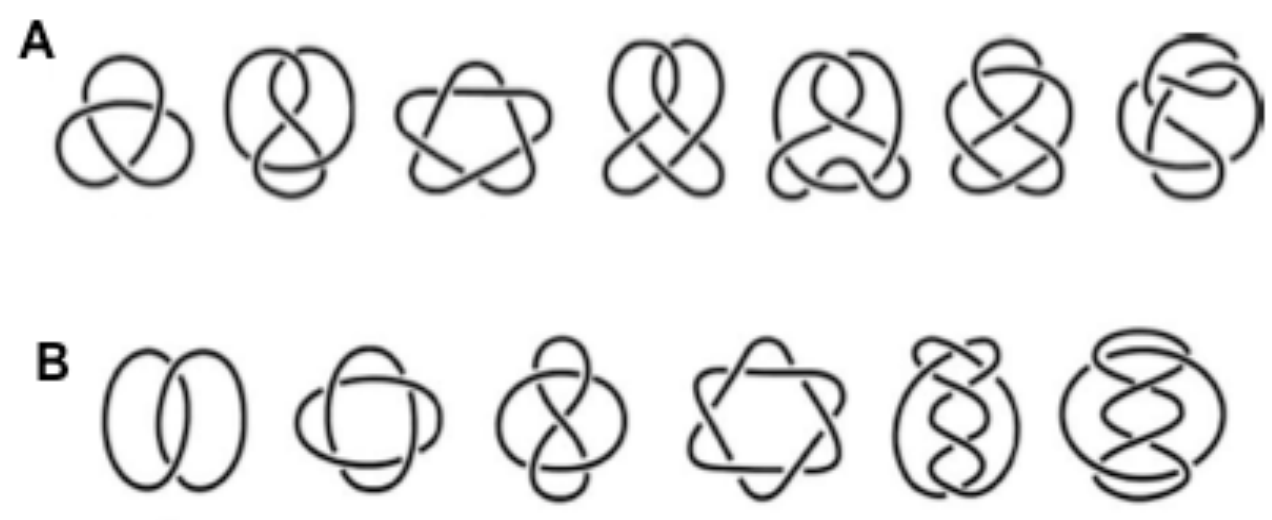

Figure I.4 The simple knots and catenanes. (A) Knots. (B) Catenanes. (Higgins and Vologodskii, 2015)

Another DNA topology state is DNA supercoiling. It is vital for DNA replication, transcription, recombination and repair processes (Magnan and Bates, 2015). Double-stranded DNA crosses the helical axis with two different hand directions. Supercoiling in DNA includes negatively supercoiled DNA and positively supercoiled DNA. Negatively supercoiled DNA is undertwisted and responsible for DNA separation (Finzi and Dunlap, 2016). Positively supercoiled 
is in the overtwisted state (Travers and Muskhelishvili, 2015). The topological structures of dsDNA change during DNA replication and recombination processes (Figure I.5). Positively supercoiled DNA is generated during the transcription process (Baranello et al., 2012). Other components such as DNA polymerases, RNA polymerase, and DNA topoisomerases are required in DNA transactions to maintain DNA topological structure (Koster et al., 2010; Seol and Neuman, 2016).
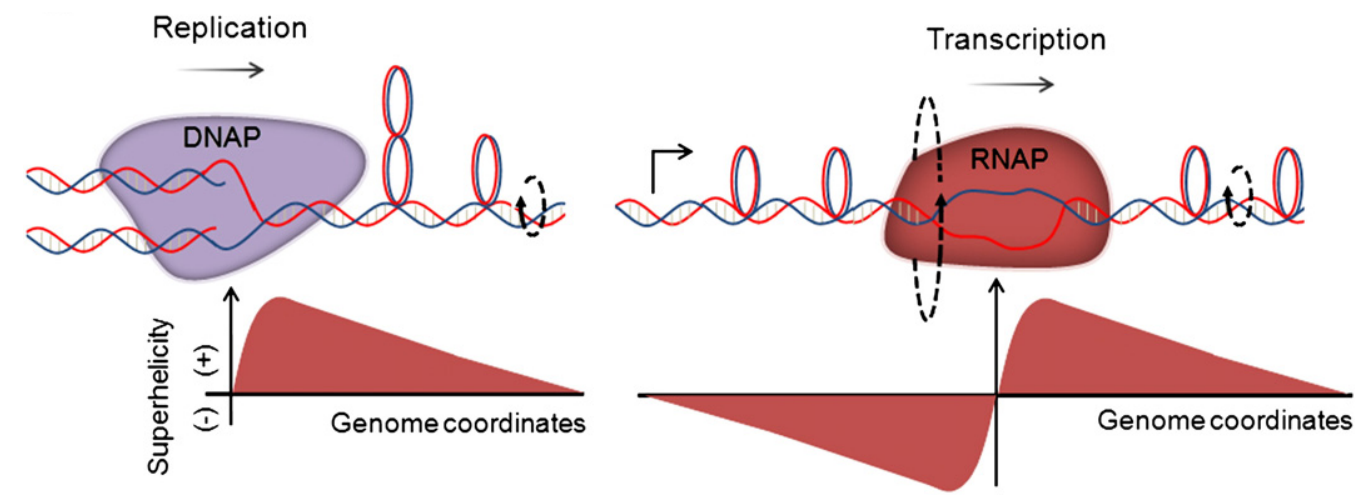

Figure 1.5 The generation of supercoiling during transcription and replication. (Baranello et al., 2012) 


\section{I.4 DNA topoisomerases}

\section{I.4.1 Classification of DNA topoisomerases}

James Wang discovered DNA topoisomerase in thr 1970s. It is called $\omega$ protein and was isolated from E. coli (Depew et al., 1978). The DNA topoisomerases are essential enzymes that are involved in DNA replication, recombination, transcriptional and repair processes. They regulate DNA topology during these processes. These enzymes are ubiquitous in both eukaryotes and prokaryotes. On the basis of the properties and mechanisms of DNA topoisomerases (Table I.1), they are divided into two types: type I topoisomerase and type II topoisomerases. The structure of type I topoisomerases is a monomer. They regulate DNA topology by a singlestranded DNA passage mechanism. The DNA type I topoisomerases cleave and rejoin a single strand of DNA (Corbett and Berger, 2004). Type II topoisomerase modify DNA topology by a double-stranded DNA passage mechanism, which is ATP-dependent. There are three sub-types of type I topoisomerases, type IA topoisomerase, type IB topoisomerase and type IC topoisomerase. Type II topoisomerases include type IIA topoisomerase and type IIB topoisomerases (Table I.2). 


\begin{tabular}{|c|c|c|c|c|c|c|c|c|c|c|c|c|c|c|}
\hline \multirow{3}{*}{\multicolumn{2}{|c|}{ Topoisomerase }} & \multirow[b]{3}{*}{ Type } & \multirow{3}{*}{$\begin{array}{l}\text { Enzyme } \\
\text { structure }\end{array}$} & \multirow{3}{*}{$\begin{array}{l}\text { No. of DNA } \\
\text { strands } \\
\text { cleaved }\end{array}$} & \multirow{3}{*}{$\begin{array}{l}5^{\prime} \text { or } 3^{\prime} \\
\text { bond } \\
\text { formed }\end{array}$} & \multirow{3}{*}{$\begin{array}{l}\text { Proposed } \\
\text { mechanism }\end{array}$} & \multirow{3}{*}{$\begin{array}{l}\text { ATP } \\
\text { dependent }\end{array}$} & \multirow{3}{*}{$\begin{array}{l}\text { Mg(II) } \\
\text { dependent }\end{array}$} & \multicolumn{6}{|c|}{ Activities } \\
\hline & & & & & & & & & \multirow{3}{*}{$\begin{array}{l}\text { Catenation/ } \\
\text { decatenation } \\
\text { Yes }^{c}\end{array}$} & \multirow{3}{*}{$\begin{array}{l}\text { Knotting/ } \\
\text { unknotting } \\
\text { Yes }^{c}\end{array}$} & \multicolumn{2}{|c|}{ Relaxation } & \multicolumn{2}{|c|}{ Supercoiling } \\
\hline & & & & & & & & & & & $-v e^{b}$ & $+\mathrm{ve}^{b}$ & -ve & $+v e$ \\
\hline \multirow[t]{2}{*}{ Topo I } & Bacterial & IA & Monomer & 1 & $5^{\prime}$ & Strand passage & No & Yes & & & Yes & No & No & No \\
\hline & Eukaryotic & IB & Monomer & 1 & $3^{\prime}$ & $\begin{array}{l}\text { Controlled } \\
\text { rotation }\end{array}$ & No & No & Yes $^{c}$ & Yes $^{c}$ & Yes & Yes & No & No \\
\hline \multicolumn{2}{|l|}{ Topo II } & IIA & Homo-dimer & 2 & $5^{\prime}$ & Strand passage & Yes & Yes & Yes & Yes & Yes & Yes & No & No \\
\hline \multicolumn{2}{|l|}{ Topo III } & IA & Monomer & 1 & $5^{\prime}$ & Strand passage & No & Yes & Yes $^{c}$ & Yes & Yes & No & No & No \\
\hline \multicolumn{2}{|l|}{ Topo IV } & IIA & Hetero-tetramer & 2 & $5^{\prime}$ & Strand passage & Yes & Yes & Yes & Yes & Yes & Yes & No & No \\
\hline \multicolumn{2}{|l|}{ Topo V } & $\mathrm{IB} / \mathrm{IC}^{a}$ & Monomer & 1 & $3^{\prime}$ & $\begin{array}{l}\text { Controlled } \\
\text { rotation }\end{array}$ & No & No & Unknown & Unknown & Yes & Yes & No & No \\
\hline \multicolumn{2}{|c|}{ Topo VI } & IIB & Hetero-tetramer & 2 & $5^{\prime}$ & Strand passage & Yes & Yes & Yes & Unknown & Yes & Yes & No & No \\
\hline \multicolumn{2}{|c|}{ DNA gyrase } & IIA & Hetero-tetramer & 2 & $5^{\prime}$ & Strand passage & Yes & Yes & $\mathrm{Yes}^{d}$ & Yes & Yes & Yes & Yes & No \\
\hline \multicolumn{2}{|c|}{ Reverse gyrase } & IA & Monomer & 1 & $5^{\prime}$ & Strand passage & Yes & Yes & No & No & Yes & No & No & Yes \\
\hline
\end{tabular}

${ }^{a}$ Topo $\mathrm{V}$ was originally described as type IB but has been proposed to form a new class (IC).

${ }^{b}$-ve indicates negatively supercoiled DNA; +ve indicates positively supercoiled DNA.

${ }^{c}$ Possible only if one substrate is nicked or single stranded.

${ }^{d}$ Decatenation by $E$. coli DNA gyrase is weak.

Table I.1 Basic structure, mechanism and properties of different DNA topoisomerases (Bush et al., 2015) 


\begin{tabular}{|l|l|}
\hline $\begin{array}{l}\text { Type IA } \\
\text { topoisomerases }\end{array}$ & $\begin{array}{l}\text { Bacterial and archael DNA topoisomerase I } \\
\text { and III } \\
\text { Yeast DNA topoisomerase III } \\
\text { Mammalian DNA topoisomerase III and III }\end{array}$ \\
\hline Type IB topoisomerases & $\begin{array}{l}\text { Eukaryotic DNA topoisomerase I } \\
\text { Mammalian mitochondrial DNA } \\
\text { topoisomerase I } \\
\text { Pox virus topoisomerase }\end{array}$ \\
\hline $\begin{array}{l}\text { Type IC } \\
\text { topoisomerases }\end{array}$ & \begin{tabular}{l} 
Methanopyrus topoisomerase V (Archael) \\
\hline $\begin{array}{l}\text { Type IIA } \\
\text { topoisomerases }\end{array}$
\end{tabular} \\
$\begin{array}{l}\text { Bacterial gyrase and DNA topoisomerase IV } \\
\text { Yeast DNA topoisomerase II } \\
\text { Mammalian DNA topoisomerase Ila and II }\end{array}$ \\
\hline $\begin{array}{l}\text { Type IIB } \\
\text { topoisomerases }\end{array}$ & Sulfolobus shibatae topoisomerase VI \\
\hline
\end{tabular}

Table I.2 Subfamilies of DNA topoisomerases (Wang, 2002)

The DNA topoisomerases cleave single or double-stranded DNA. The active site tyrosine of DNA topoisomerases attack the phosphate in the DNA backbone, an enzyme-DNA intermediate complex forms at the same time. In the intermediate forming process, the 3'-hydroxyl group of DNA leaves the DNA backbone, and the active site tyrosine of type IA and type IIA topoisomerases covalently links to the 5'-phosphate to form a phosphotyrosyl bond (Pommier, 2013). Whereas the active site tyrosine of type IB topoisomerase attacks the phosphate of the DNA group to form a 3'-phosphotyrosyl bond (Pommier, 2013; Wang, 2002). 


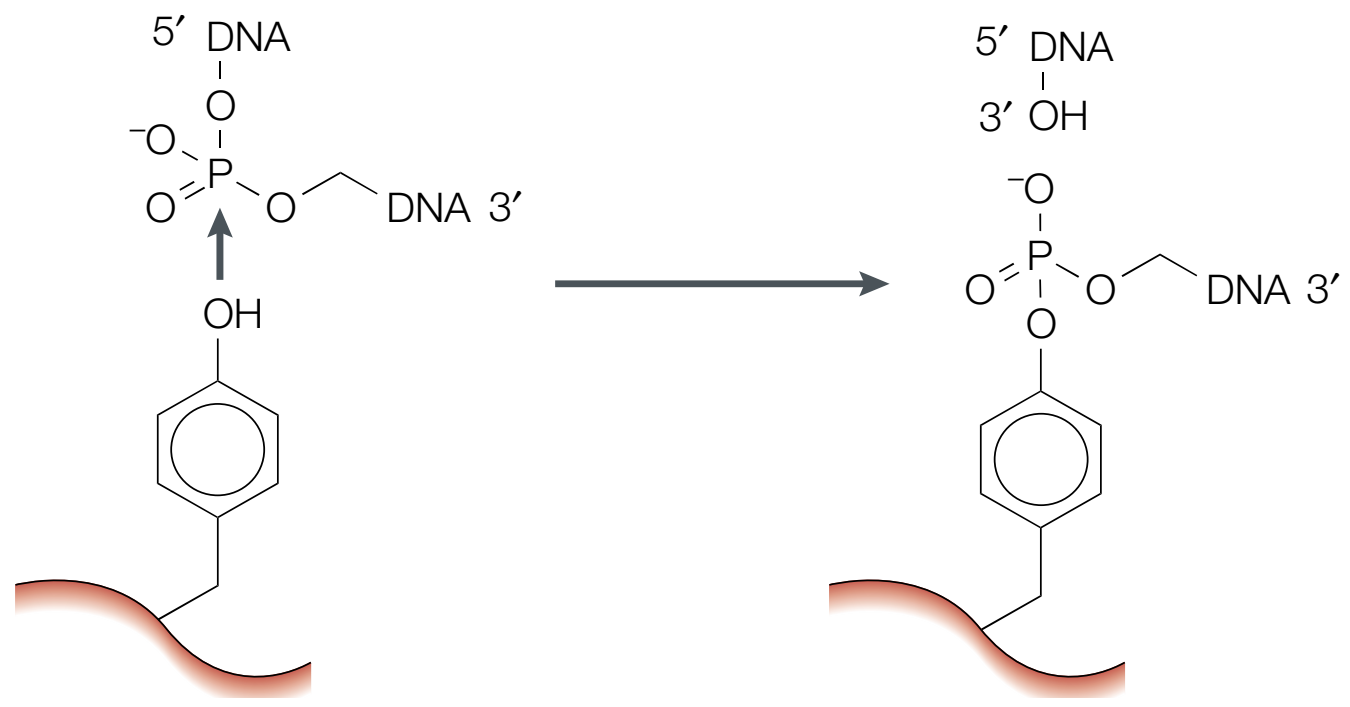

Figure I.6 Catalysis of transient breakage of DNA by type IA DNA topoisomerases (Wang, 2002).

\section{I.4.2 Type II topoisomerases}

Type II topoisomerases are essential enzymes for all organisms. Type IIA topoisomerases include bacterial DNA gyrase, topoisomerase IV and eukaryotic topoisomerase II. They cleave double-strand DNA in a DNA duplex and process DNA strand passage (Gentry and Osheroff, 2013). All Type II topoisomerases can catenate/decatenate, knot/unknot circular duplex DNA, and relax positively and negatively supercoiled DNA (Figure I.7). They are important for maintaining the stability of the DNA topological structure. In vertebrate species, Topoisomerase Ila (TOPIla) and Topoisomerase II $\beta$ (TOPII $\beta$ ) are two kinds of 
type IIA topoisomerases (Gentry and Osheroff, 2013). Topoisomerase Ila is involved in the survival of proliferating cells during the cell cycle. The enzyme topoisomerase $\| \beta$ participates in the neural development. Type IIA topoisomerases are clinical therapeutic targets for anticancer and antibacterial drugs. These drugs include poison and catalytic inhibitors (Nitiss, 2009). Quinolones are broad-spectrum antibacterial drugs. As well as first line antituberculosis drugs. Quinolones are poison inhibitors, which target DNA gyrase. Amsacrine, etoposide, and doxorubicin are poison anticancer drugs, which target human type II topoisomerases (Pommier et al., 2010).

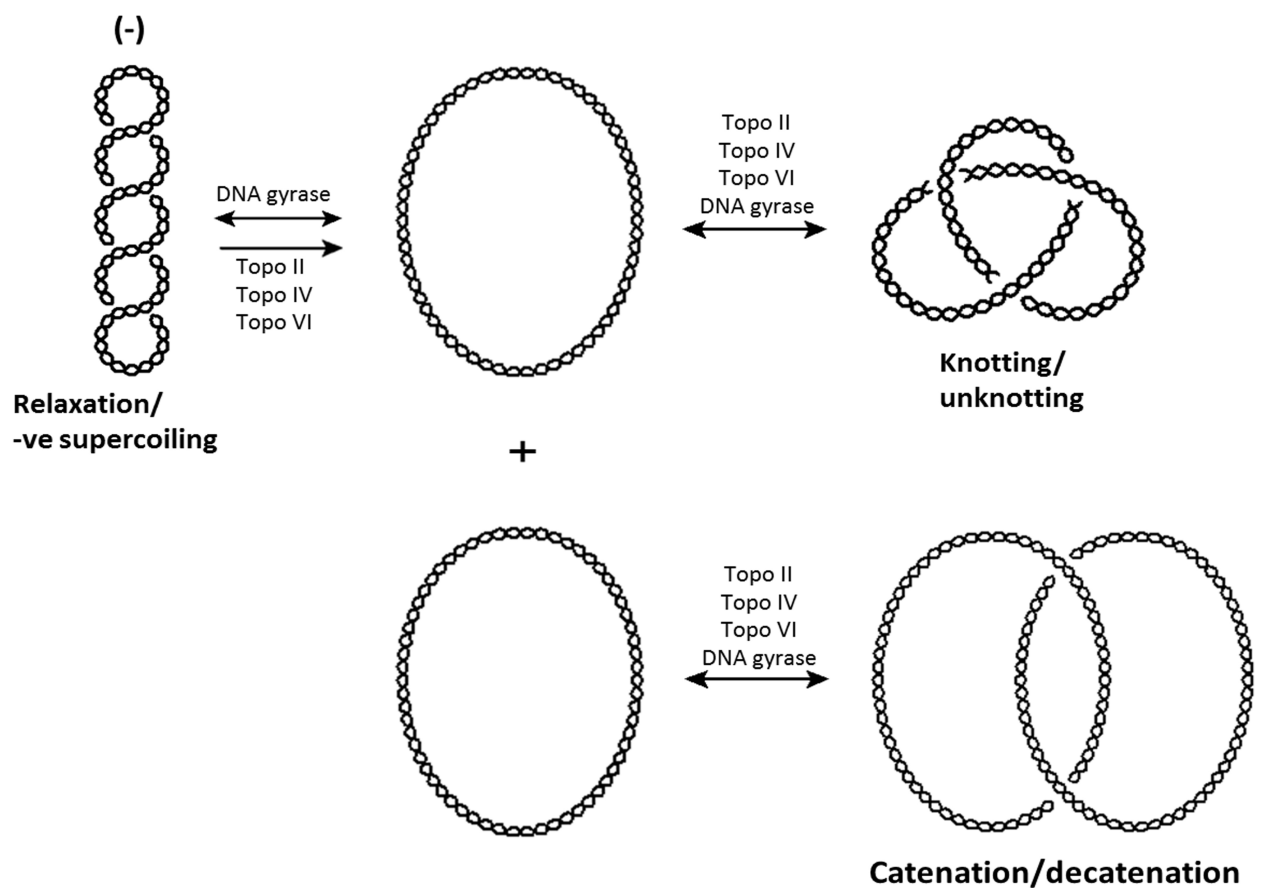

Figure I.7 Catalytic reactions of type II topoisomerases (Bush et al., 2015) 
Type II topoisomerases function as homo-dimers. Eukaryotic type II topoisomerases are dimeric $\left(\mathrm{A}_{2}\right)$, and prokaryotic type II topoisomerases are tetrameric $\left(A_{2} B_{2}\right)$ (Berger and Wang, 1996). Yeast type II topoisomerase is $(B A)_{2}$ homo-dimers. Type II topoisomerases have three interfaces, N-gate, DNAgate, and C-gate (Figure I.8). The catalytic process of type II topoisomerases is ATP-dependent. Briefly, they bind a double-stranded DNA ( $G$ segment), cleave it and let the second double-stranded DNA ( $T$ segment) through the cleaved double-stranded DNA. Two ATP molecules are required for the hydrolysis process (Gentry and Osheroff, 2013). Magnesium is also needed for catalysis. The enzyme DNA gyrase is bacterial topoisomerase II (Lee et al., 2012). Two GyrA and two GyrB subunits form the DNA gyrase. Escherichia coli DNA gyrase is about $400 \mathrm{kDa}$. The GyrB and GyrA subunits of DNA gyrase are homologous to the $\mathrm{N}$ - and C-terminal halves of eukaryotic topoisomerase II, respectively. The tyrosine active site of DNA gyrase is in the GyrA subunit. ATP molecule binds to $\mathrm{N}$-terminal of eukaryotic topoisomerase II and GyrB subunit of DNA gyrase. There are identified as ATPase domains, which use ATP binding and hydrolysis to promote strand passage mechanism in $S$. cerevisiae topoisomerase II (Schmidt et al., 2012). 


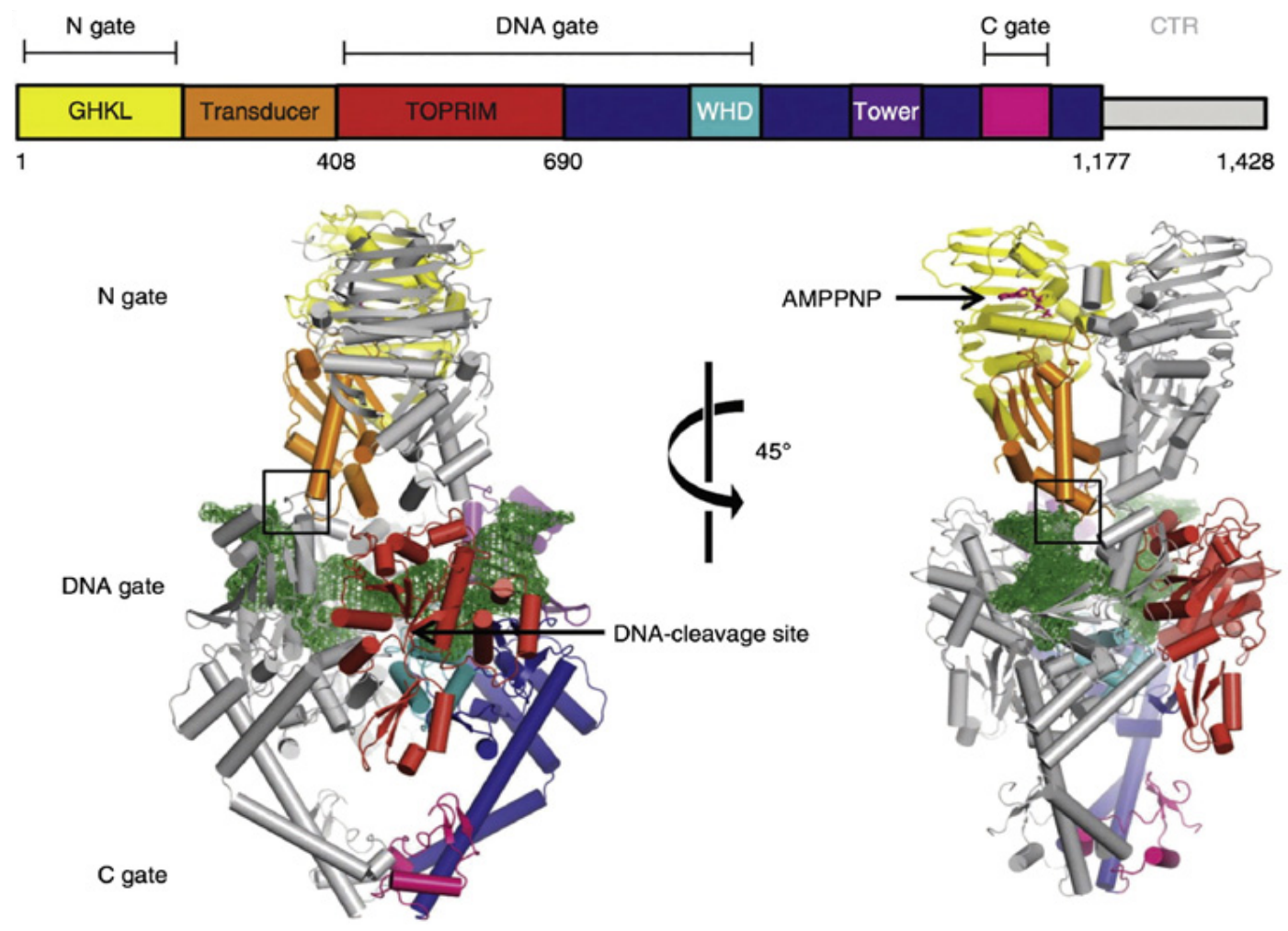

Figure I.8 Crystal structure of S. cerevisiae type II topoisomerase (Basu et al., 2016).

\section{I.4.3 Type I topoisomerases}

All organisms contain at least one type I topoisomerase. They have the ability to relax, unknot/knot or decatenate/catenate single-stranded DNA or double-stranded nicked DNA with a gap in one of the strand (Figure I.8) (Forterre and Gadelle, 2009). Type I topoisomerases include type IA topoisomerase, type IB topoisomerase and type IC topoisomerase. Type IA topoisomerase can relax negatively supercoiled DNA. Type IB topoisomerase relaxes positively and negatively supercoiled DNA. Type I topoisomerase requires $\mathrm{Mg}^{2+}$ in the relaxation process. 

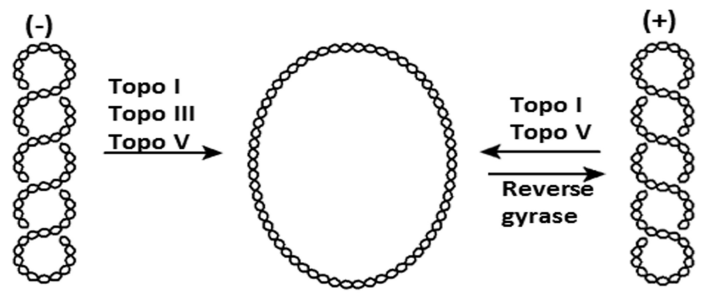

Relaxation/

+ve Supercoiling

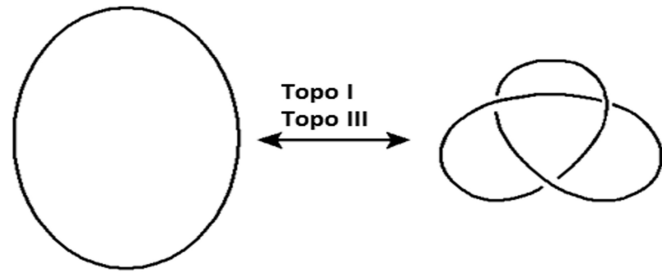

Knotting/ unknotting
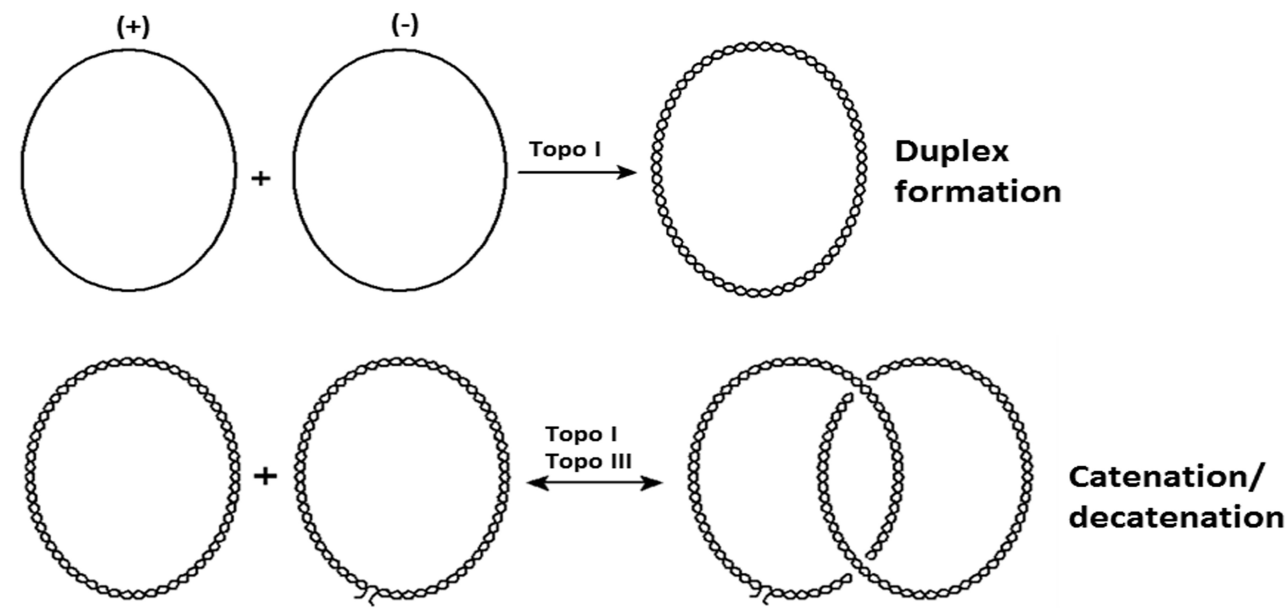

Figure I.9 Catalytic reactions of type I topoisomerases (Bush et al., 2015) 
Type IB topoisomerases are present in all eukaryotic organisms. Animal virus topoisomerase I and mammalian mitochondrial topoisomerase I belong to the type IB topoisomerase family (Patel et al., 2010). Type IB topoisomerases relax duplex DNA by a "controlled rotation mechanism". They nick a singlestranded DNA and allow the DNA strands to rotate around each other (Forterre et al., 2007). Type IB topoisomerases participate in replication, transcription, repair, and chromatin modification processes. They also target anticancer drugs including topotecan and irinotecan (Capranico et al., 2017).

Type IA topoisomerases regulate DNA topology by a cleavage and strand passage mechanism. During the cleavage and religation process, one single strand of DNA is cleaved, and the other single strand of DNA pass the gap at the strand break. A covalent intermediate of DNA and enzyme forms in the cleavage process and disappears in the religation process. There is a conformational change of the enzyme during this process (Figure I.10). The type IA subfamily include bacterial DNA topoisomerase I, bacterial DNA topoisomerase III, eukaryotic DNA topoisomerase III and reverse gyrase (Table I.2). Bacterial type IA topoisomerases are classified to relax only negatively supercoiled DNA with $\mathrm{Mg}^{2+}$ requirement. As type IA topoisomerase, bacterial topoisomerase $\mathrm{I}$ is considered as a potential target for antibacterial drugs (Tse-Dinh, 2009). 


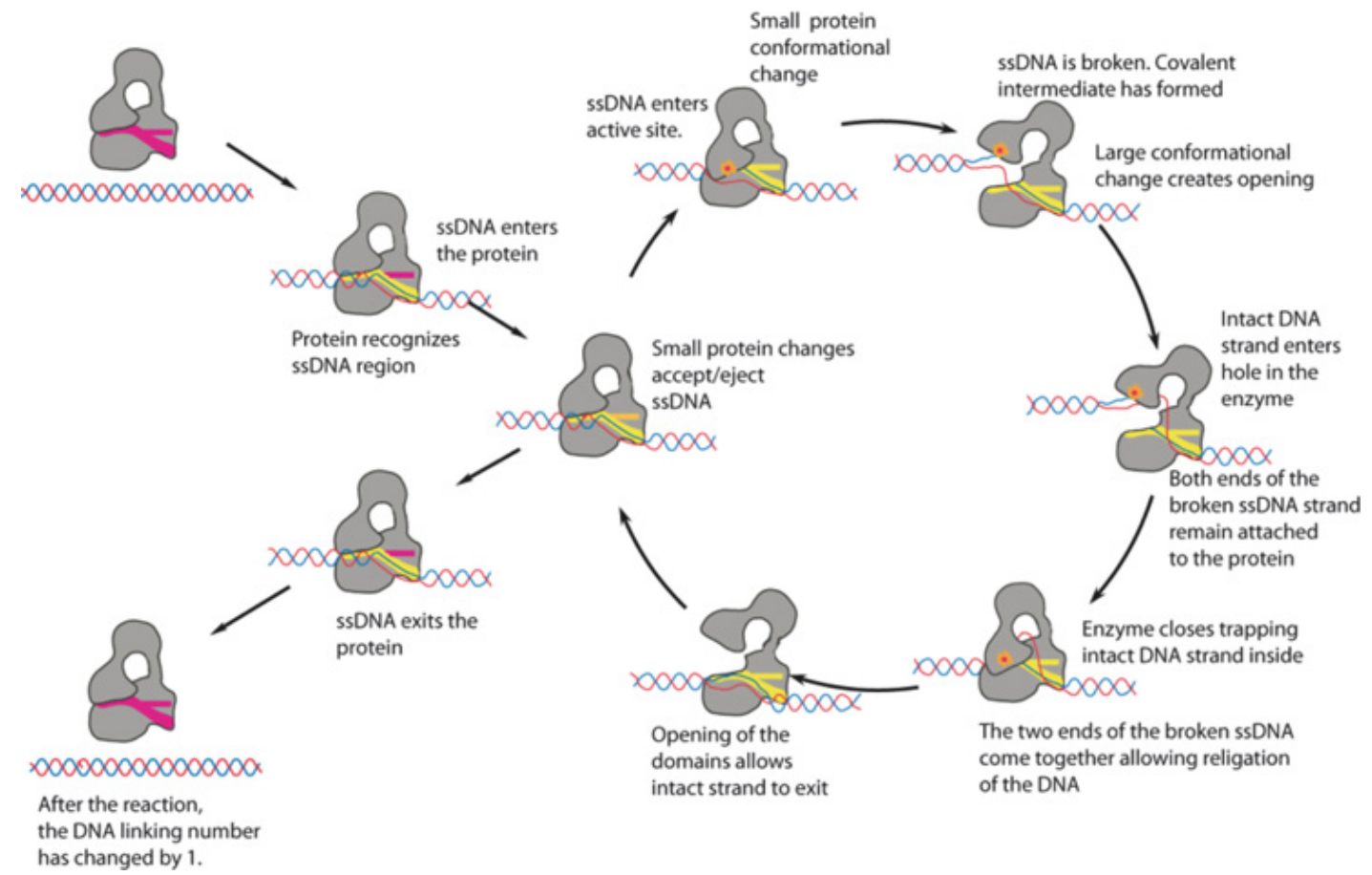

Figure I.10 Proposed mechanism of type IA topoisomerase (Terekhova et al., 2013)

In type IA topoisomerases, the tyrosine active site is in the NTD. The Nterminal domain of type IA topoisomerase has the DNA binding, cleavage and religation activity. The $\mathrm{N}$-terminal domain of type IA topoisomerases is conserved within bacterial topoisomerases and includes the topoisomeraseprimase domain (TOPRIM) (Aravind et al., 1998). However, the CTD is variable within bacterial species (Figure I.11). Escherichia coli topoisomerase I (EcTOP I) contains three tetracysteine zinc ribbon motifs in its CTD. These $\mathrm{Zn}^{2+}$ binding domains include Cys- $\mathrm{X}_{2}-$ Cys-Gly- $\mathrm{X}_{2}-$ Met- $_{12-13}-\mathrm{Cys}_{1}-\mathrm{X}_{4-10}-$ Cys sequence (TseDinh and Beran-Steed, 1988). The Zinc ribbon motifs are essential for the activity of $E$. coli topoisomerase I are proposed to bind to DNA and facilitate stand passage. If these cysteine amino acids are mutated, EcTOP I loses 
activity. Streptomyces topoisomerase I CTD contains lysine repeats and end with acidic amino acids. Other bacterial topoisomerase I also contain lysine repeats with different position and sequence length (Strzalka et al., 2017). The lysine repeats in Streptomyces topoisomerase I are able to stabilize the topoisomeraseDNA complex and maintain the enzyme processivity. The CTD in Streptomyces topoisomerase $\mathrm{I}$ is responsible for DBA binding and the cellular growth of Streptomyces.

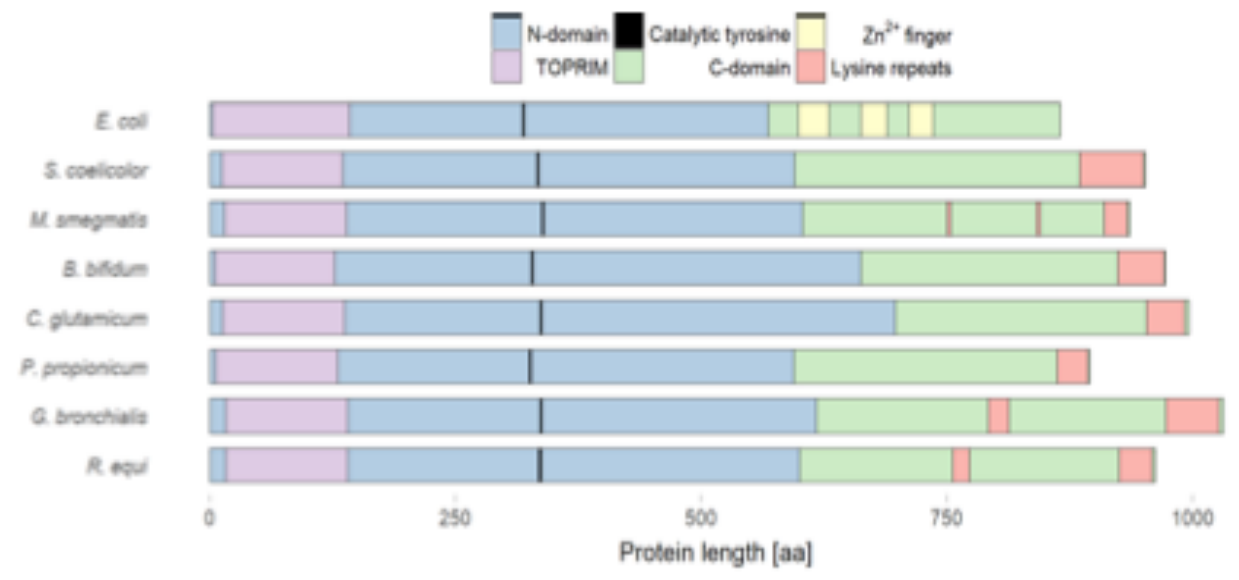

Figure I.11 Comparison of topoisomerase I sequences from various bacterial species. N-terminal domain (blue); C-terminal domain (red); TOPRIM domain (purple) is conserved in NTD; the catalytical tyrosine residue (black); Zinc ribbon motifs (yellow); lysine repeats (red) (Strzalka et al., 2017). 


\section{I.4.4 The cellular function of DNA topoisomerases}

DNA topoisomerases affect DNA replication, transcription, recombination, and repair at the cellular level (Chen et al., 2013; Wang, 2002). It is reported that DNA topoisomerases play an important role in all the steps of replication, in initiation, elongation, and termination (Wang, 2002). In E. coli, DNA topoisomerase III's strand passage function controls the DNA recombination mechanism (Harmon et al., 1999). The replication process is initiated from specific supercoiled origins in both eukaryotes and prokaryotes (Wu et al., 2014). Eukaryotes activate replication by loading origin recognition complex to chromatin (Parker et al., 2017). Topoisomerases are needed to work with specific origins to control replication initiation (Magnan and Bates, 2015; Rampakakis et al., 2010; Vos et al., 2011). In the DNA elongation step, replicative helicase progress brings overwinding and potential distortion positive helical stress to the DNA duplex. In the eukaryote, type II and type IB topoisomerases are able to remove positively supercoiled DNA ahead of the replication fork (Keszthelyi et al., 2016). Topoisomerase III is also observed to support the nascent chain elongation during DNA replication in E. coli (Hiasaand and Marians, 1994). The new precatenanes are resolved by type II topoisomerases (Figure I.12). If two replication forks are too close, the two precatenates form a hemicatenane. Topoisomerase III is able to resolve this topological state with RecQ and stablilize the DNA topology (Nurse et al., 2003; Suski and Marians, 2008). In yeast cells, topoisomerase II mediated replication termination by segregation of chromosomes (Bailey et al., 2015; Dinardo et al., 
1984; Fachinetti et al., 2010).

The enzyme RNA polymerase and its bounded proteins regulate transcription process. In the elongation step of transcription, the DNA topology is dynamic and stressful. Positive DNA supercoiling is generated ahead of the elongating RNA polymerase, and negatively supercoiled DNA is released or rearranged behind the transcription company (Kouzine et al., 2014). The DNA topoisomerases are required to stabilize the DNA topology and remove the topological stress by interacting with DNA (Keszthelyi et al., 2016). In E. coli, gyrase is observed to bind positively supercoiled DNA to start transcription (Chong et al., 2014). In eukaryotic cells, Type IB and type II topoisomerases are able to remove positively supercoiled DNA in this step. Both type I and type II topoisomerase are able to relax the negatively supercoiled DNA for transcription elongation (Vos et al., 2011; Wang, 2002). A current study shows that DNA topoisomerase I interacts with RNA polymerase via a 27 amino acid tail in its CTD in M. smegmatis (Banda et al., 2017). These interactions enable DNA topoisomerase I in $M$. smegmatis to work with RNA polymerases in the transcription process. 


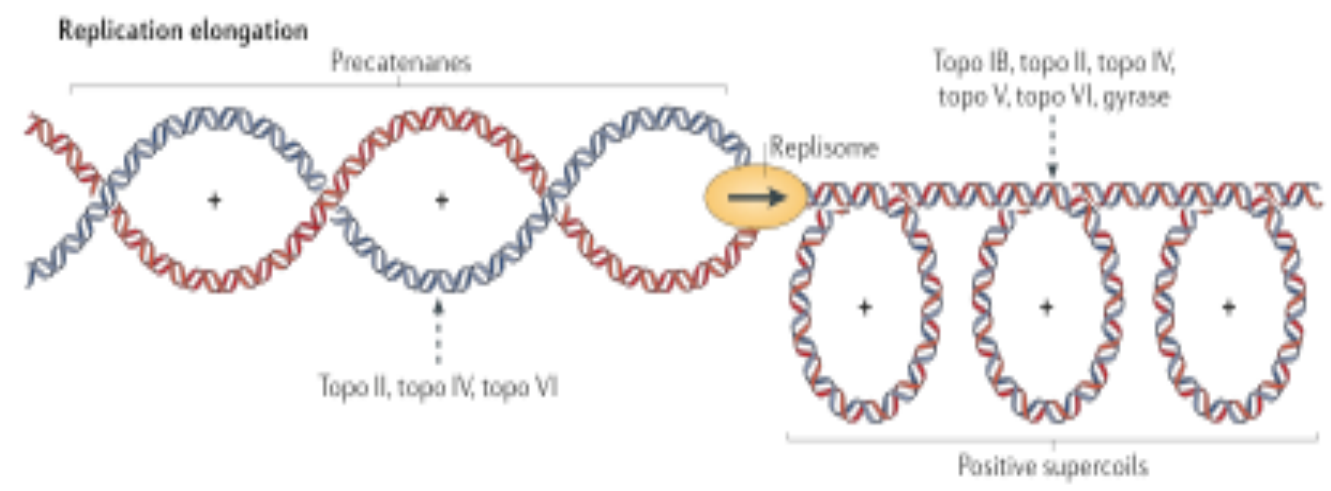

Figure I.12 Topoisomerase function in replication elongation. (Vos et al., 2011)

\section{I.5 Bacterial topoisomerase I}

\section{I.5.1 E. coli type IA topoisomerases}

Escherichia coli topoisomerase I is the first discovered and well-studied topoisomerase. The $67 \mathrm{kDa}$ NTD of EcTOP I is required in its DNA cleavage and religation activity (Ahumada and Tse-Dinh, 2002). Both ssDNA and dsDNA could interact with EcTOP I. It was also observed to have catenation and decatenation activity (Ahumada and Tse-Dinh, 2002; Terekhova et al., 2014). The NTD of EcTOP I contains active site and DNA interaction region with active site tyrosine (Y319) and TOPRIM motif (Narula and Tse-Dinh, 2012). Without the DXD TOPRIM motif, the $\mathrm{Mg}^{2+}$ binding ability of EcTOP I decreased (Cheng et al., 2009). The TOPRIM mutation affected religation activity. Thus the DNAtopoisomerase covalent complex was trapped. As a $\mathrm{Zn}^{2+}$ binding protein, the 
CTD of EcTOP I contains three repetitive Zinc ribbon domains (Lu et al., 2011; Tse-Dinh and Beran-Steed, 1988). The C-terminal domain of EcTOP I binds to ssDNA but not dsDNA. It also interacts with RNA polymerase in transcription process (Cheng et al., 2003). The crystal structure of EcTOP I with ssDNA revealed that the Zinc ribbon motifs bind to ssDNA (Figure I.12) (Tan et al., 2015). As mentioned, E. coli topoisomerase III (EcTOP III) plays an important role in DNA recombination. Escherichia coli topoisomerase III catenates covalently closed DNA and interacts with helicase (Harmon et al., 2003). Escherichia coli topoisomerase III also decatenates catenated both dsDNA and ssDNA with RecQ (Suski and Marians, 2008). Kinetic studies revealed that the decatenation activity of EcTOP III is more efficient than that of EcTOP I (Terekhova et al., 2014). Escherichia coli topoisomerase III contains a decatenation loop in its CTD. While EcTOP I is more efficient for DNA relaxation (Terekhova et al., 2012). Different structures of these two topoisomerases lead to different pathways in their catalytic activities. The NTD is conserved (Figure I.13). Subdomain I contains the TOPRIM motif. Active site tyrosine is in subdomain III (D3). Unlike EcTOP I, EcTOP III has a short CTD without $\mathrm{Zn}^{2+}$ binding domains (Terekhova et al., 2013). 
A
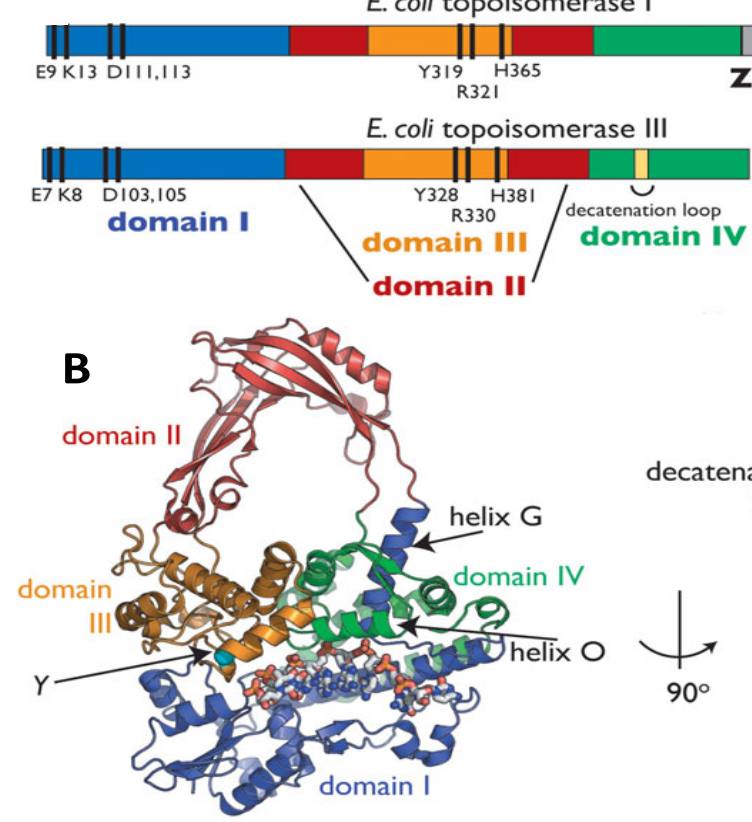

Zn ribbon domains
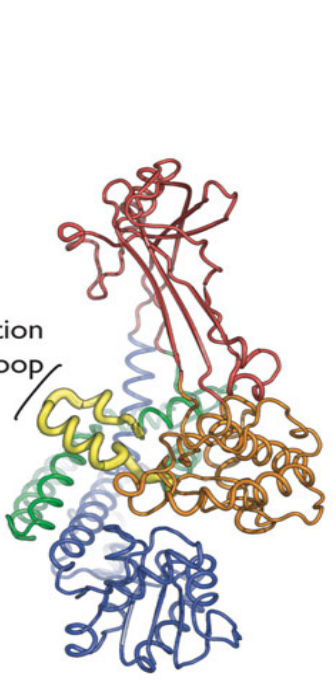
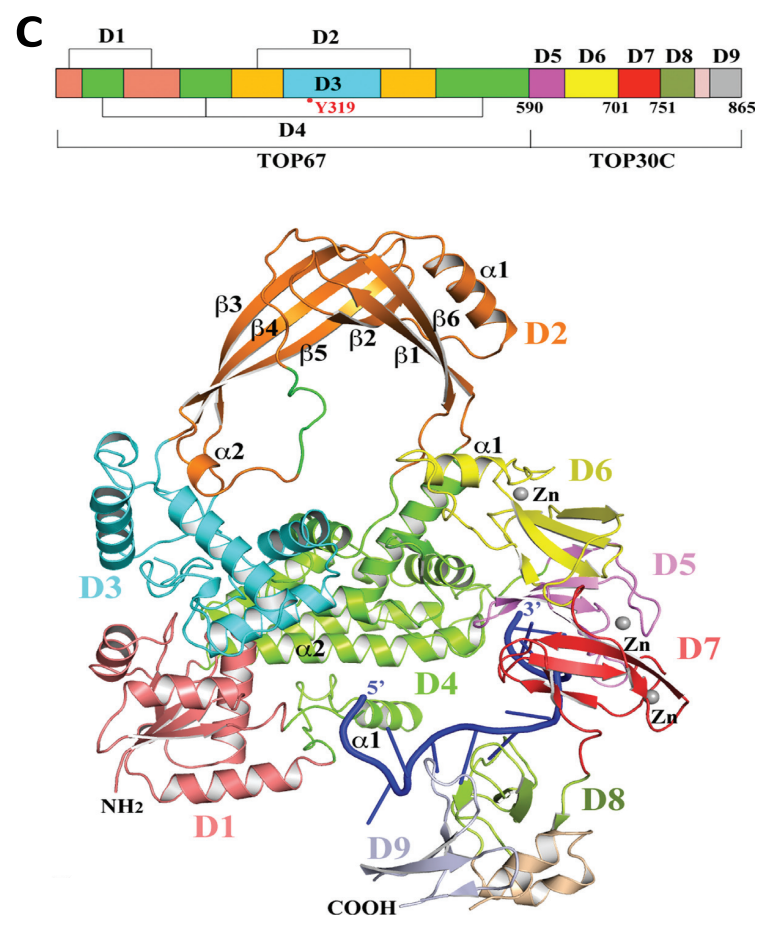

Figure I.13 Structures of EcTOP I and EcTOP III. (A) The organization of EcTOP I and EcTOP III. (B) The crystal structure of EcTOP III. (C) The crystal structure of EcTOP I and DNA complex (Schoeffler and Berger, 2008; Tan et al., 2015) 


\section{I.5.2 Mycobacterial topoisomerase I}

There is only one type I topoisomerase in mycobacteria. Mycobacterium tuberculosis DNA topoisomerase I is validated as a target for TB therapy (Nagaraja et al., 2017). The challenge of the study of $M$. tuberculosis is that it is an infection and slow-growing bacteria. But $M$. smegmatis growth is faster than $M$. tuberculosis; it serves as a noninfection model to study $M$. tuberculosis DNA topoisomerase I from $M$. smegmatis $\mathrm{MC}^{2} 155$ contains 936 residues (MsTOP1), and DNA topoisomerase I from M. tuberculosis H37RV contains 934 residues (MtTOP1). Previous studies revealed that MtTOP1 is essential for the cell

survival of M. tuberculosis (Ahmed et al., 2014). Mycobacterial topoisomerase $\mathrm{I}$ is essential for maintenance of cellular phenotype, cell growth characteristics and gene expression in mycobacteria (Ahmed et al., 2014; Ahmed et al., 2015).

Mycobacterium smegmatis DNA topoisomerase I and Mycobacterium tuberculosis DNA topoisomerase I were both reported to have the DNA cleavage, religation, binding, relaxation and catenation activities (Bhaduri et al., 1998). The NTD of mycobacterial topoisomerase $I$ is sufficient for the DNA binding, DNA cleavage and religation steps, but requires CTD for relaxation of negatively supercoiled DNA (Jain and Nagaraja, 2006). Both NTD and CTD of MsTOP1 could bind to ssDNA and dsDNA, but NTD of MsTOP1 can bind specific and nonspecific DNA (Jain and Nagaraja, 2006). Mycobacterial topoisomerase I proteins have 
no $\mathrm{Zn}^{2+}$ binding domains in their CTD (Jain and Nagaraja, 2006). A recent study reported that the CTD of MsTOP1 contains three highly conserved stretches of basic amino acids. These basic amino acids are involved in DNA binding and promotion of strand passage mechanism (Ahmed et al., 2013). Depletion of these basic amino acids lead to the loss of catalytic activity and affect the growth of M. smegmatis. Besides, Dr. Nagaraja's study revealed that wild-type MsTOP1 and mutant enzyme with deletion of stretch $1(\mathrm{KKGKK})$ could bind two DNA molecules (Ahmed et al., 2013). Dr. Nagaraja revealed that MsTOP1 contained two DNA binding sites, one is in NTD and another is in CTD. A recent study showed metal binding amino acids (D108 and E112) in MtTOP1 (Godbole et al., 2015).

\section{I.6 Overview of the study}

Type IA topoisomerases are essential in all organisms. Mycobacterial topoisomerase I is the important enzyme for mycobacteria. It plays important roles in DNA replication, transcription and recombination process. It is required in mycobacteria cellular growth, phenotype, gene stability and expression. However, the exact structure and mechanism of mycobacterial topoisomerase I remain to be fully elucidated. The NTD's function is conserved within type IA topoisomerases, but the CTD's sequence and domain organization of mycobacterial topoisomerase I are different from other type IA topoisomerases, such as EcTOP I and EcTO 
III. Hence, the overall goal of this study is to reveal the structure and mechanism of mycobacterial topoisomerase I with X-ray crystallography and biochemical catalytic activity analysis.

The first aim of the current study is to determine the effects of deletion of proposed C-terminal subdomains on mycobacterial topoisomerase I activity. The CTD of mycobacterial topoisomerase I could be divided into four subdomains and a C-terminal tail. The catalytic activity assays are carried out to study the function of each subdomain at the molecular level. The second aim of the study is to determine the crystal structure of deletion mutants, and the catalytic roles of conserved amino acid residues in the active site of mycobacteria topoisomerase I. Crystal structures of MtTOP1 were obtained. The crystal structures revealed that certain conserved amino acids are required for DNA binding or divalent ion interaction. Conserved amino acids include MtTOP1 E24 and MsTOP1 E21, were studied. 


\title{
CHAPTER 1: MECHANISM AND FUNCTION OF SUBDOMAINS IN MYCOBACTERIAL TOPOISOMERASE I C-TERMINAL DOMAIN
}

\begin{abstract}
DNA topoisomerase I is an essential enzyme for eukaryotes and prokaryotes. Mycobacterial topoisomerase I overcomes the topological problems of chromosomes in mycobacteria and maintain the growth of mycobacteria. The NTD of mycobacterial topoisomerase I contain the active site for DNA binding, cleavage and religation. The CTD of mycobacterial topoisomerase I (Mycobacterium tuberculosis topoisomerase I and Mycobacterium smegmatis topoisomerase I) can be divided into four subdomains (D5-D8) and a positively charged tail. Each subdomain has a GxxGPY sequence motif. The current study shows the involvement of subdomains in catalysis of different reactions by mycobacterial topoisomerase I. Subdomains D8 and D7 are required for maintaining the relaxation activity of mycobacterial topoisomerase I. Subdomain D5 in the absence of the other C-terminal subdomains is sufficient for the DNA cleavage, religation, catenation and decatenation activity.
\end{abstract}




\section{INTRODUCTION}

Tuberculosis (Rosenbaum et al.) is a global infectious disease. It has infected about one-third of the world's populations. The World Health Organization reported 6.3 million new cases of TB in 2016 (WHO, 2017). Multidrug-resistance TB (MDR-TB) is a global problem for TB treatment (Mishra et al., 2015). As a top cause of death from the infectious disease, more efficient treatment for TB and MDR-TB is an urgent need. Tuberculosis is caused by various strains of mycobacteria, usually Mycobacterium tuberculosis (M. tuberculosis) (Veatch and Kaushal, 2017).

DNA topoisomerases are ubiquitous in both eukaryotes and prokaryotes. They are involved in DNA replication, recombination, transcription, and repair processes. They are essential enzymes that could regulate DNA topology for optimal growth of eukaryotic and prokaryotic organisms (Vos et al., 2011). There are two types of topoisomerases, type I topoisomerase (Topo I) and type II topoisomerases (Topo II) (Bush et al., 2015). Type I DNA topoisomerases cleave and rejoin a single strand of DNA. There are three sub-types of type I topoisomerases, topoisomerase IA, topoisomerase IB and type IC topoisomerase (Chen et al., 2013). The enzymes of type IA subfamily include bacterial DNA topoisomerase I, bacterial DNA topoisomerase III, eukaryotic DNA topoisomerase III and reverse gyrase (Tse-Dinh, 1998). 
Type I topoisomerases can relax supercoiled DNA and type IA topoisomerases are classified to relax only negatively supercoiled DNA with $\mathrm{Mg}^{2+}$ requirement. In mycobacteria, there are two types of topoisomerases, mycobacterial topoisomerase I and gyrase. Mycobacterial topoisomerase I and E. coli topoisomerase I both belong to the type IA topoisomerase family. The bacterial topoisomerase I can bind and cleave single-stranded DNA. It also has the ability to unknot/knot or decatenate/catenate single-stranded DNA circles or double-stranded DNA circles with a nick (Bugreev and Nevinsky, 2010). The NTD of type IA topoisomerase I are conserved, but the CTD can be found with a variety in size and sequence (Strzalka et al., 2017; Viard and de la Tour, 2007). The CTD of E. coli topoisomerase I contains three tetracysteine Zinc ribbon motifs. These Zinc ribbon motifs are specified by Cys- $\mathrm{X}_{2}-\mathrm{Cys}-\mathrm{Gly}-$ $\mathrm{X}_{2}-$ Met- $\mathrm{X}_{12-13}-\mathrm{Cys}_{\mathrm{s}} \mathrm{X}_{4-10}-\mathrm{Cys}$ sequence (Tse-Dinh and Beran-Steed, 1988), and are essential for the relaxation activity of E. coli topoisomerase I. It has been proposed that the Zinc ribbon motifs bind to single-stranded DNA and facilitate DNA stand passage (Ahumada and Tse-Dinh, 2002). Mycobacterial topoisomerase $\mathrm{I}$ is essential for maintenance of the phenotype, growth and gene expression in mycobacteria (Ahmed et al., 2014; Ahmed et al., 2015). Mycobacterium tuberculosis topoisomerase 1 (MtTOP1) is validated as a potential target for anti-tuberculosis therapy (Ravishankar et al., 2015; Tse-Dinh, 2009). In MtTOP1, the active site Tyr342 is in the NTD (Tan et al., 2016). The NTD of M. smegmatis 
topoisomerase I (MsTOP1) is required during the DNA cleavage and religation steps (Jain and Nagaraja, 2006). The CTD of MsTOP1 is proposed to be required for interaction with the passing strand of DNA (Ahmed et al., 2013). We hypothesize that mycobacterial topoisomerase I C-terminal has repeated motifs distinct from the Zinc ribbon motifs that play the important function in catalysis. Deletion mutants (Figure1.1) were unstructured to examine the roles of the individual subdomains. To study the CTD of mycobacterial topoisomerase I, the CTD was divided into four subdomains and a positively charged tail (Figure1.1, Table1.1). Each subdomain contains a GxxGPY sequence motif. Our structure studies showed that each subdomain comprises of four $\beta$-strands and one $C$ terminal a-helix (Figure 1.2) (Tan et al., 2016) 


\begin{tabular}{|c|c|c|c|c|c|c|c|c|c|c|c|c|}
\hline D1 & D4 & D1 & D4 & D2 & D3 & D2 & D4 & D5 & D6 & D7 & D8 & Wild-type MTTOP1/MsTOP1 \\
\hline D1 & D4 & D1 & D4 & D2 & D3 & D2 & D4 & D5 & D6 & D7 & D8 & MtTOP1-910t/MsTOP1-909t \\
\hline D1 & D4 & D1 & D4 & D2 & D3 & D2 & D4 & D5 & D6 & D7 & & MtTOP1-840t/MsTOP1-839t \\
\hline D1 & D4 & D1 & D4 & D2 & D3 & D2 & D4 & D5 & D6 & & & MtTOP1-786t/MsTOP1-785t \\
\hline D1 & D4 & D1 & D4 & D2 & D3 & D2 & D4 & D5 & & & & MtTOP1-704t/MsTOP1-701t \\
\hline
\end{tabular}

Figure 1.1 The subdomain organization of mycobacterial topoisomerase I. The CTD mutants of mycobacterial topoisomerase I are constructed with deletions of D5, D6, D7 and D8 subdomain.

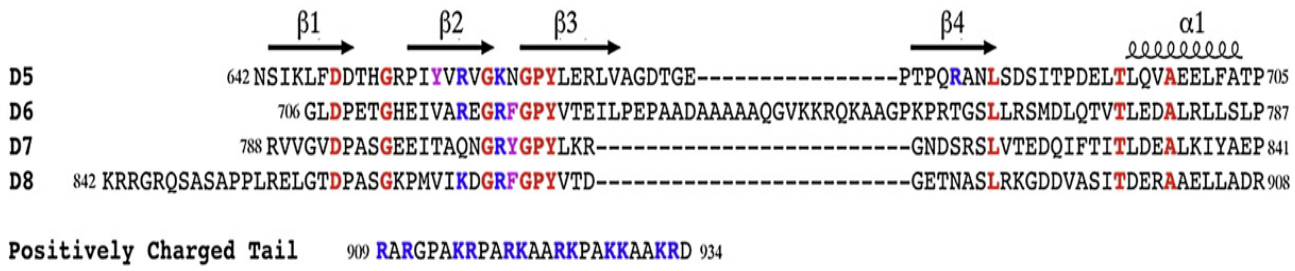

Figure 1.2 Division of the C-terminal domain of M. tuberculosis topoisomerase I in four subdomains and a flexible tail. The conserved residues among the four subdomains are highlighted in red, including the GxxGPY sequence motif. 


\begin{tabular}{|l|c|c|c|c|c|}
\hline & $\begin{array}{c}\text { NTD+D5+D6 } \\
\text { +D7+D8+tail }\end{array}$ & $\begin{array}{c}\text { NTD+D5+D6 } \\
\text { +D7+D8 }\end{array}$ & $\begin{array}{c}\text { NTD+D5+D6+D } \\
7\end{array}$ & NTD+D5+D6 & NTD+D5 \\
\hline $\begin{array}{l}\text { Mycobacterium } \\
\text { tuberculosis } \\
\text { topoisomerase I }\end{array}$ & $\begin{array}{c}\text { MtTOP1 } \\
(2-934)\end{array}$ & $\begin{array}{c}\text { MtTOP1-910t } \\
(2-910)\end{array}$ & $\begin{array}{c}\text { MtTOP1-840t } \\
(2-840)\end{array}$ & $\begin{array}{c}\text { MtTOP1-786t } \\
(2-786)\end{array}$ & MtTOP1-704t \\
(MtTOP1) & & & & & \\
\hline $\begin{array}{l}\text { Mycobacterium } \\
\text { smegmatis }\end{array}$ & MsTOP1 & MsTOP1-909t & MsTOP1-839t & MsTOP1-785t & MsTOP1-701t \\
topoisomerase I & $(1-936)$ & $(2-909)$ & $(1-839)$ & $(1-785)$ & $(1-701)$ \\
(MsTOP1) & & & & & \\
\hline
\end{tabular}

Table 1.1 The construction of wild-type and mutant recombinant mycobacterial topoisomerase I clones that include the residues shown in the brackets. 


\section{MATERIALS AND METHOD}

\section{Construction of plasmids and clones}

The $M$. smegmatis topA gene was cloned from $M$. smegmatis $M C^{2} 155$. The genomic DNA was purified from $M$. smegmatis $M C^{2} 155$ with Quick-DNA Fungal/Bacterial Kit (Zymo Research). The M. tuberculosis topA gene was cloned from M. tuberculosis H37RV. Mycobacterium tuberculosis H37RV genomic DNA was provided by BEI resources. The polymerase chain reaction (PCR) was used to amplify wild-type and mutant mycobacterial topoisomerase I coding sequence. The MsTOP1 plasmid was constructed with the Gibson Assembly method to insert the MsTOP1 gene into a pET-His6-Mocr TEV-LIC cloning vector (2O-T). The 2O-T MtTOP1 plasmid was constructed in our lab (Annamalai et al., 2009). NEBbuilder HIFI DNA Assembly method was used to insert coding sequence for MsTOP1-909t and MtTOP1-910t into the 2O-T vector. MsTOP1-839t, MsTOP1-786t, MsTOP1-701t, MtTOP1-840t, MtTOP1786t, MtTOP1-704t were cloned by site directed mutagenesis to substitute a stop codon in the 2O-T MsTOP1 and 2O-T MtTOP1 plasmid. The primers (from Sigma Genosys) used for cloning are listed in Table 1.2. (IBC-16-009-CR02)

In the construction of 2O-T MsTOP1, the linear 2O-T plasmid was amplified using the Q5 High-Fidelity DNA Polymerase (New England Biolabs) and $2 \mathrm{O}-\mathrm{T}$ plasmid as template $\left(35\right.$ cycles of $98^{\circ} \mathrm{C}$ for $30 \mathrm{sec}$, $70^{\circ} \mathrm{C}$ for $30 \mathrm{sec}, 72^{\circ} \mathrm{C}$ for $\left.3.5 \mathrm{~min}\right)$. M. smegmatis $\mathrm{MC}^{2} 155$ genomic DNA 
was used as the template to amplify MsTOP1 coding gene with Q5 Hot Start High-Fidelity DNA Polymerase $\left(35\right.$ cycles of $98^{\circ} \mathrm{C}$ for $30 \mathrm{sec}, 72^{\circ} \mathrm{C}$ for $3 \mathrm{~min}$ ). After PCR reaction, the PCR products were purified by electrophoresis in 1\% agarose gel with Tris-acetate-EDTA buffer (TAE, 40 $\mathrm{mM}$ Tris, $20 \mathrm{mM}$ acetic acid, and $1 \mathrm{mM}$ EDTA). The gels were stained with $1 \mu \mathrm{g} / \mathrm{mL}$ concentration ethidium bromide for 1 hour and photographed over UV light. The PCR products were purified from the excised gel slice with GeneJET PCR Purification Kit (Thermo Scientific). Purified PCR product MsTOP1 $(0.45 \mathrm{pmol})$ and $2 \mathrm{O}-\mathrm{T}(0.14 \mathrm{pmol})$ (the ratio is $3: 1)$ were incubated with Gibson Assembly Master Mix (New England Biolabs) at $50^{\circ} \mathrm{C}$ for $15 \mathrm{~min}$. Assembled product was transformed into NEB turbo competent cells (New England Biolabs). The transformants were plated on LB $+100 \mu \mathrm{g} / \mathrm{ml}$ carbenicillin $+2 \%$ glucose plates and incubated at $37^{\circ} \mathrm{C}$ overnight.

In the construction of 2O-T MsTOP1-909t and 2O-T MtTOP1-910t, the linear 2O-T plasmid was amplified using the Q5 Hot Start High-Fidelity DNA Polymerase (New England Biolabs). 2O-T MsTOP1 and 2O-T MtTOP1 plasmids were used as template for 2O-T MsTOP1-909t and 2OT MtTOP1-910t. The PCR reaction to amplify 2O-T MsTOP1-909t used Q5 Hot Start High-Fidelity DNA Polymerase for 35 cycles of $98^{\circ} \mathrm{C}$ for 30 sec, $71^{\circ} \mathrm{C}$ for $30 \mathrm{sec}, 72^{\circ} \mathrm{C}$ for $2.5 \mathrm{~min}$. The PCR reaction to amplify $2 \mathrm{O}-\mathrm{T}$ MtTOP1-910t used Q5 Hot Start High-Fidelity DNA Polymerase to react for 35 cycles of $98^{\circ} \mathrm{C}$ for $30 \mathrm{sec}, 71^{\circ} \mathrm{C}$ for $30 \mathrm{sec}, 72^{\circ} \mathrm{C}$ for 2 min. After 
PCR reaction, the PCR products were purified by electrophoresis in $1 \%$ agarose gel with TAE buffer. The gels were stained with $1 \mu \mathrm{g} / \mathrm{mL}$ concentration ethidium bromide for 1 hour and photographed over UV light. The PCR products were purified from the excised gel slice with GeneJET PCR Purification Kit. Purified PCR product MsTOP1 (0.014 pmol) and 2O-T (0.14 pmol) (the ratio is about 2:1) were incubated with NEBuilder HiFi DNA Assembly Master Mix (New England Biolabs) at $50^{\circ} \mathrm{C}$ for $15 \mathrm{~min}$. Assembled product was transformed into NEB turbo competent cells. The transformants were plated in the LB $+100 \mu \mathrm{g} / \mathrm{ml}$ carbenicillin $+2 \%$ glucose plates and incubated at $37^{\circ} \mathrm{C}$ overnight.

The materials and protocol for site-detected mutagenesis are described in Table 1.3. After PCR mutagenesis reactions, the PCR products were purified by electrophoresis in $1 \%$ agarose gel with TAE buffer. The template plasmids were digested by treatment with Dpn1 restriction enzyme (New England Biolabs) or KLD mix (kinase, ligase, Dpnl; New England Biolabs). NEB turbo competent cells and NEB $5 a$ competent cells (New England Biolabs) were used for the transformation of mutant plasmids. The transformants were plated on the LB $+100 \mu \mathrm{g} / \mathrm{ml}$ carbenicillin $+2 \%$ glucose plates

Wild-type and mutant plasmids were purified by GeneJET Plasmid Miniprep Kit (Thermo Scientific). Nucleotide sequencing (Genewiz and Eurofins genomics) was used to verify the sequence of the complete coding region of plasmids. 


\begin{tabular}{|c|c|}
\hline Primer name & Primer sequence (5'-3') \\
\hline MsTOP1 forward & $\begin{array}{l}\text { GGGATCGAGGAAAACCTGTACTTCCAAATGGCTGGCG } \\
\text { GCGACCG }\end{array}$ \\
\hline MsTOP1 reverse & $\begin{array}{l}\text { GCGGATCCGTTATCCACTTCCAATATTGTTCGGCGGA } \\
\text { AACCTAGGCCTTCTT }\end{array}$ \\
\hline $\begin{array}{l}\text { MsTOP1-909t } \\
\text { forward }\end{array}$ & $\begin{array}{l}\text { GGGATCGAGGAAAACCTGTACTTCCAAATGGCTGGCG } \\
\text { GCGACCG }\end{array}$ \\
\hline $\begin{array}{l}\text { MsTOP1-909t } \\
\text { reverse }\end{array}$ & GAGTCCGGACACCTTGGAAGTACAGGTTTTCC \\
\hline $\begin{array}{l}\text { MsTOP1-839t } \\
\text { forward }\end{array}$ & CGGCCACGGCGTTTCTACTCGGCGTAGATCTT \\
\hline $\begin{array}{l}\text { MsTOP1-839t } \\
\text { reverse }\end{array}$ & AAGATCTACGCCGAGTAGAAACGCCGTGGCCG \\
\hline $\begin{array}{l}\text { MsTOP1-785t } \\
\text { forward }\end{array}$ & GCCCACGACGCGCTACAGCGACAGCAGC \\
\hline $\begin{array}{l}\text { MsTOP1-785t } \\
\text { reverse }\end{array}$ & GCTGCTGTCGCTGTAGCGCGTCGTGGGC \\
\hline $\begin{array}{l}\text { MsTOP1-701t } \\
\text { forward }\end{array}$ & GCGTCCCTCTTGCTATGTGGCGAAGAGCTTTTCGG \\
\hline $\begin{array}{l}\text { MsTOP1-701t } \\
\text { reverse }\end{array}$ & CCGAAAAGCTCTTCGCCACATAGCAAGAGGGACGC \\
\hline $\begin{array}{l}\text { MtTOP1-910t } \\
\text { forward }\end{array}$ & $\begin{array}{l}\text { GATCGAGGAAAACCTGTACTTCCAATTGGCTGACCCG } \\
\text { AAAACGAAGGG }\end{array}$ \\
\hline $\begin{array}{l}\text { MtTOP1-910t } \\
\text { reverse }\end{array}$ & $\begin{array}{l}\text { GCGGATCCGTTATCCACTTCCAATATTGCTAGGCTCG } \\
\text { GCGATCGGCCAA }\end{array}$ \\
\hline $\begin{array}{l}\text { MtTOP1-840t } \\
\text { forward }\end{array}$ & CCGGCCACGACGTTTCTACTCTGCGTAGATCTTC \\
\hline $\begin{array}{l}\text { MtTOP1-840t } \\
\text { reverse }\end{array}$ & GAAGATCTACGCAGAGTAGAAACGTCGTGGCCGG \\
\hline $\begin{array}{l}\text { MtTOP1-786t } \\
\text { forward }\end{array}$ & GCTGTCACTGTAGCGCGTGGTCG \\
\hline $\begin{array}{l}\text { MtTOP1-786t } \\
\text { reverse }\end{array}$ & AGCCTCAGCGCGTCTTCG \\
\hline $\begin{array}{l}\text { MtTOP1-704t } \\
\text { forward }\end{array}$ & GTCCCTGTTGCTATGTGGCAAAGAGCTCTTCGGC \\
\hline $\begin{array}{l}\text { MtTOP1-704t } \\
\text { reverse }\end{array}$ & GCCGAAGAGCTCTTTGCCACATAGCAACAGGGAC \\
\hline 2O-T forward & TTGGAAGTACAGGTTTTCCTCGATCCC \\
\hline 2O-T reverse & CAATATTGGAAGTGGATAACGGATCCGC \\
\hline
\end{tabular}

Table 1.2 Primer sequences used for clone construction. 


\begin{tabular}{|c|c|c|c|c|}
\hline $\begin{array}{l}\text { Plasmid } \\
\text { name }\end{array}$ & $\begin{array}{l}\text { DNA polymerase } \\
\text { used for cloning }\end{array}$ & Methods and Protocol & $\begin{array}{c}\text { Digestion } \\
\text { enzyme }\end{array}$ & $\begin{array}{l}\text { Transformation } \\
\text { competent cells }\end{array}$ \\
\hline $\begin{array}{l}\text { 2O-T } \\
\text { MsTOP1-839t }\end{array}$ & $\begin{array}{l}\text { Phusion Hot Start II } \\
\text { High-Fidelity DNA } \\
\text { Polymerase (Thermo } \\
\text { Scientific) }\end{array}$ & $\begin{array}{l}\text { QuickChange site-directed } \\
\text { mutagenesis }\left(30 \text { cycles of } 95^{\circ} \mathrm{C}\right. \\
\text { for } 30 \mathrm{sec}, 70^{\circ} \mathrm{C} \text { for } 30 \mathrm{sec}, 72^{\circ} \mathrm{C} \\
\text { for } 4.5 \mathrm{~min})\end{array}$ & Dpn1 & NEB turbo \\
\hline $\begin{array}{l}\text { 2O-T } \\
\text { MsTOP1-785t }\end{array}$ & $\begin{array}{l}\text { Phusion Hot Start II } \\
\text { High-Fidelity DNA } \\
\text { Polymerase (Thermo } \\
\text { Scientific) }\end{array}$ & $\begin{array}{l}\text { QuickChange site-directed } \\
\text { mutagenesis }\left(30 \text { cycles of } 95^{\circ} \mathrm{C}\right. \\
\text { for } 30 \mathrm{sec}, 70^{\circ} \mathrm{C} \text { for } 30 \mathrm{sec}, 72^{\circ} \mathrm{C} \\
\text { for } 4.5 \mathrm{~min})\end{array}$ & Dpn1 & NEB turbo \\
\hline $\begin{array}{l}\text { 2O-T } \\
\text { MsTOP1-701t }\end{array}$ & $\begin{array}{l}\text { Phusion Hot Start II } \\
\text { High-Fidelity DNA } \\
\text { Polymerase (Thermo } \\
\text { Scientific) }\end{array}$ & $\begin{array}{l}\text { QuickChange site-directed } \\
\text { mutagenesis }\left(30 \text { cycles of } 95^{\circ} \mathrm{C}\right. \\
\text { for } 30 \mathrm{sec}, 70^{\circ} \mathrm{C} \text { for } 30 \mathrm{sec}, 72^{\circ} \mathrm{C} \\
\text { for } 4.5 \mathrm{~min})\end{array}$ & Dpn1 & NEB turbo \\
\hline $\begin{array}{l}\text { 2O-T } \\
\text { MtTOP1-840t }\end{array}$ & $\begin{array}{l}\text { Phusion Hot Start II } \\
\text { High-Fidelity DNA } \\
\text { Polymerase (Thermo } \\
\text { Scientific) }\end{array}$ & $\begin{array}{l}\text { QuickChange site-directed } \\
\text { mutagenesis }\left(30 \text { cycles of } 95^{\circ} \mathrm{C}\right. \\
\text { for } 30 \mathrm{sec}, 70^{\circ} \mathrm{C} \text { for } 30 \mathrm{sec}, 72^{\circ} \mathrm{C} \\
\text { for } 4.5 \mathrm{~min})\end{array}$ & Dpn1 & NEB turbo \\
\hline $\begin{array}{l}\text { 2O-T } \\
\text { MtTOP1-786t }\end{array}$ & $\begin{array}{l}\text { Q5 Hot Start High- } \\
\text { Fidelity Master Mix } \\
\text { (New England } \\
\text { Biolabs) }\end{array}$ & $\begin{array}{l}\text { Q5 site-directed mutagenesis } \\
\left(25 \text { cycles of } 95^{\circ} \mathrm{C} \text { for } 30 \mathrm{sec},\right. \\
\left.65^{\circ} \mathrm{C} \text { for } 30 \mathrm{sec}, 72^{\circ} \mathrm{C} \text { for } 4.5 \mathrm{~min}\right)\end{array}$ & KLD mix & NEB $5 \alpha$ \\
\hline $\begin{array}{l}\text { 2O-T } \\
\text { MtTOP1-704t }\end{array}$ & $\begin{array}{l}\text { Phusion Hot Start II } \\
\text { High-Fidelity DNA } \\
\text { Polymerase (Thermo } \\
\text { Scientific) }\end{array}$ & $\begin{array}{l}\text { QuickChange site-directed } \\
\text { mutagenesis }\left(30 \text { cycles of } 95^{\circ} \mathrm{C}\right. \\
\text { for } 30 \mathrm{sec}, 70^{\circ} \mathrm{C} \text { for } 30 \mathrm{sec}, 72^{\circ} \mathrm{C} \\
\text { for } 4.5 \mathrm{~min})\end{array}$ & Dpn1 & NEB turbo \\
\hline
\end{tabular}

Table 1.3 Methods and materials used for site directed mutagenesis of mycobacterial topoisomerase I 


\section{Protein expression and purification}

Wild-type MsTOP1 and its mutant proteins were overexpressed in E. coli BL21 star (DE3) strain (Invitrogen). Wild-type MtTOP1 and its mutant proteins were overexpressed in E. coli T7 Express crystal strain (New England Biolabs). The cells were grown at $30^{\circ} \mathrm{C}$ overnight. Overnight cell cultures diluted 1:100 were incubated in LB medium with $100 \mu \mathrm{g} / \mathrm{ml}$ carbenicillin at $30^{\circ} \mathrm{C}$ to exponential phase $\left(\mathrm{OD}_{600}=0.4\right)$. $1 \mathrm{mM}$ IPTG was added to BL21 star (DE3) cell culture. 0.4 mM IPTG was added to T7 express crystal cell culture. Induced cell culture was grown at $22^{\circ} \mathrm{C}$ overnight. Cell cultures were centrifuged at $4500 \mathrm{rpm}$ at $4^{\circ} \mathrm{C}$ for $30 \mathrm{~min}$. Cell pellets were resuspended in lysis buffer (50 mM sodium phosphate, $0.3 \mathrm{M} \mathrm{NaCl}, 10 \mathrm{mM}$ imidazole, and $1 \mathrm{mg} / \mathrm{ml}$ lysozyme, $\mathrm{pH} 8.0$ ). The resuspended cell mixture was left on ice for $1 \mathrm{hr}$. Four cycles of freeze-thawing were used to lyse cell. The cell lysate was centrifuged at $32000 \mathrm{rpm}$ at $4^{\circ} \mathrm{C}$ for $2 \mathrm{hr}$. The soluble cell lysate were collected and mixed with Ni-Sepharose 6 Fast Flow beads (GE Healthcare) at $4^{\circ} \mathrm{C}$ for $1 \mathrm{hr}$. The beads were packed into a column and the AKTA purifier 100 (GE healthcare Life Sciences) was used for purification. About $350 \mathrm{ml}$ of wash buffer $(50 \mathrm{mM}$ sodium phosphate, $0.3 \mathrm{M}$ $\mathrm{NaCl}, 20 \mathrm{mM}$ imidazole, $\mathrm{pH}$ 8.0) were used to wash column after sample loading. Recombinant proteins were eluted with elution buffer (50 mM sodium phosphate, $0.3 \mathrm{M} \mathrm{NaCl}, 400 \mathrm{mM}$ imidazole, $\mathrm{pH}$ 8.0). The eluted fractions were analyzed with $10 \%$ SDS-PAGE gel and eluted fractions with recombinant proteins were dialyzed against buffer A (20 mM potassium phosphate, $1 \mathrm{mM}$ EDTA pH 8.0, $10 \%$ glycerol) $+0.1 \mathrm{M} \mathrm{KCl}$. TEV protease (tobacco etch virus protease) (Kapust 
et al., 2002) was added to the purified protein after dialysis at the ratio of 1:40 (TEV protease: purified protein). The His-tagged TEV protease was purified in our lab. The recombinant protein with His-Mocr tag was digested at $20^{\circ} \mathrm{C}$ for $6 \mathrm{hr}$ followed by incubation at $4^{\circ} \mathrm{C}$ overnight in reaction buffer $(50 \mathrm{mM}$ Tris- $\mathrm{HCl}, 0.5$ mM EDTA and $1 \mathrm{mM}$ DTT, pH 8.0). Ni-Sepharose 6 Fast Flow resin (GE Healthcare Life Sciences) was used to remove cleaved N-terminal His6-Mocr tag and His-tagged TEV protease. The recombinant proteins were eluted with wash buffer (20 mM Tris- $\mathrm{HCl}, 0.3 \mathrm{mM} \mathrm{KCl}, \mathrm{pH}$ 8.0) and concentrated with Ultra Centrifugal Filters (EMD Millipore) to $\sim 10 \mathrm{ml}$. Recombinant proteins were then loaded onto size exclusion chromatography column HiPrep ${ }^{\mathrm{TM}}$ 26/60 Sephacryl ${ }^{\circledR}$ S-200 (GE Healthcare Life Sciences) to remove nuclease and proteins co-eluted in previous steps. Recombinant proteins were eluted with column buffer (20 mM Tris- $\mathrm{HCl}, 0.3 \mathrm{M} \mathrm{KCl}, \mathrm{pH} 8.0)$ and dialyzed against storage buffer (0.1 M potassium phosphate, $0.2 \mathrm{mM}$ EDTA pH 8.0, 50\% glycerol). The final step is to measure the protein concentrations with the Bio-Rad Bradford protein assay using bovine serum albumin (BSA, Bio-Rad) as standard.

\section{Complementation of topA temperature sensitive mutation in E. coli AS17 strain}

Wild-type and mutant mycobacterial topoisomerase I clones in the 20-T vector were electro-transformed into E. coli AS17 ( $\mathrm{F}^{-}$topA17(am) pLL1(Tet supD43,74)) strain. The AS17 transformants were grown at $30^{\circ} \mathrm{C}$ overnight, in LB medium with $100 \mu \mathrm{g} / \mathrm{ml}$ carbenicillin. The $\mathrm{OD}_{600}$ of overnight cultures were 
checked and adjusted to $\mathrm{OD}_{600}=1$ with $\mathrm{LB}$ medium $(100 \mu \mathrm{g} / \mathrm{ml}$ carbenicillin $)$. The adjusted cell culture was serially diluted with LB medium $(100 \mu \mathrm{g} / \mathrm{ml}$ carbenicillin) and $5 \mu \mathrm{l}$ each dilution was spotted on LB agar plate with $100 \mu \mathrm{g} / \mathrm{ml}$ carbenicillin. The plates in duplicates were incubated at $30^{\circ} \mathrm{C}$ and $42^{\circ} \mathrm{C}$ for 2 days.

\section{Relaxation assay}

Wild-type and mutant mycobacterial topoisomerase I proteins were serially diluted. Diluted proteins were incubated with $250 \mathrm{ng}$ negatively supercoiled plasmid $\mathrm{pBAD} /$ thio (purified by $\mathrm{CsCl}$ density gradient centrifugation) in the volume of $20 \mu \mathrm{L}$ with $10 \mathrm{mM}$ Tris- $\mathrm{HCl}(\mathrm{pH} 8.0), 100 \mathrm{mM} \mathrm{NaCl}, 0.1 \mathrm{mg} / \mathrm{ml}$ gelatin, and $5 \mathrm{mM} \mathrm{MgCl} 2$ at $37^{\circ} \mathrm{C}$ for 30 min. The reactions were terminated by addition of $4 \mu \mathrm{L}$ of stop buffer (50 mM EDTA, $50 \%$ glycerol and $0.5 \%(\mathrm{v} / \mathrm{v})$ bromophenol blue). The DNA was then electrophoresed in a 1\% agarose gel with TAE buffer (40 mM Tris-acetate, $\mathrm{pH}$ 8.0, $2 \mathrm{mM}$ EDTA). The gels were stained with $1 \mu \mathrm{g} / \mathrm{mL}$ concentration ethidium bromide for $1 \mathrm{hr}$ and photographed over UV light.

In the relaxation rate assay of wild-type and mutant proteins without Cterminal tail, $30 \mathrm{ng}$ wild-type MtTOP1, wild-type MsTOP1, MtTOP1-910t and MsTOP1-909t was incubated with $250 \mathrm{ng}$ negatively supercoiled plasmid pBAD/thio in $20 \mu \mathrm{l}$ of $10 \mathrm{mM}$ Tris- $\mathrm{HCl}(\mathrm{pH} 8.0), 100 \mathrm{mM} \mathrm{NaCl}, 0.1 \mathrm{mg} / \mathrm{ml}$ gelatin, and $5 \mathrm{mM} \mathrm{MgCl}_{2}$ at $37^{\circ} \mathrm{C}$ for $1,2,3,6,9,12,15,30 \mathrm{~min}$. The reactions were terminated with $4 \mu \mathrm{L}$ of stop buffer and analyzed by electrophoresis in $0.8 \%$ agarose gel with TAE buffer. The gels were stained with $1 \mu \mathrm{g} / \mathrm{mL}$ ethidium bromide for 1 hour and photographed over UV light. 
In the relaxation assay of wild-type MsTOP1 and MsTOP1-839t, $100 \mathrm{ng}$ MsTOP1, $100 \mathrm{ng}$ MsTOP1-839t and $400 \mathrm{ng}$ MsTOP1-839t were incubated with $250 \mathrm{ng}$ negatively supercoiled plasmid pBAD/thio in $20 \mu \mathrm{l}$ of $10 \mathrm{mM}$ Tris- $\mathrm{HCl}$ (pH 8.0), $50 \mathrm{mM} \mathrm{NaCl}, 0.1 \mathrm{mg} / \mathrm{ml}$ gelatin, and $5 \mathrm{mM} \mathrm{MgCl} 2$ at $37^{\circ} \mathrm{C}$ for different times, the reactions were terminated with $4 \mu$ of stop buffer and analyzed by electrophoresis in 1\% agarose gel with TAE buffer. The gels were stained with 1 $\mu \mathrm{g} / \mathrm{mL}$ concentration ethidium bromide for 1 hour and photographed over UV light.

\section{Electrophoretic mobility shift assay (EMSA)}

The oligonucleotide substrates STS32 and MT3 (Table 1.4) were labeled with $\mathrm{y}^{32} \mathrm{P}$-ATP at the 5 ' end by T4 polynucleotide kinase (New England BioLabs). The labeling reactions were carried out at $37^{\circ} \mathrm{C}$ for $30 \mathrm{~min}$ and terminated at $75^{\circ} \mathrm{C}$ for $15 \mathrm{~min}$. $\quad \mathrm{y}^{-32} \mathrm{P}$ labeled oligonucleotide substrates were purified after the labeling reaction using a Sephadex G-50 spin column (STS32) or Sephadex G-25 column (MT3) (GE Healthcare). Purified substrates were eluted in $10 \mathrm{mM}$ Tris- $\mathrm{HCl}, \mathrm{pH}$ 8.0. The electrophoretic mobility shift assay was carried out in $10 \mu \mathrm{l}$ of $20 \mathrm{mM}$ Tris-HCl (pH8.0), $100 \mu \mathrm{g} / \mathrm{ml} \mathrm{BSA}, 18 \%$ glycerol, 0.5 mM EDTA. In the STS32 mobility shift assay, 1-4 pmol wild-type MtTOP1 and MsTOP1, or mutant proteins were incubated with 5 pmol STS32 at $37^{\circ} \mathrm{C}$ for 5 min. In the MT3 electrophoretic mobility shift assay, 1-10 pmol wild-type MtTOP1 and MsTOP1, mutant proteins MtTOP1-704t and MsTOP1-701t were incubated with $2.5 \mathrm{pmol} \mathrm{MT} 3$ at $37^{\circ} \mathrm{C}$ for $5 \mathrm{~min}$. The reactions were then placed on ice for 5 
min. The non-covalent protein-DNA complex and free substrate were separated by electrophoresis in $8 \%$ polyacrylamide gel with $0.5 \times \mathrm{TBE}(45 \mathrm{mM}$ Tris- $\mathrm{HCl}, 45$ $\mathrm{mM}$ Borate, $1 \mathrm{mM}$ EDTA, $\mathrm{pH}$ 8.3) buffer at $6 \mathrm{~V} / \mathrm{cm}$ for 4.5 hours. The gels were vacuum dried at $80^{\circ} \mathrm{C}$ for 2 hours. The dried gel was analyzed by PhosphorImager.

\section{Cleavage assay}

The oligonucleotide substrates in Table 1.4 were labeled with $\mathrm{y}^{32} \mathrm{P}$-ATP at the 5 ' end. 1 pmol of wild-type MtTOP1 and MtTOP1-704t were incubated with 0.5 pmol ${ }^{32}$ P-labeled oligonucleotide substrates STS32, MT2-13, MT2-14, MT3, MT3-N13, MT3-C13 in $5 \mu$ of $10 \mathrm{mM}$ Tris- $\mathrm{HCl}(\mathrm{pH} 8.0)$ at $37^{\circ} \mathrm{C}$ for $30 \mathrm{~min}$. Wild-type MtTOP1, wild-type MsTOP1 and mutant proteins were serially diluted to $2 \mathrm{pmol} / \mu \mathrm{l}, 1 \mathrm{pmol} / \mu \mathrm{l}, 0.5 \mathrm{pmol} / \mu \mathrm{l}, 0.25 \mathrm{pmol} / \mu \mathrm{l}, 0.125 \mathrm{pmol} / \mu \mathrm{l}$, and 0.63 $\mathrm{pmol} / \mu \mathrm{l}$. $0.5 \mathrm{pmol}$ oligonucleotide substrates were incubated with serially diluted proteins in $5 \mu \mathrm{l}$ of $10 \mathrm{mM}$ Tris $-\mathrm{HCl}(\mathrm{pH} 8.0)$ at $37^{\circ} \mathrm{C}$ for $30 \mathrm{~min}$. The equal volume of loading buffer $(79 \%$ formamide, $0.2 \mathrm{M} \mathrm{NaOH}, 0.04 \%$ bromophenol blue) was added to terminate the cleavage reactions. All the reactions were then heated at $95{ }^{\circ} \mathrm{C}$ for $5 \mathrm{~min}$. The long oligo (STS32 and MT2) cleavage products were electrophoresed in 15\% sequencing gel. The short oligo (MT3, MT2-13 and so on) cleavage products were electrophoresed in $20 \%$ sequencing gel. The TBE buffer (89 mM Tris-Cl, $89 \mathrm{mM}$ Borate, $2 \mathrm{mM}$ EDTA pH 8.3) was used as running buffer. Gels were analyzed by Phosphor-Imager. 
In the cleavage assay using substrate $\mathrm{MT} 3$ with $\mathrm{Mg}^{2+}$, the oligonucleotide substrate MT3 was labeled with $\mathrm{y}^{32} \mathrm{P}$-ATP at the $5^{\prime}$ end. 1 pmol wild-type MtTOP1, MtTOP1-840t, MtTOP1-786t and MtTOP1-704t were incubated with 0.5 pmol oligonucleotide substrate MT3 in $5 \mu$ of $10 \mathrm{mM}$ Tris $-\mathrm{HCl}(\mathrm{pH} 8.0)$ at $37^{\circ} \mathrm{C}$ for 15 min. $1 \mathrm{M} \mathrm{NaCl}$ and $5 \mathrm{mM} \mathrm{MgCl} 2$ were added into the cleavage reaction for $15 \mathrm{~min}$ further incubation at $37^{\circ} \mathrm{C}$. Another reaction condition is to add $2 \mathrm{mM}$ $\mathrm{MgCl}_{2}$ into the cleavage reaction for 5 min further incubation at $37{ }^{\circ} \mathrm{C}$. The reactions were terminated with equal volume of loading buffer ( $79 \%$ formamide, $0.2 \mathrm{M} \mathrm{NaOH}, 0.04 \%$ bromophenol blue) and heated at $95{ }^{\circ} \mathrm{C}$ for $5 \mathrm{~min}$. The reaction products were analyzed by electrophoresis in $15 \%$ sequencing gel. The TBE buffer was used as running buffer. Gels were analyzed by PhosphorImager.

\begin{tabular}{|c|c|}
\hline Oligo name & Oligo sequence (5'-3') \\
\hline STS32 & 5'-CAGTGAGCGAGCTTCCGC $\downarrow T T G A C A T C C C A A T A-3^{\prime}$ \\
\hline MT2 & 5'-CAGTGAGCGAGCTTCCGC $\downarrow T T G A C T T-3 '$ \\
\hline MT2-14 & 5'-CTTCCGC $\downarrow T T G A C T T-3 '$ \\
\hline MTS2-13 & 5'-TTCCGC $\downarrow T T G A C T T-3^{\prime}$ \\
\hline MT3 & 5'-CTTCCGC $\downarrow T T G A C A T-3 '$ \\
\hline MT3-C13 & 5'-TTCCGC $\downarrow T T G A C A T-3 '$ \\
\hline MT3-N13 & 5'-CTTCCGC $\downarrow T T G A C A-3 '$ \\
\hline
\end{tabular}

Table 1.4 Oligos used in cleavage assay. Arrows indicate the cleavage site. 


\section{Religation assay}

The oligonucleotide substrate STS32 were labeled with $\mathrm{y}^{32}{ }^{32} \mathrm{P}-\mathrm{ATP}$ at the 5' end. In the religation assay, 1 pmol wild-type and mutant proteins were incubated with $0.5 \mathrm{pmol}$ oligonucleotide substrate STS32 in $5 \mu \mathrm{l}$ of $10 \mathrm{mM}$ Tris$\mathrm{HCl}(\mathrm{pH} 8.0)$ at $37^{\circ} \mathrm{C}$ for 15 min. $1 \mathrm{M} \mathrm{NaCl}, 5 \mathrm{mM}$ or $10 \mathrm{mM} \mathrm{MgCl}$ were added into the cleavage reaction respectively for $15 \mathrm{~min}$ further incubation at $37^{\circ} \mathrm{C}$. The reactions were terminated with equal volume of loading buffer $(79 \%$ formamide, $0.2 \mathrm{M} \mathrm{NaOH}, 0.04 \%$ bromophenol blue) and heated at $95^{\circ} \mathrm{C}$ for $5 \mathrm{~min}$. The reaction products were analyzed by electrophoresis in $15 \%$ sequencing gel. The TBE buffer was used as running buffer. Gels were analyzed by PhosphorImager.

\section{Catenation assay}

Catenation of M13mp18 ssDNA circles was assayed with a protocol similar to previously described conditions (Bhaduri et al., 1998). Wild-type MsTOP1, Wild-type MtTOP1, MtTOP1-704t was diluted into $0.5 \mathrm{pmol} / \mu \mathrm{l}, 0.25$ $\mathrm{pmol} / \mu \mathrm{l}, 0.125 \mathrm{pmol} / \mu \mathrm{l}$. The reaction volume of $20 \mu \mathrm{l}$ contained $20 \mathrm{mM}$ Tris- $\mathrm{HCl}$ (pH 8.0), $20 \mathrm{mM} \mathrm{KCl}, 2 \mathrm{mM} \mathrm{MgCl}$, $0.05 \mathrm{mg} / \mathrm{ml} \mathrm{BSA}, 10 \mathrm{mM}$ spermidine, $30 \%$ glycerol, and $0.5 \mu \mathrm{g}$ of M13mp18 ssDNA (from Bayou Biolabs). After incubation with the indicated amount of topoisomerase protein for $1 \mathrm{hr}$ at $52^{\circ} \mathrm{C}$, the reactions were terminated with the addition of $1 \%$ SDS, $5 \mathrm{mM}$ EDTA, and $12 \mu \mathrm{g}$ of proteinase $\mathrm{K}$ (New England Biolabs) and were left at $37^{\circ} \mathrm{C}$ for $1 \mathrm{hr}$ before electrophoresis in $0.8 \%$ agarose gel. The TAE buffer was used as running 
buffer. The gels were stained with $1 \mu \mathrm{g} / \mathrm{mL}$ concentration ethidium bromide for 1 hr and photographed over UV light.

\section{Decatenation assay}

Decatenation of kinetoplast DNA (kDNA) was carried out in the reaction volume of $20 \mu$ containing $50 \mathrm{mM}$ Tris- $\mathrm{HCl}(\mathrm{pH} 8.0), 120 \mathrm{mM} \mathrm{KCl}, 10 \mathrm{mM} \mathrm{MgCl}_{2}$, $30 \mathrm{mg} / \mathrm{ml} \mathrm{BSA}, 0.5 \mathrm{mM}$ DTT, 30\% glycerol, and $150 \mathrm{ng} \mathrm{kDNA}$ (from Topogen). MtTOP1 and MtTOP1-704t was diluted to $6 \mathrm{pmol} / \mu \mathrm{l}, 3 \mathrm{pmol} / \mu \mathrm{l}$ and $1.5 \mathrm{pmol} / \mu \mathrm{l}$. 1 $\mu \mathrm{l}$ diluted topoisomerase protein was added to decatenation reaction and incubated at $45^{\circ} \mathrm{C}$ for $1 \mathrm{~h}$. To test the stability of kDNA in $45^{\circ} \mathrm{C}$, kDNA was incubated without enzyme at $45^{\circ} \mathrm{C}$ for $1 \mathrm{hr}$. The human topoisomerase lla was used as the positive control for decatenaton activity, The human TOPIla decatenation reaction was carried in $50 \mathrm{mM}$ Tris- $\mathrm{HCl}(\mathrm{pH} 8.0), 120 \mathrm{mM} \mathrm{KCl}, 10$ $\mathrm{mM} \mathrm{MgCl} 2,3 \mathrm{mM} \mathrm{ATP}, 30 \mathrm{mg} / \mathrm{ml} \mathrm{BSA}, 0.5 \mathrm{mM}$ DTT, $30 \%$ glycerol, and $150 \mathrm{ng}$ kDNA (from Topogen). Reactions were terminated with the addition of $4 \mu \mathrm{l}$ of $5 \%$ sarkosyl, $0.025 \%$ bromophenol and $50 \%$ glycerol before electrophoresis in $1 \%$ agarose gel. TAE buffer containing $0.5 \mu \mathrm{g} / \mathrm{ml}$ ethidium bromide was used as running buffer. The gels photographed over UV light. 


\section{RESULTS}

\section{Complementation of topA temperature sensitive mutation in E. coli AS17 by}

recombinant mycobacterial topoisomerase I

Previous studies showed that $E$. coli AS17 with the temperature sensitive mutation in topoisomerase I gene (top $A^{\text {ts }}$ ) complemented by recombinant MtTOP1 could grow at the non-permissive temperatures of $37^{\circ} \mathrm{C}$ and $42^{\circ} \mathrm{C}$ (Narula et al., 2010). In the current study, plasmids with mutant MtTOP1 and MsTOP1 genes in the 2O-T vector were transformed into E. coli AS17 strain. Escherichia coli AS17 strain complemented with 20-T vector was used as a negative control. Escherichia coli AS17 strain complemented with plasmids 2OTMtTOP1 and 2OT-MsTOP1 were used as positive control. As the results showed in Figure 1.3, E. coli AS17 with vector could not grow at $42^{\circ} \mathrm{C}$. Wild-type MtTOP1 and MsTOP1 complemented the top $A^{\text {ts }}$ mutation in the chromosome of E. coli AS17 and they are sufficient for the growth of E. coli AS17. Strains transformed with mutant plasmids, AS17/2OT MtTOP1-910t, AS17/2OT MtTOP1-840t, AS17/2OT MsTOP1-909t, and AS17/2OT MsTOP1-839t also grew at $42^{\circ} \mathrm{C}$. Mutant strains AS17/2OT MtTOP1-786t, AS17/2OT MtTOP1-704t, AS17/2OT MsTOP1-839t, and AS17/2OT MsTOP1-701t had no growth or little growth at $42^{\circ} \mathrm{C}$. These data showed that NTD combined with C-terminal subdomains D5 and D6 could not support the growth of E. coli. The addition of subdomain D7 is minimally require for in vivo viability. 
$30^{\circ} \mathrm{C}$

AS17/2OT

AS17/2OT-MtTOP1

AS17/2OT MtTOP1-910t

AS17/2OT MtTOP1-840t

AS17/2OT MtTOP1-786t

AS17/2OT MtTOP1-704t

AS17/2OT

AS17/2OT MsTOP1

AS17/2OT MsTOP1- 909t

AS17/2OT MsTOP1-839t

AS17/2OT MsTOP1-785t

AS17/2OT MsTOP1-701t $42^{\circ} \mathrm{C}$
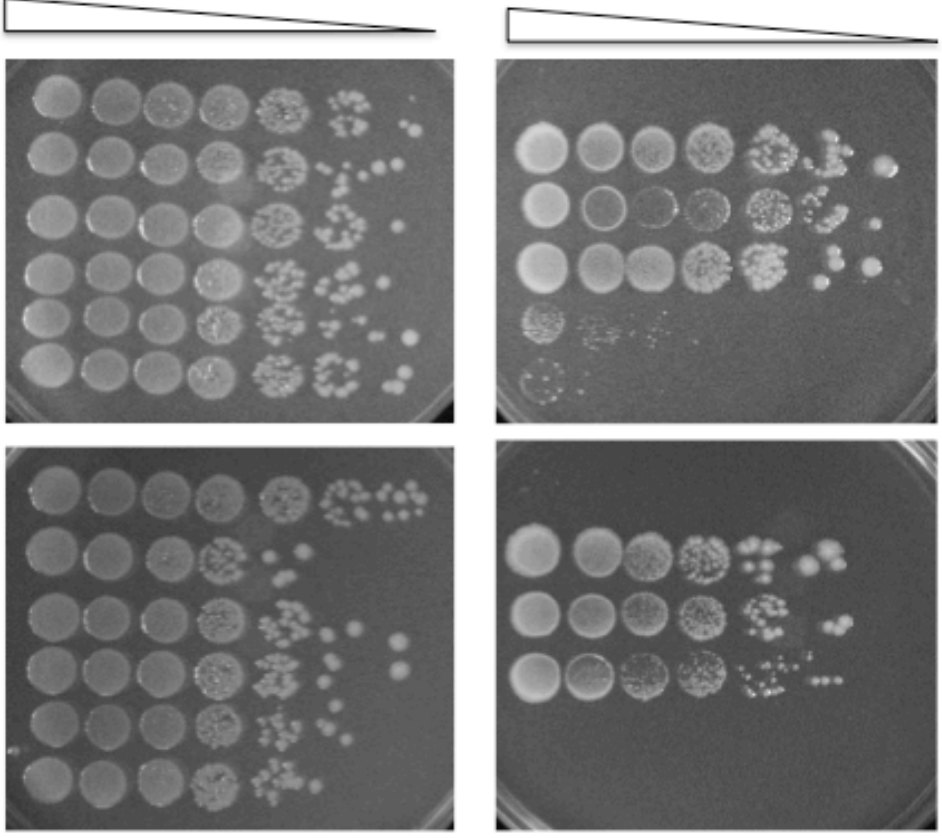

Figure 1.3 Growth of $E$. coli AS17 complemented by recombinant mycobacterial topoisomerase $\mathrm{I}$ at $30^{\circ} \mathrm{C}$ and $42^{\circ} \mathrm{C}$ in LB agar plates. 


\section{Relaxation assay of mycobacterial topoisomerase I with negatively supercoiled DNA}

Previous studies showed that MsTOP1 with only NTD (D1-D4) or CTD (D5-D8+basic tail) lost the relaxation activity (Jain and Nagaraja, 2006). The truncated proteins of mycobacterial topoisomerase I that retained individual subdomains of the CTD may maintain partial relaxation activity. In the agarose gel electrophoresis results, $100 \mathrm{ng}$ wild-type MsTOP1 and wild-type MtTOP1 fully relaxed the $250 \mathrm{ng}$ negatively supercoiled DNA substrate (Figure 1.4, Figure 1.5). In contrast, $200 \mathrm{ng}$ truncated enzyme MsTOP1-701t and MtTOP1-704t that retained D1-D5 did not show any relaxation activity (Figure 1.4A, Figure1.5A). In Figure 1.4B and Figure 1.5B, $100 \mathrm{ng}$ truncated enzyme MsTOP1-785t and MsTOP1 786t with D1-D6 did not show any difference from negative control. In Figure 1.4C and Figure 1.5C, $200 \mathrm{ng}$ MsTOP1-839t and MtTOP1-840t showed partial weak relaxation activity. Compared to the wild-type mycobacterial topoisomerase I, the relaxation activity of MtTOP1-840t and MsTOP1-839t was reduced about 16-fold. Mutant proteins MtTOP1-910t and MsTOP1-909t are more active than other truncated enzymes in relaxation assays (Figure 1.4D, Figure1.5D). Compared with products from each reaction of wild-type MtTOP1 and MsTOP1, the relaxation activity of MtTOP1-910t and MsTOP1-909t decreased 2- to 4-fold. This data shows that truncation mutants with C-terminal subdomains D1-D7 retain partial relaxation activity, and it is sufficient for supporting the viability of $E$. coli in vivo when present in high copy number

plasmid 2O-T. Subdomain D5 and D6 subdomains combined with NTD could not 
maintain the relaxation activity of mycobacterial topoisomerase I. Subdomain D7 needs to be present for the relaxation of negatively supercoiled DNA. Serial dilutions of MtTOP1-910t and MsTOP1-909t showed that the truncated mutations with D1-D8 that were miss the basic tail at the C-terminus had a slight reduction in relaxation activity when compared to wild-type.

Mutant proteins MtTOP1-909t and MsTOP1-910t were incubated with 250 ng negatively supercoiled DNA for 1, 2, 3, 6, 9, 15, 30, 15 and 60 min and compared with $30 \mathrm{ng}$ wild-type MtTOP1 and MsTOP1 incubated at the same conditions and times (Figure 1.6). At each time point, wild-type MtTOP1 and MsTOP1 are more active than MtTOP1-910t and MsTOP1-909t. Mutant proteins MtTOP1-910t and MsTOP1-909t have reduced relaxation catalytic rate. The final products are more fully relaxed for the wild-type enzymes. The C-terminal tail that is absent in MtTOP1-910t and MsTOP1-909t enhanced the relaxation activity and processivity of mycobacterial topoisomerase I.

Removed of negative supercoils by $30 \mathrm{ng}$ of wild-type and mutant mycobacterial topoisomerase I began slow starting from 9-15 min, as the partially relaxed DNA has less single-stranded DNA region for binding to the enzyme. In Figure 1.7, 100 and $400 \mathrm{ng}$ MsTOP1-839t was incubated with $250 \mathrm{ng}$ negatively supercoiled DNA at $37^{\circ} \mathrm{C}$ up to $180 \mathrm{~min}$. MsTOP1-839t exhibited only partial relaxation activity even at $180 \mathrm{~min}$ and a slow catalytic rate. This result showed that while the presence of D5-D7 can allow relaxation of negatively supercoiled 
DNA by mycobacterial topoisomerase I, subdomain D8 played an important role in the catalysis of the relaxation reaction.

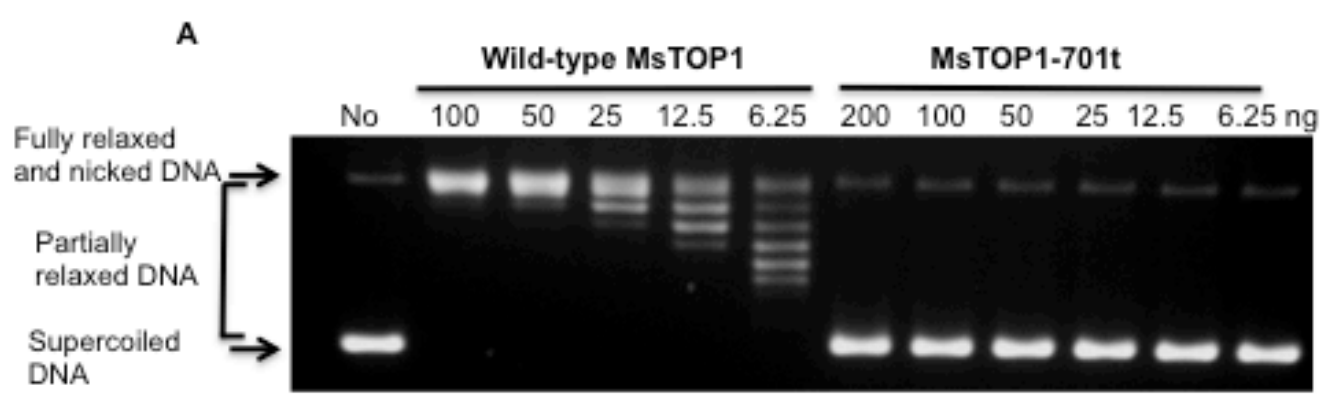

B
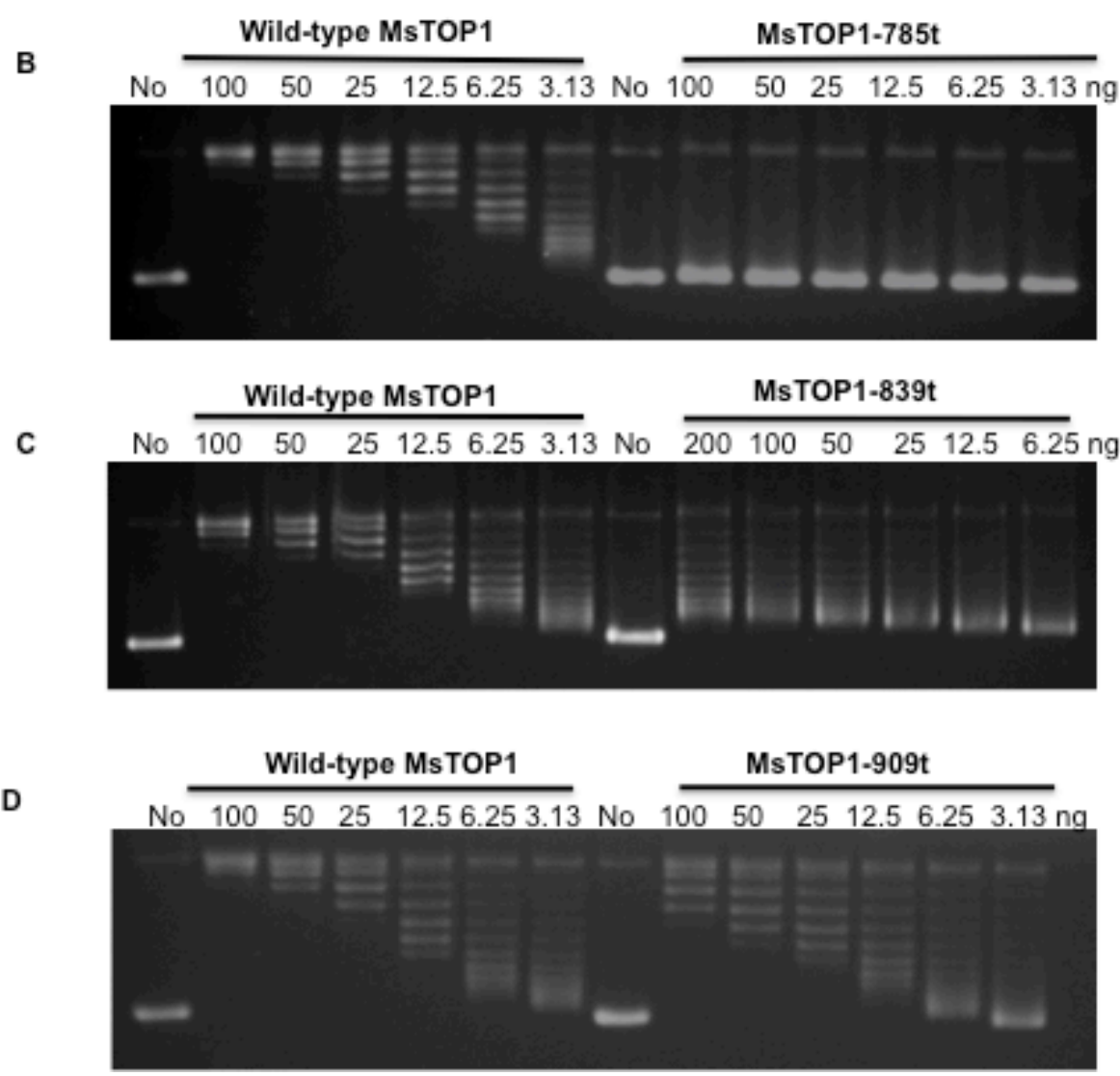

Figure 1.4 Relaxation assays of serially diluted wild-type and mutant MsTOP1 with negatively supercoiled pBAD/Thio DNA. (A) Relaxation assay of wild-type MsTOP1 and MsTOP1-701t. (B) Relaxation assay of wild-type MsTOP1 and MsTOP1-785t. (C) Relaxation assay of wild-type MsTOP1 and MsTOP1-839t. (D) Relaxation assay of wildtype MsTOP1 with MsTOP1-909t. No, no enzyme added. 

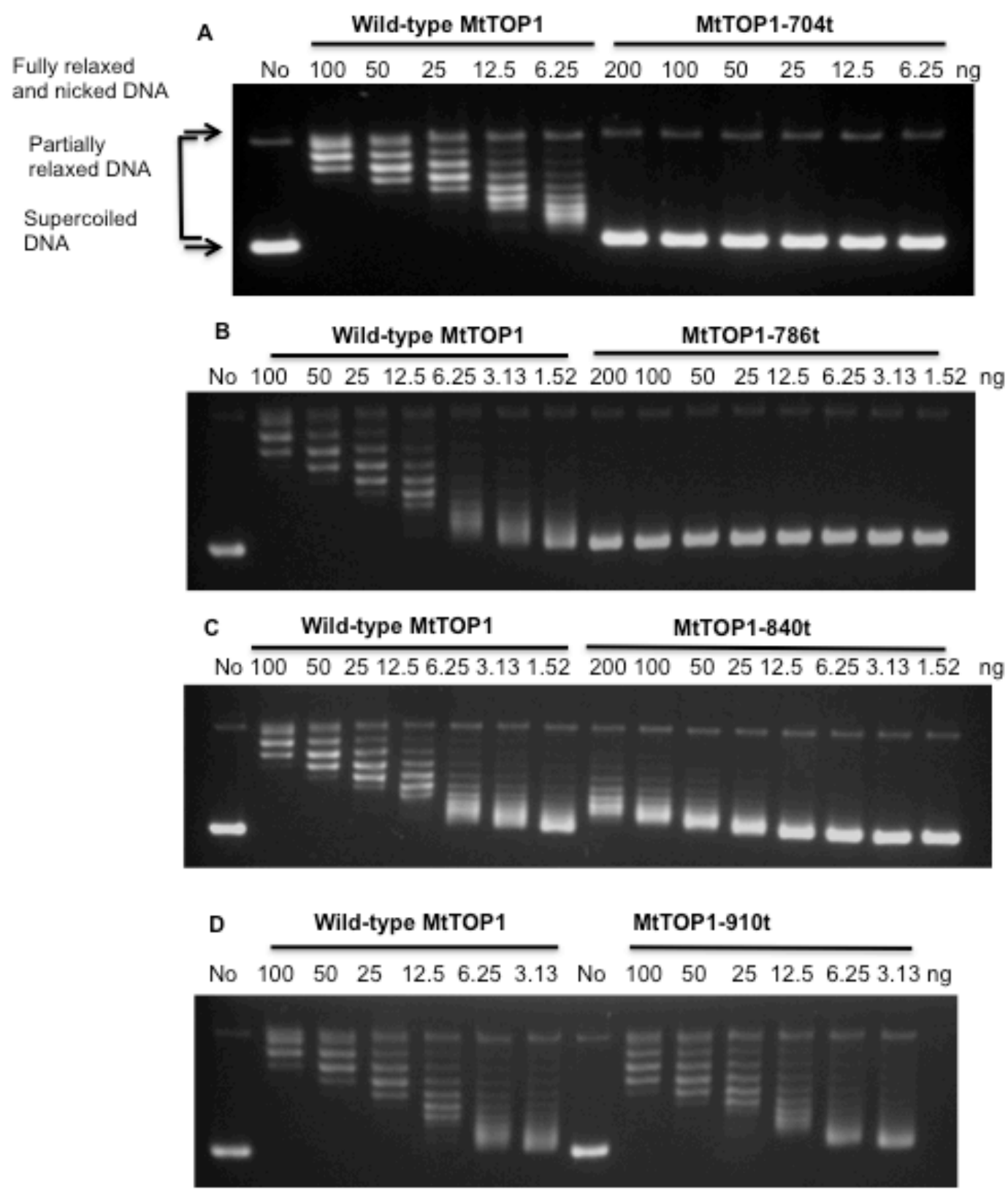

Figure 1.5 Relaxation assays of serially diluted wild-type and mutant MtTOP1 with negatively supercoiled pBAD/Thio DNA. (A) Relaxation assay of wild-type MtTOP1 with MtTOP1-704t. (B) Relaxation assay of wild-type MtTOP1 and MtTOP1-786t. (C) Relaxation assay of wild-type MtTOP1 and MtTOP1-840t. (D) Relaxation assay of wild-type MtTOP1 and MtTOP1-910t. No, no enzyme added. 


\section{A}
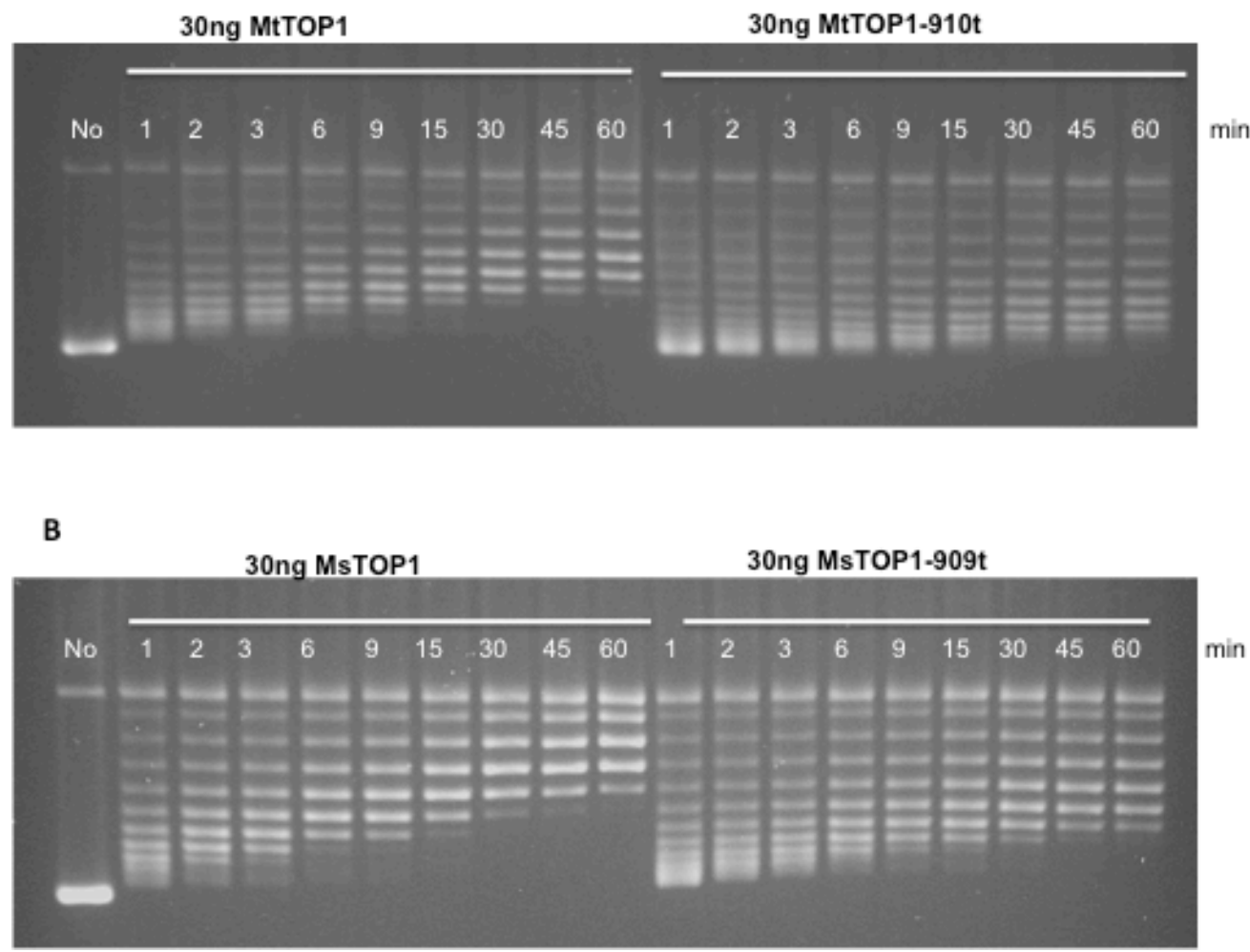

Figure 1.6 Relaxation time course for mycobacterial topoisomerase I with negatively supercoiled pBAD/Thio DNA. (A) Assays of $30 \mathrm{ng}$ wild-type MtTOP1 and MtTOP1-910t. (B) Assays of $30 \mathrm{ng}$ wild-type MsTOP1 and $30 \mathrm{ng}$ MsTOP1-909t. No, no enzyme added. 

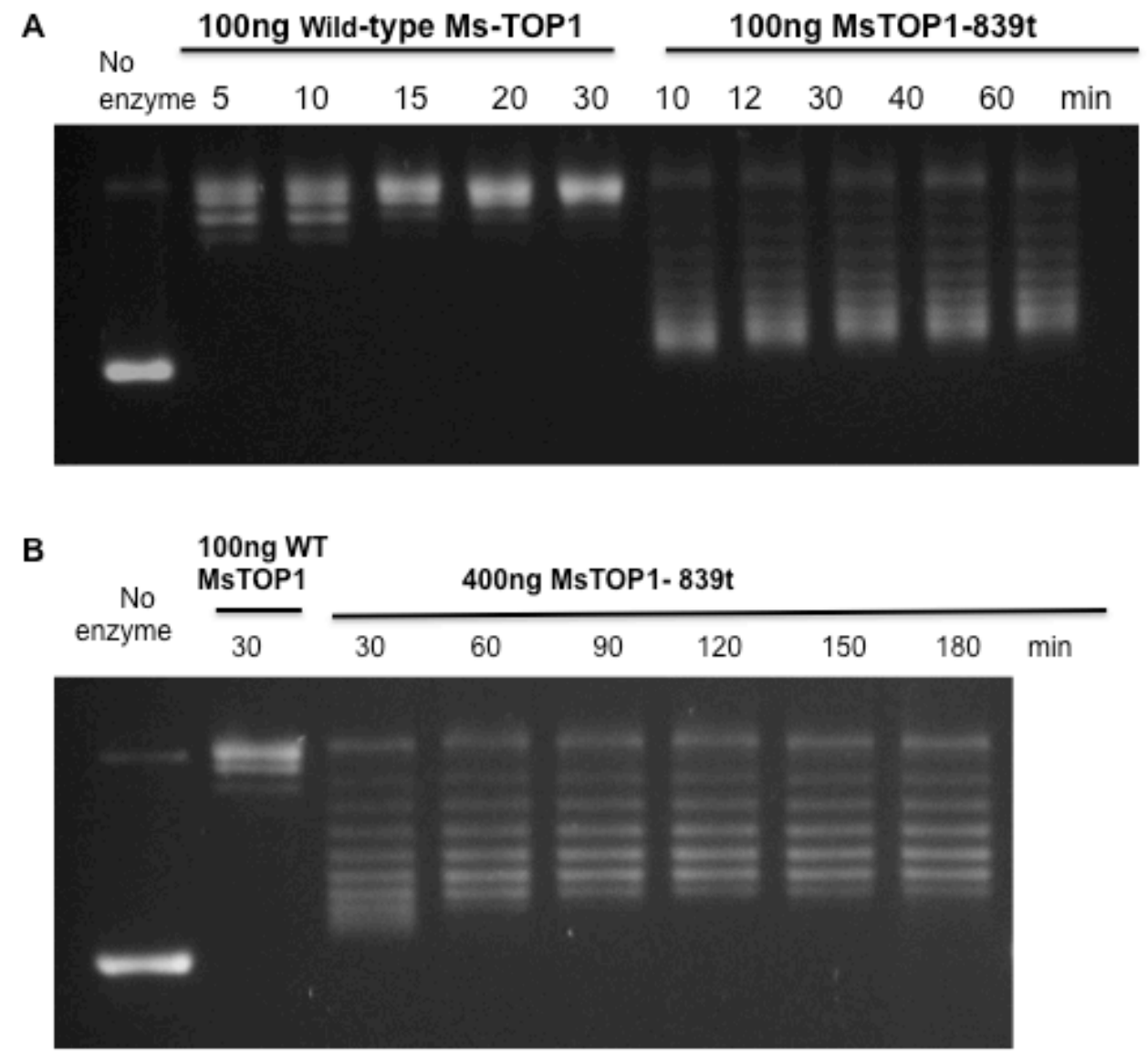

Figure 1.7 Relaxation time course for wild-type MsTOP1 and MsTOP1-839t with negatively supercoiled pBAD/Thio DNA. (A) $100 \mathrm{ng}$ MsTOP1 and $100 \mathrm{ng}$ MsTOP1$839 \mathrm{t}$ were incubated at $37^{\circ} \mathrm{C}$ for different times (5-60 min). (B) $400 \mathrm{ng}$ MsTOP1 was incubated at $37^{\circ} \mathrm{C}$ for different times for $30,60,120,150,180 \mathrm{~min}$. 


\section{Mycobacterial topoisomerase I truncated mutant proteins with C-terminal subdomain D5 only have reduced binding to oligonucleotide STS32 and MT3}

In an earlier study, the NTD and CTD of mycobacterial topoisomerase I were found to each bind to DNA (Jain and Nagaraja, 2006). In this study, the EMSA of oligonucleotide STS32 and MT3 were used to study the DNA binding activity of wild-type and mutant mycobacterial topoisomerase (Figure 1.8, Figure 1.9). In the DNA binding assay of STS32, MtTOP1-786t, MtTOP1-704t, MsTOP1-785t and MsTOP1-701t showed less binding activity than wild-type and other mutant mycobacterial topoisomerase I (Figure 1.8). Deletion mutation proteins MsTOP1-701t and MtTOP1-704t that with NTD and C-terminal subdomain D5 have significantly reduced DNA binding activity when compared to wild-type mycobacterial topoisomerase I with oligonucleotide STS32. Wild-type MtTOP1 and MsTOP1 also have significantly higher binding activity than MtTOP1-704t and MsTOP1-701t with oligonucleotide MT3 (Figure 1.9). These results show that truncated mutant proteins with NTD and C-terminal subdomain D5 only have significantly reduced binding to short ssDNA when compared to wild-type mycobacterial topoisomerase I. The C-terminal subdomains likely contribute significantly to binding of one of the unwound DNA strand during relaxation of negatively supercoiled DNA by mycobacterial topoisomerase I. 


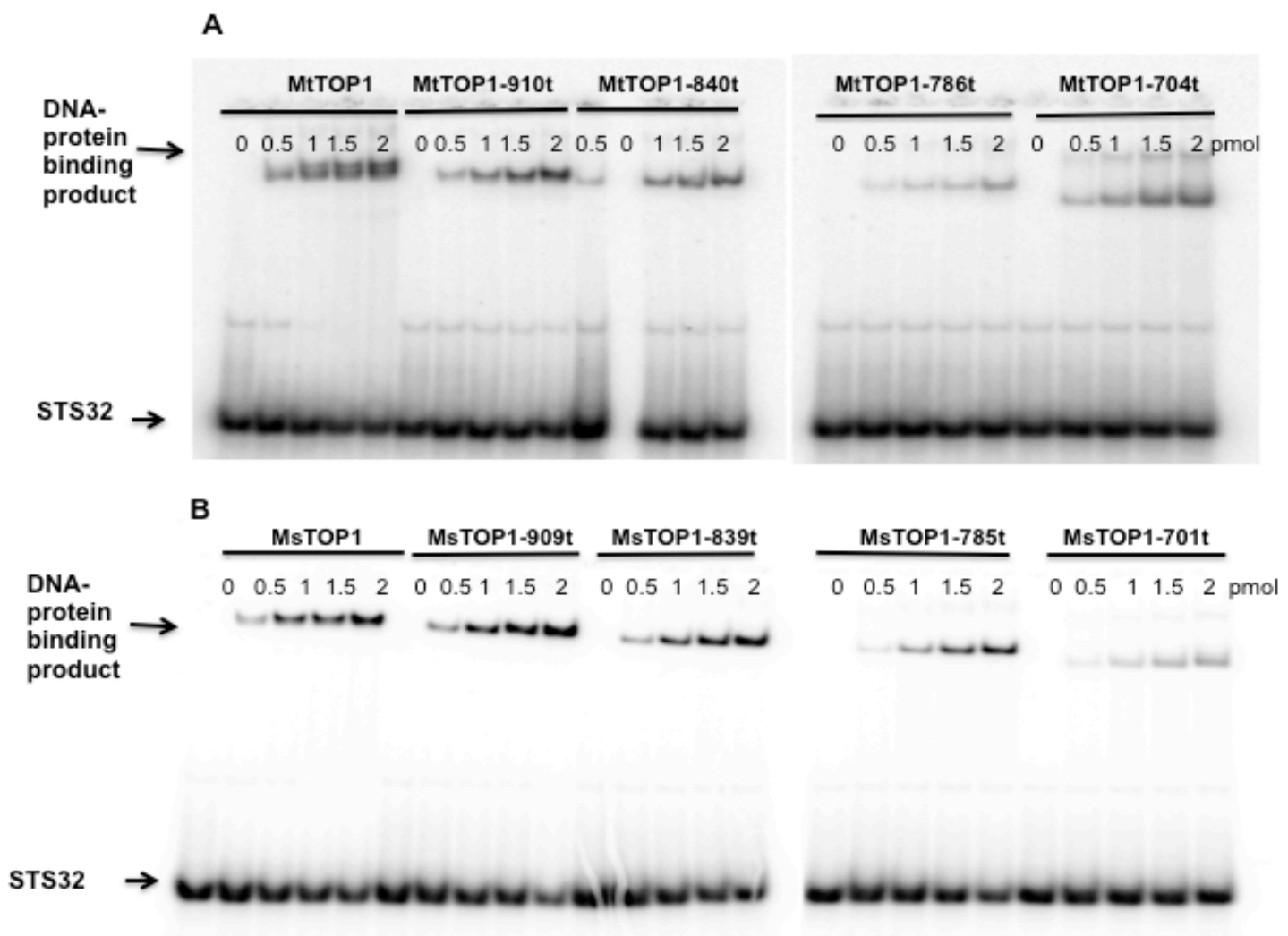

Figure 1.8 Electrophoretic mobility shift assay for formation of non-covalent complex between labeled STS32 oligonucleotide and mycobacterial

topoisomerase I. (A) EMSA assay of wild-type MtTOP1 and truncate mutant MtTOP1. (B) EMSA assay of wild-type MsTOP1 and truncate mutant MsTOP1. 


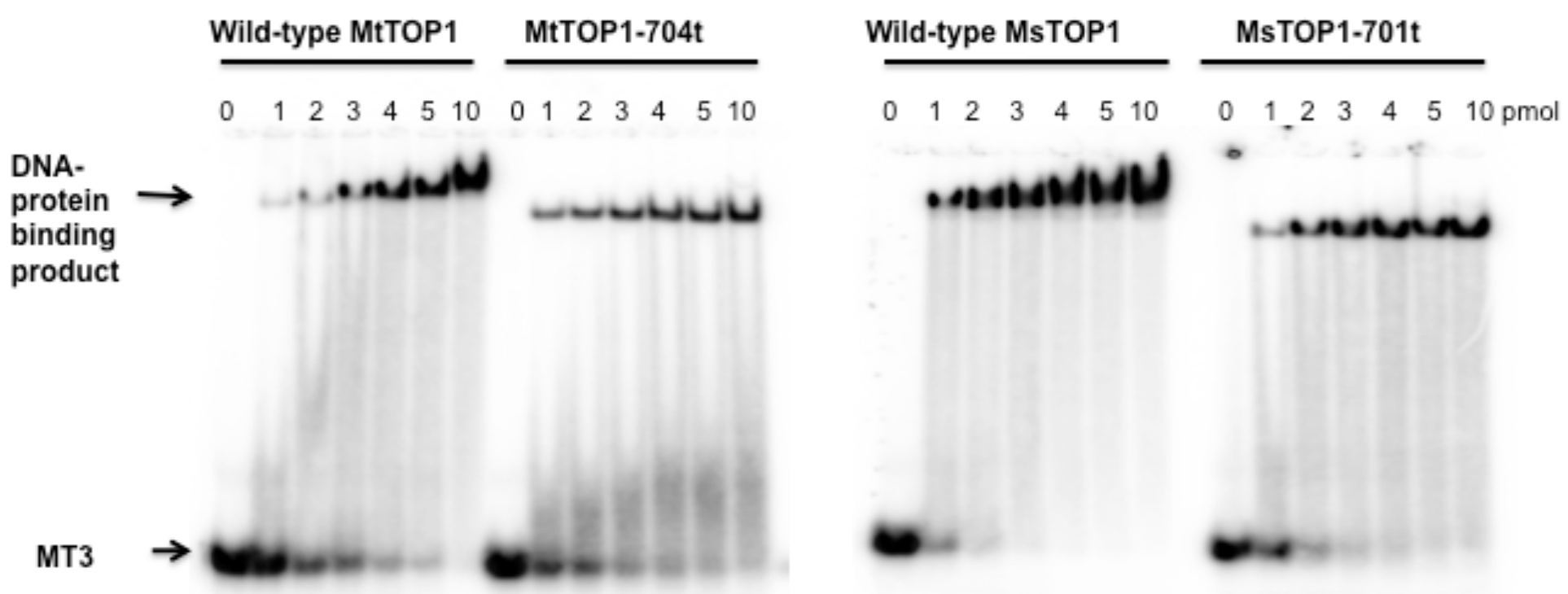

Figure 1.9 Electrophoretic mobility shift assay of MtTOP1, MtTOP1-704t, MsTOP1 and MsTOP1-701t with labeled MT3 oligonucleotide. 


\section{Cleavage activity of mycobacterial topoisomerase I with 32 nucleotide long STS32 and 25 nucleotide long MT2 substrate}

We used serially diluted protein to test the cleavage activity of wild-type and mutant mycobacterial topoisomerase I with 5'-labeled oligonucleotide STS32 and MT2. Oligonucleotide STS32 contains 32 nucleotides, and MT2 contains 25 nucleotides. The results of wild-type MtTOP1, MtTOP1-910t, MtTOP1-840t, MtTOP1-786t and MtTOP1-704t cleavage activity assay with STS32 substrate show that all the truncated mutant $M$. tuberculosis topoisomerase I can cleave this substrate (Figure 1.10). The cleavage activity assay results of wild-type MsTOP1, MsTOP1-909t, MsTOP1-839t, MsTOP1-785t and MsTOP1-701t with oligonucleotide STS32 also show that all the truncated mutant $M$. smegmatis topoisomerase I have cleavage activity with oligonucleotide STS32 (Figure 1.11). The cleavage activity results in Figure 1.12 show that wild-type MsTOP1, MsTOP1-909t, MsTOP1-839t, MsTOP1-785t and MsTOP1-701t performed DNA cleavage on substrate MT2. Figure 1.13 showed that MtTOP1-704t formed a higher level of cleavage product than wild-type MtTOP1 with MT2 substrate. Similar results were observed between MsTOP1 and MsTOP1-701t (Figure 1.12). The deletion of C-terminal subdomains D6-D8 of mycobacterial topoisomerase I did not lead to the loss of the cleavage activity. A previous study has concluded that the NTD of MsTOP1 forming at residues 616 can cleave DNA (Jain and Nagaraja, 2006). These studies show that active site of mycobacterial topoisomerase I in the NTD can carry out DNA cleavage in the absence of most of the CTD. The results in Figure 1.13 suggest that 
subdomains D6-D8 may compete with the active site in NTD for binding to the 25 nucleotides long MT2 substrate, so that more cleavage product is formed from the NTD+D5 form of mycobacterial topoisomerase I with the rest of the CTD not present. As protein/oligonucleotide ratio increases, more cleavage product is formed from MtTOP1-704t, while cleavage by wild-type becomes suppressed because the CTD subdomains may have higher affinity for the MT2 substrate than the NTD active site. The longer length STS substrate may be able to interact simultaneously with both the NTD and CTD. This is further investigated with shorter oligonucleotide substrates. 


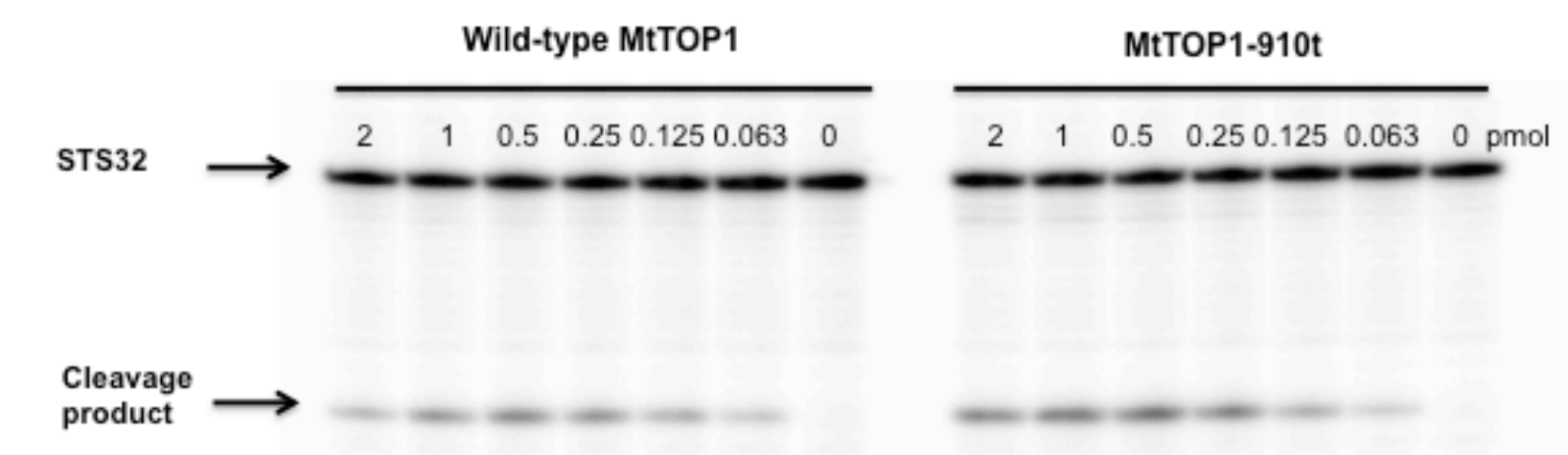

MtTOP1-840t

$\begin{array}{llllllll}2 & 1 & 0.5 & 0.25 & 0.125 & 0.063 & 0\end{array}$

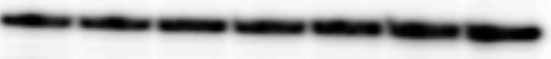

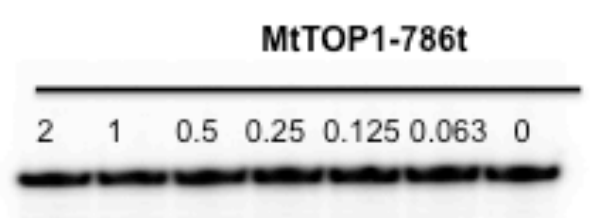

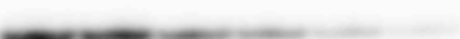

MtTOP1-704t

$\begin{array}{lllllllll}2 & 1 & 0.5 & 0.25 & 0.125 & 0.063 & 0 & \mathrm{pmol}\end{array}$ $-1-1-1-$

$-1-0-1-$

Figure 1.10 Cleavage activity assay wild-type MtTOP1, MtTOP1-910t, MtTOP1-840t, MtTOP1-786t and MtTOP1704t with STS32 substrate. 

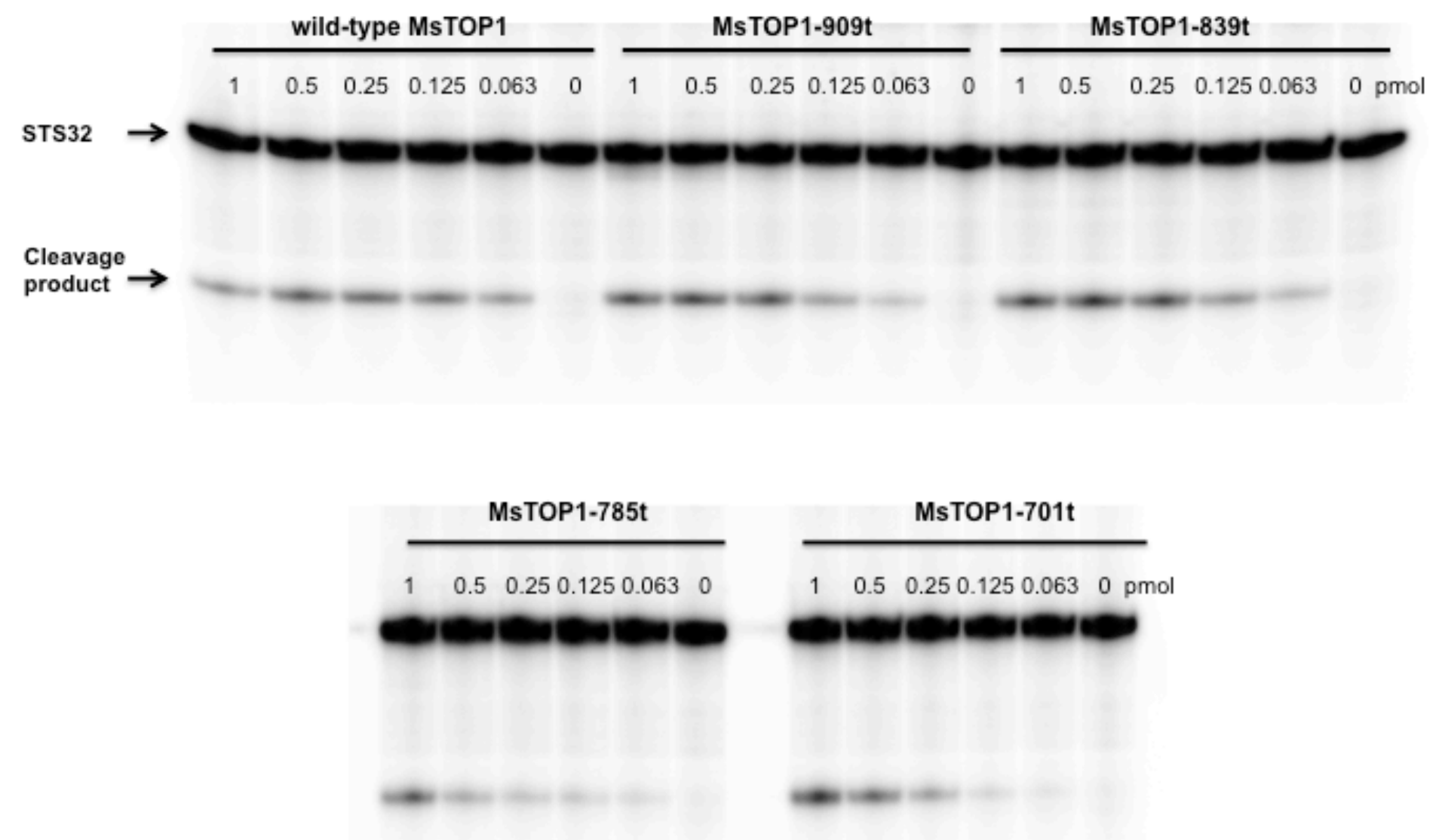

Figure 1.11 Cleavage activity assay of wild-type MsTOP1, MsTOP1-909t, MsTOP1-839t, MsTOP1-785t and MsTOP1-701t with STS32 substrate. 

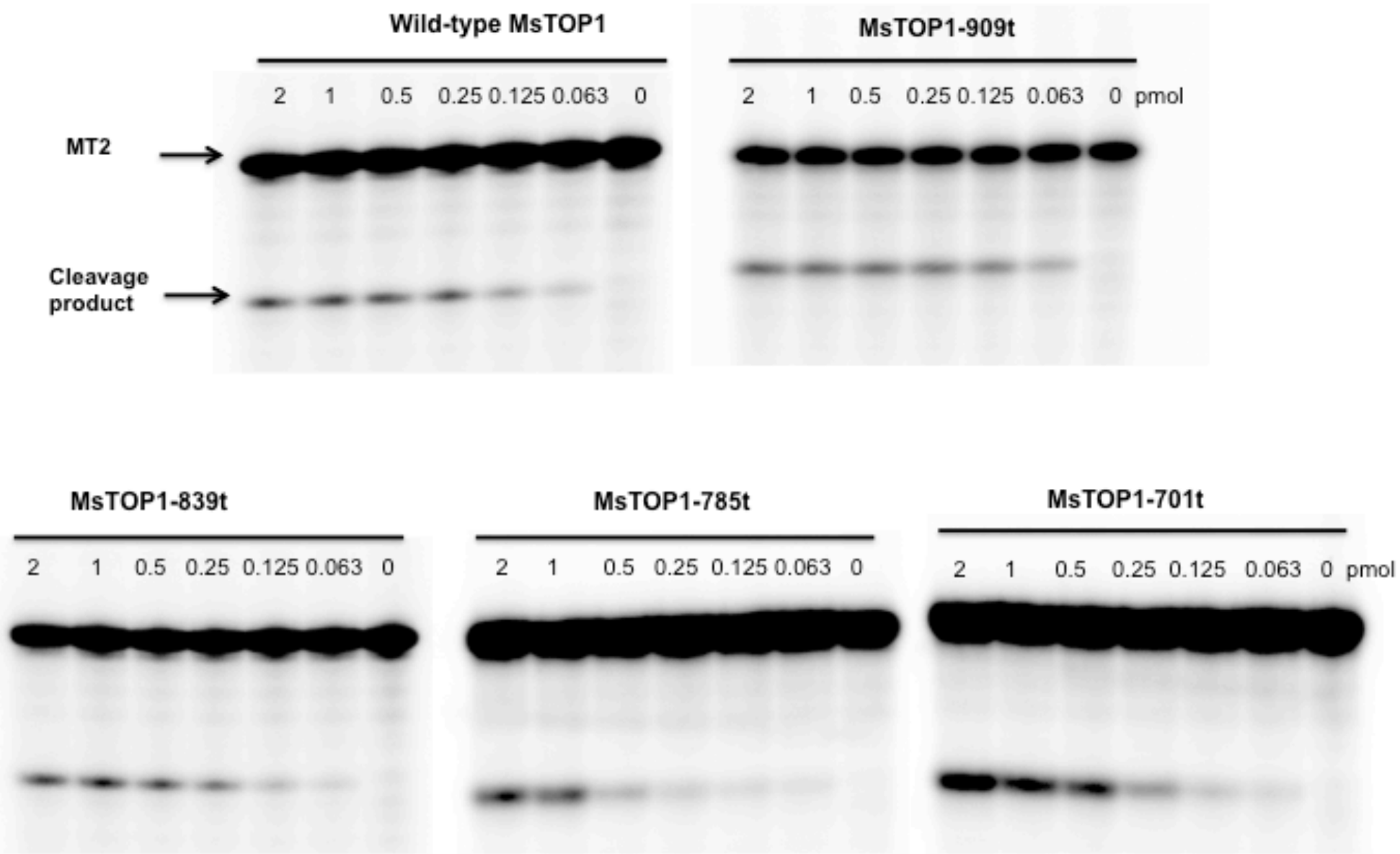

Figure 1.12 Cleavage activity assay of wild-type MsTOP1, MsTOP1-909t, MsTOP1-839t, MsTOP1-785t and MsTOP1-701t with MT2 substrate. 


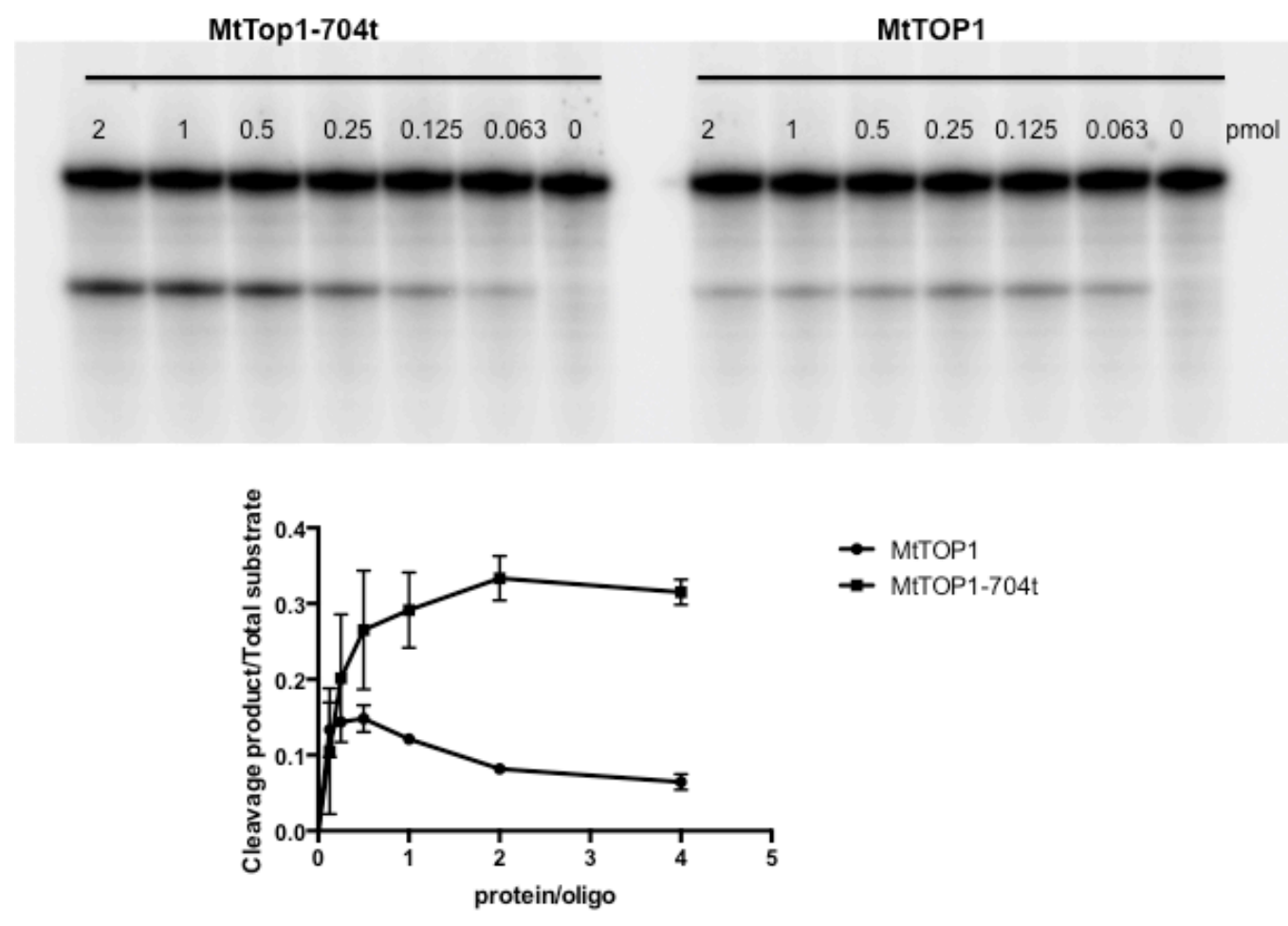

Figure 1.13 Cleavage of MT2 substrate by MtTOP1-704t is more robust than wildtype MtTOP1. (A) Assay of MT2 substrate cleavage by serially diluted MtTOP1-704t and MtTOP1 cleavage assay with MT2. (B) Analysis of percentage cleavage product analysis. The average deviation from two experiments is shown.

\section{Cleavage assay of mycobacterial topoisomerase I with short oligonucleotides}

Short oligonucleotides (Figure 1.14) MT2-14, MT2-13, MT3-N13 and MT3 contain 13-14 nucleotides. wild-type MtTOP1 at 1 pmol cleavage assay reaction did not show any cleavage activity with these short oligos. However, high cleavage activity was observed with 1 pmol MtTOP1-704t and these short oligos. Oligonucleotide MT3 (14 nucleotides) is shorter than the 32-nucleotide-long 
STS32 and 25-nucleotide-long MT2. When MT3 was titrated with $0.25-2$ pmol of MtTOP1 and MsTOP1, cleavage activity of substrate MT3 (0.5 pmol) was not observed. However, MtTOP1 and MsTOP1 at lower stoichiometry (0.063 and $0.125 \mathrm{pmol}$ ) produced cleavage product from MT3 (Figure 1.15, Figure 1.16). In contrast mutant proteins with deletions in CTD produced cleavage product from MT3 at both high and low stoichiometry of enzymes (Figure 1.15, Figure 1.16).

The DNA binding assay (Figure 1.9) showed that MsTOP1 and MtTOP1 bind MT3 at higher protein: DNA stoichiometry even when DNA cleavage was not observed (Figure 1.15). These data suggest that the short oligonucleotide MT3 has higher affinity for the CTD than the NTD. When the CTD of mycobacterial topoisomerase I was fully occupied, additional short oligonucleotide will then bind to the NTD active site for DNA cleavage to occur. This result shows that the CTD in mycobacterial topoisomerase I is responsible for recognition of negatively supercoiled duplex DNA by interacting with one strand of the unwound DNA and directing the complementary strand to the NTD active site for DNA cleavage. 


\begin{tabular}{|l|c|c|c|c|c|c|c|c|c|c|c|c|c|c|c|c|c|c|}
\hline & \multicolumn{3}{|c|}{ STS32 } & \multicolumn{3}{|c|}{ MT2-14 } & \multicolumn{3}{|c|}{ MTS2-13 } & \multicolumn{3}{c|}{ MT3 } & \multicolumn{3}{l|}{ MT3-N13 } & \multicolumn{2}{l|}{ MT3-C13 } \\
\hline 1 pmol MtTOP1 & - & + & - & - & + & - & - & + & - & - & + & - & - & + & - & - & + & - \\
\hline $\begin{array}{l}1 \mathrm{pmol} \\
\text { MtTOP1-704t }\end{array}$ & - & - & + & - & - & + & - & - & + & - & - & + & - & - & + & - & - & + \\
\hline
\end{tabular}

Figure 1.14, Cleavage of short 13-14 base long oligo by MtTOP1-704t but not wild-type MtTOP1. Wild-type MtTOP1 and MtTOP1-704t were incubated with STS32, MT2-14, MTS2-13, MT3, MT3-N13, MT3-C13 at $37^{\circ} \mathrm{C}$ for 30 $\min$. 

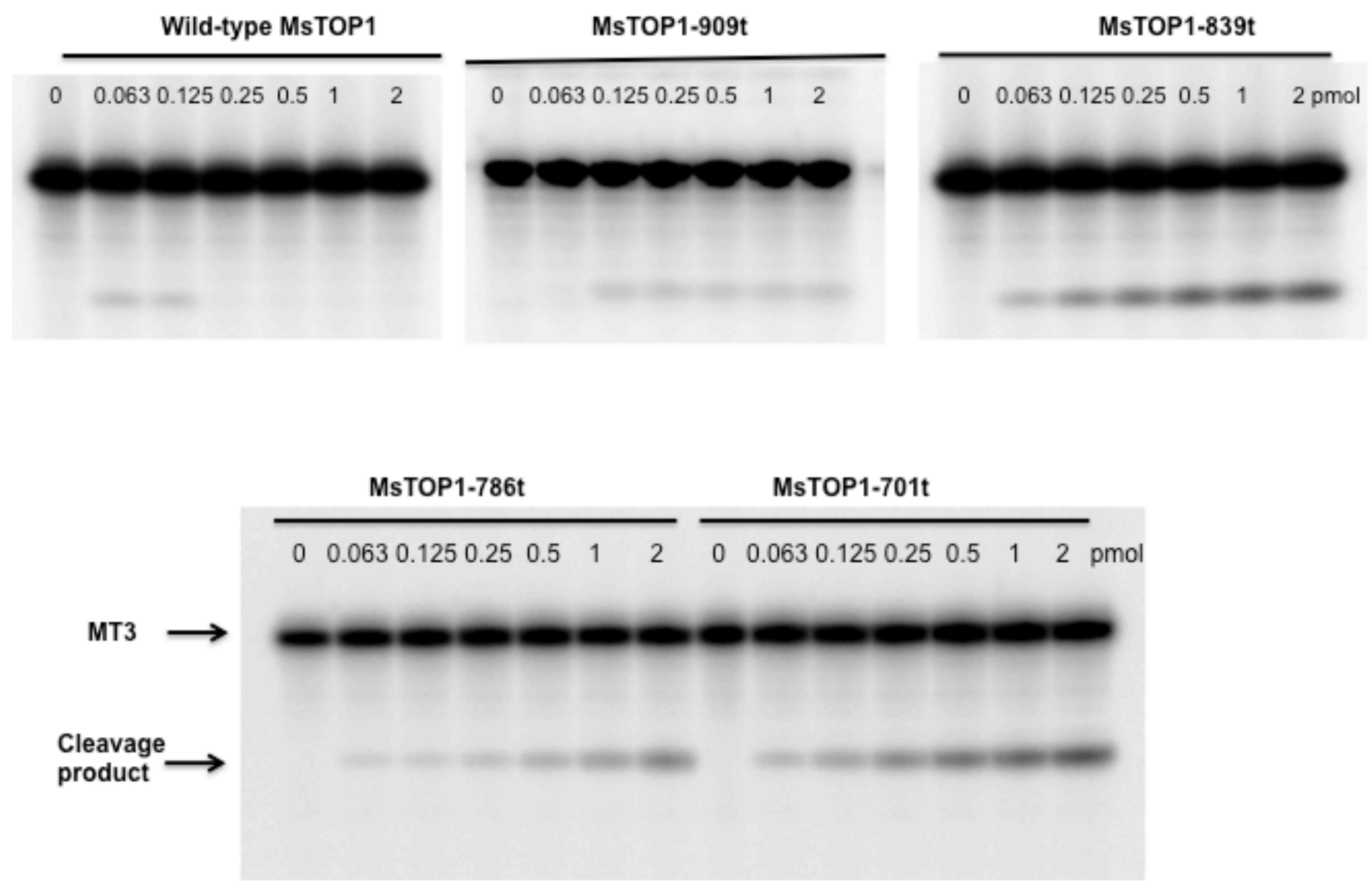

Figure 1.15 Cleavage activity assay of wild-type MsTOP1, MsTOP1-909t, MsTOP1-839t, MsTOP1-785t and MsTOP1-701t with MT3 oligonucleotide substrate. 

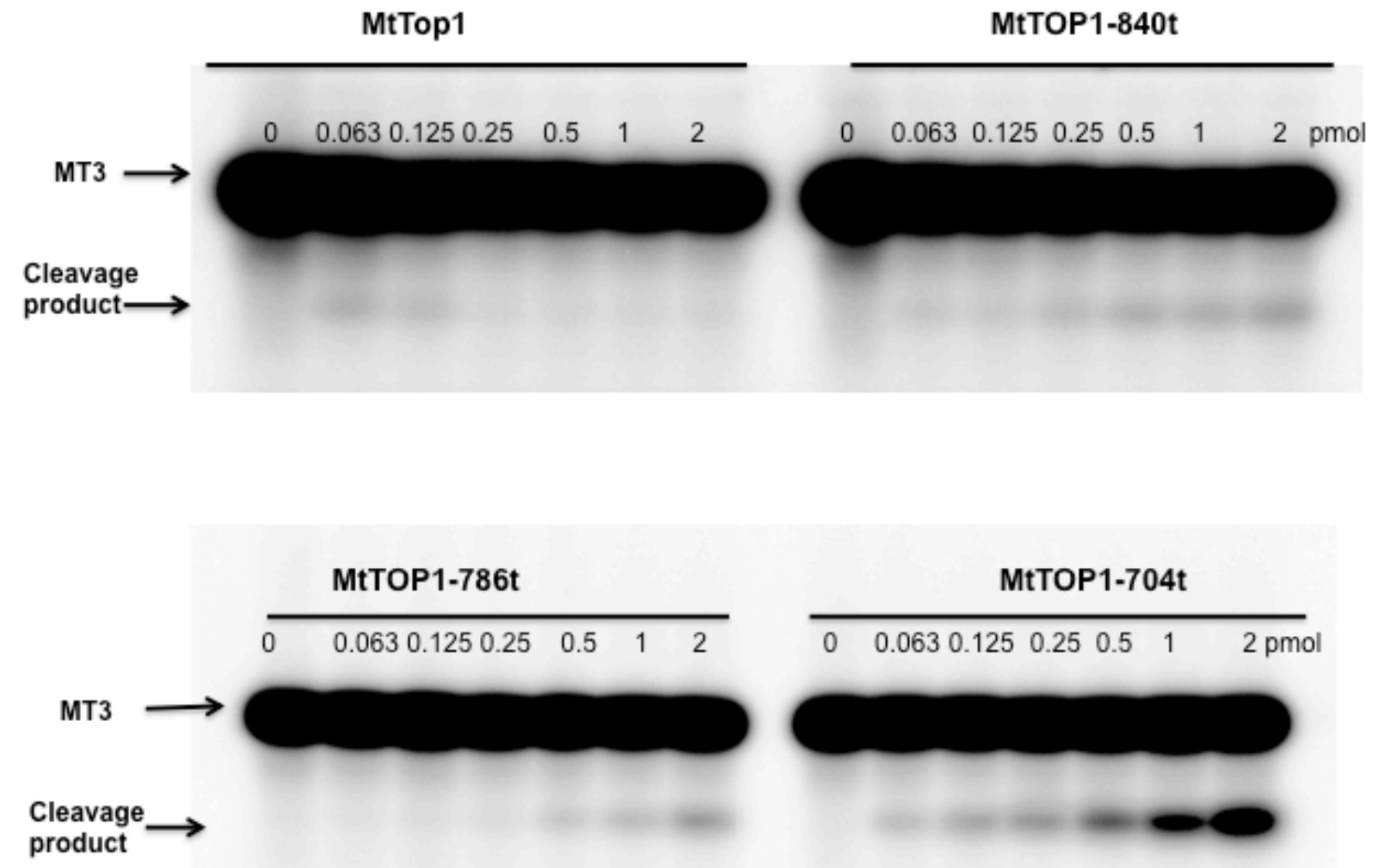

Figure 1.16 Cleavage activity assay of wild-type MtTOP1, MtTOP1-840t, MtTOP1-786t and MtTOP1-704t with MT3 oligonucleotide substrate. 


\section{Cleavage oligonucleotide MT3 in the presence of Mg (II)}

It is observed that 1 pmol wild-type MtTOP1 was not able to cleave short oligonucleotides in $10 \mathrm{mM}$ Tris- $\mathrm{HCl}$ at $37^{\circ} \mathrm{C}$. However, in the cleavage activity assay at the presence of $2 \mathrm{mM} \mathrm{Mg}^{2+}$ at $37^{\circ} \mathrm{C}, 1$ pmol wild-type MtTOP1 is observed to cleave the short oligonucleotide MT3 (Figure 1.17). In the cleavage reaction with $\mathrm{Mg}^{2+}, \mathrm{MtTOP1-840t}$ also displayed higher cleavage activity for MT3 than reaction without $\mathrm{Mg}^{2+}$. Mutant protein MtTOP1-786t did not show difference of cleavage activity with or without $\mathrm{Mg}^{2+}$. However, the cleavage product of MtTOP1-704t was decreased in the presence of $\mathrm{Mg}^{2+}$ likely because DNA religation is favored in this reaction. In the reactions with $\mathrm{Mg}^{2+}$ and $1 \mathrm{M} \mathrm{NaCl}$ added following DNA cleavage, DNA religation takes place followed by dissociation of the enzyme from the religated substrate. MtTOP1-704t with D5 subdomain exhibits cleavage activity without $\mathrm{Mg}^{2+}$, but religation activity with $\mathrm{Mg}^{2+}$ for short oligo. It is hypothesized that although the CTD subdomains D6-

D8 have high binding affinity for short oligo, $\mathrm{NaCl}$ and $\mathrm{Mg}^{2+}$ dissociate the short oligos from topoisomerase CTD and allow short oligos to bind to active site for cleavage. 
A

\begin{tabular}{|c|c|c|c|c|c|c|c|c|c|c|c|c|c|c|c|c|}
\hline & \multicolumn{3}{|c|}{ Wild-type MtTop1 } & \multicolumn{3}{c|}{ MtTop1-840t } & \multicolumn{3}{c|}{ MtTop1- 786t } & \multicolumn{3}{c|}{ MtTop1-704t } \\
\hline $\begin{array}{c}1 \mathrm{pmol} \\
\text { enzyme }\end{array}$ & - & + & + & + & - & + & + & + & - & + & + & + & - & + & + & + \\
\hline $5 \mathrm{mM} \mathrm{MgCl}$ & - & - & + & + & - & - & + & + & - & - & + & + & - & - & + & + \\
\hline $1 \mathrm{M} \mathrm{NaCl}$ & - & - & - & + & - & - & - & + & - & - & - & + & - & - & - & + \\
\hline
\end{tabular}

Cleavage product

B

\begin{tabular}{|c|c|c|c|c|c|c|c|c|c|}
\hline \multirow[b]{2}{*}{$1 \mathrm{pmol}$ protein } & \multirow[b]{2}{*}{-} & \multicolumn{2}{|c|}{ MtTOP1 } & \multicolumn{2}{|c|}{$\begin{array}{l}\text { MtTOP1- } \\
840 t\end{array}$} & \multicolumn{2}{|c|}{$\begin{array}{c}\text { MtTOP1- } \\
786 \mathrm{t}\end{array}$} & \multicolumn{2}{|c|}{$\begin{array}{c}\text { MtTOP1- } \\
704 t\end{array}$} \\
\hline & & + & + & + & + & + & + & + & + \\
\hline $2 \mathrm{mM} \mathrm{MgCl}_{2}$ & - & - & + & - & + & - & + & $\ldots$ & + \\
\hline
\end{tabular}

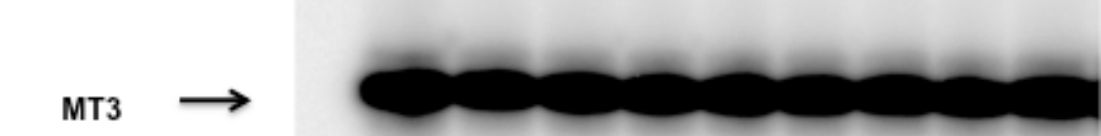

Cleavage product

Figure 1.17 Cleavage of short oligonucleotide MT3 in the presence of $\mathrm{Mg}$ (II). (A) Cleavage assay of wild-type and mutant $M$. tuberculosis topoisomerase I with $5 \mathrm{mM}$ $\mathrm{Mg}^{2+}$ and $1 \mathrm{M} \mathrm{NaCl}$. (B) Cleavage assay of wild-type and mutant $M$. tuberculosis topoisomerase I with $2 \mathrm{mM} \mathrm{Mg}^{2+}$. 


\section{Religaton assay of mycobacterial topoisomerase I with oligonucleotide STS32}

The effect of C-terminal subdomains of mycobacterial topoisomerase I on religation activity of the longer oligonucleotide substrate STS32 was also investigated. Wild-type and mutant mycobacterial topoisomerase I all have religation activity to convert the STS32 cleavage product back to the substrate when $\mathrm{Mg}^{2+}$ is added to the cleavage reaction. Wild-type MtTOP1 and MtTOP1910t showed less efficient religation activity than MtTOP1-840t, MtTOP1-786t and MtTOP1-704t (Figure 1.18, Table 1.5). Wild-type MsTOP1 and its mutant proteins showed similar results as MtTOP1 and its mutant proteins. Because the active site is in the NTD of mycobacterial topoisomerase I, the mutants with deletion of the CTD in mycobacterial topoisomerase I can retain religation activity. The DNA binding function of CTD may influence the DNA interaction at the active site in NTD or the enzyme conformational change required for bringing the ends of the cleaved DNA back together, so MtTOP1, MsTOP1, MtTOP1-910t and MsTOP1-909t showed less efficient religation activity. Relaxation of negatively supercoiled DNA requires passage of the complementary DNA strand through the break of the strand cleaved at the active site. The strand passage has to take place prior to religation of the DNA break at the active site. We hypothesize that C-terminal subdomain D8 and C-terminal tail are involved in binding and passage of a strand of the unwound duplex DNA during relaxation of negatively supercoiled DNA by mycobacterial topoisomerase I. 

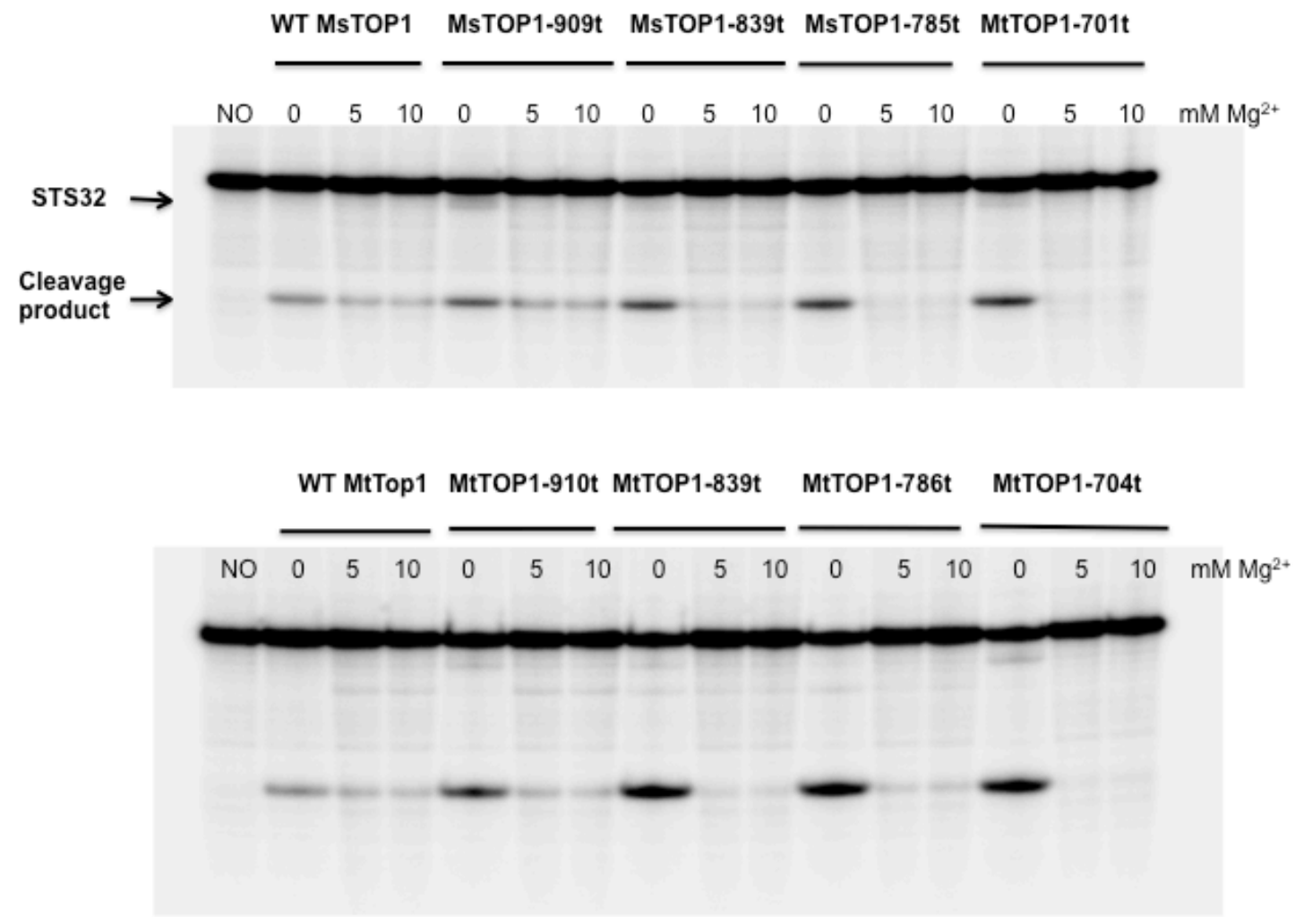

Figure 1.18 Comparison of religation activity of wild-type and mutant mycobacterial topoisomerase I with oligonucleotide STS32 substrate. 
A

\begin{tabular}{|l|c|c|c|c|c|c|c|c|c|c|c|c|c|c|c|}
\hline & \multicolumn{4}{|c|}{ WT MsTOP1 } & \multicolumn{3}{c|}{ MsTOP1-909t } & \multicolumn{3}{c|}{ MsTOP1-839t } & \multicolumn{3}{c|}{ MsTOP1-785t } & \multicolumn{2}{|c|}{ MsTOP1-701t } \\
\hline $\left.\mathbf{M g}^{2+1} \mathbf{m M}\right)$ & $\mathbf{0}$ & $\mathbf{5}$ & $\mathbf{1 0}$ & $\mathbf{0}$ & $\mathbf{5}$ & $\mathbf{1 0}$ & $\mathbf{0}$ & $\mathbf{5}$ & $\mathbf{1 0}$ & $\mathbf{0}$ & $\mathbf{5}$ & $\mathbf{1 0}$ & $\mathbf{0}$ & $\mathbf{5}$ & $\mathbf{1 0}$ \\
\hline $\begin{array}{l}\text { Cleavage } \\
\text { product } \\
\text { level }\end{array}$ & 0.07 & 0.03 & 0.03 & 0.10 & 0.05 & 0.03 & 0.11 & 0.01 & 0.01 & 0.12 & - & - & 0.17 & - & - \\
\hline
\end{tabular}

B

\begin{tabular}{|l|c|c|c|c|c|c|c|c|c|c|c|c|c|c|c|}
\hline & \multicolumn{3}{|c|}{ WT MtTOP1 } & \multicolumn{3}{c|}{ MtTOP1-910t } & \multicolumn{3}{c|}{ MtTOP1-841t } & \multicolumn{3}{c|}{ MtTOP1-786t } & \multicolumn{3}{c|}{ MtTOP1-704t } \\
\hline $\left.\mathbf{M g}^{2+1} \mathbf{m M}\right)$ & $\mathbf{0}$ & $\mathbf{5}$ & $\mathbf{1 0}$ & $\mathbf{0}$ & $\mathbf{5}$ & $\mathbf{1 0}$ & $\mathbf{0}$ & $\mathbf{5}$ & $\mathbf{1 0}$ & $\mathbf{0}$ & $\mathbf{5}$ & $\mathbf{1 0}$ & $\mathbf{0}$ & $\mathbf{5}$ & $\mathbf{1 0}$ \\
\hline $\begin{array}{l}\text { Cleavage } \\
\text { product level }\end{array}$ & 0.07 & 0.02 & 0.01 & 0.2 & 0.03 & 0.02 & 0.35 & - & - & 0.35 & - & - & 0.37 & - & - \\
\hline
\end{tabular}

Table 1.5 Product analysis of religation activity of wild-type and mutant mycobacterial topoisomerase I with oligonucleotide STS32 substrate. (A), Product analysis of Wild-type and mutant MsTOP1. (B), Product analysis of wild-type and mutant MtTOP1. The cleavage product was calculated by Cleavage product/total oligo substrate. 


\section{Catenation assay and decatenation assay}

There are two types of IA family topoisomerases, topoisomerase I and topoisomerase III in most species of bacteria that have been studied. Single molecule studies have shown that E. coli topoisomerase III (EcTOP III) is much more efficient than EcTOP I in DNA catenation/decatenation, while EcTOP I can remove negative supercoils much more rapidly (Terekhova et al., 2013, 2014). Since M. tuberculosis and other mycobacteria only have one type of IA topoisomerase enzyme, MtTOP1 is likely to be required for the resolution of ssDNA recombination and replication intermediates. The catenation activity of MsTOP1 has been demonstrated previously with M13 ssDNA since MtTOP1704t was found to have robust DNA cleavage-religation capabilities, the truncated enzyme was assayed for catenation of single-stranded M13mp18 DNA circles to determine if it can catalyze passage of a ssDNA through the break created by enzyme cleavage on another ssDNA circle. The results (Figure 1.19) showed that MtTOP1-704t has comparable catenation activity to that of fulllength MtTOP1 and MsTOP1. The catenated DNA network in kDNA is stable at $45^{\circ} \mathrm{C}$ without topoisomerase treatment (Figure 1.20). Human topoisomerase II can decatenate kDNA to generate the monomeric DNA. This monomeric DNA includes nicked open circular DNA and closed circular relaxed DNA. Wild-type MtTOP1 has the ability to decatenate kDNA into nicked, open circular DNA, but is not able to release decatenated closed circular relaxed DNA because cutting of a double-strand of DNA is required. These results indicated that mycobacterial topoisomerase I should be able to resolve topological 
intermediates in replication and recombination that need passing a single-strand of DNA across another single-stranded DNA. Deletion protein MtTOP1-704t has comparable decatenation activity when compared to that of full-length MtTOP1. The CTD is not required for this activity.

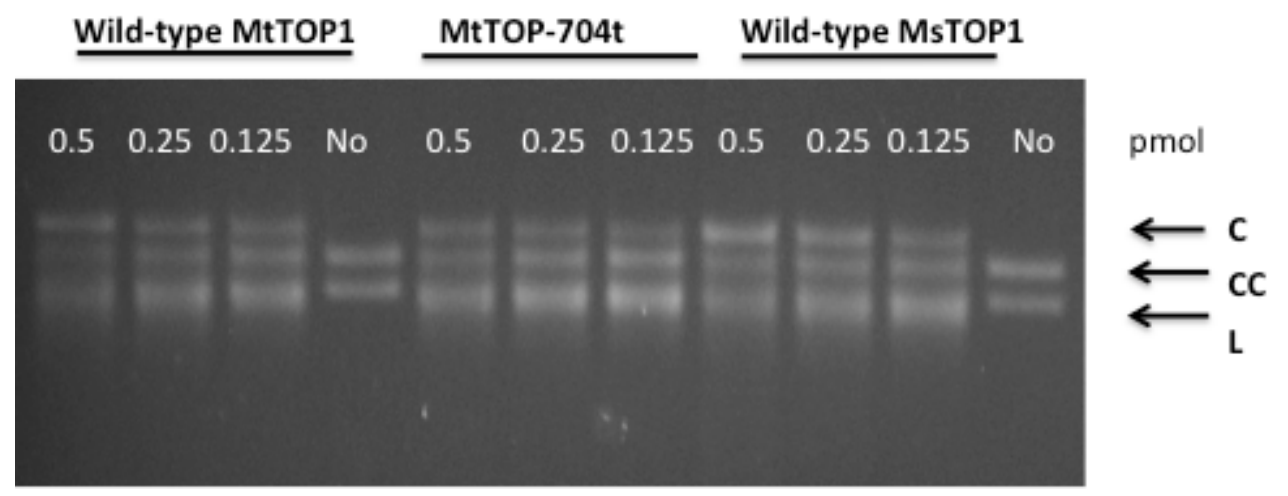

Figure 1.19 Catenation of single-stranded M13mp18DNA by MsTOP1, MtTOP1 and MtTOP1-704t. Single-stranded M13mp18 DNA was incubated with the indicated amount of MtTOP1 or MtTOP1-704t before proteinase $\mathrm{K}$ treatment. C: circular ssDNA; L: linear ssDNA; CC: catenated circular ssDNA.

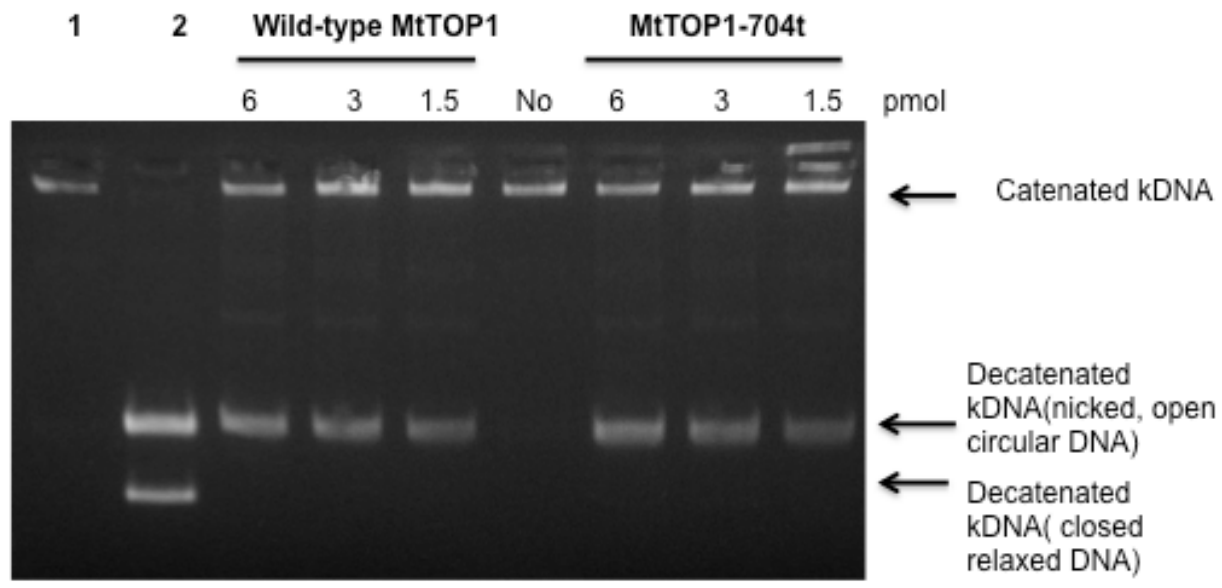

Figure 1.20 Decatenation of kDNA network by MtTOP1 and MtTOP1 704t. Lane 1, negative control, no enzyme; Lane 2, positive control, human topoisomerase lla. 


\section{DISCUSSION}

Mutant enzyme MtTOP1-704t maintains cleavage, religation, catenation and decatenation activities. One reason is that the active site tyrosine of mycobacterial topoisomerase I is in the NTD. Deletion of C-terminal subdomain D6, D7, D8 and the C-terminal tail does not affect those activities at active site and events at the catalytic regions in the NTD. Escherichia coli AS17 with top ${ }^{\text {ts }}$ mutation cannot be complemented by MtTOP1-704t or MtTOP1-786t strains at $42^{\circ} \mathrm{C}$ (Figure 1.3) because MtTOP1-704t and MtTOP1-786t lacked the relaxation activity required during the cellular process of E. coli AS17. Partial relaxation activities of MtTOP1-840t, MtTOP1-910t, MsTOP1-839t and MsTOP1-909t enable growth of $E$. coli AS17 complemented strains at $42^{\circ} \mathrm{C}$. Proteins with NTD+D5+D6+D7 domains that were expressed from a high copy number plasmid are sufficient to solve the genomic topological barriers and support the growth of E. coli AS17.

In the DNA binding assay with long oligo STS32 and short oligo MT3, wildtype MsTOP1 and MtTOP1 displayed higher binding activity than mutant enzyme MsTOP1-701t and MtTOP1-704t. These results demonstrate that CTD for mycobacterial topoisomerase I contribute significantly to ssDNA binding. The CTD DNA binding site of mycobacterial topoisomerase I can bind ssDNA with higher affinity than the NTD. The results from the cleavage activity assay of MT3 with short 14-nucleotide-substrate with and without $\mathrm{Mg}^{2+}$ indicated that before the active site is occupied, ssDNA binds to CTD first. This could explain why for wild-type topoisomerase I cleavage of long oligonucleotides STS32 and MT2 
produces less cleavage products form from $2 \mathrm{pmol}$ and 1 pmol MsTOP1 and MtTOP1 than 0.5 pmol of enzyme. Since CTD of mycobacterial topoisomerase I has high affinity for ssDNA, higher amount of enzyme binds more ssDNA in its CTD. The increased enzyme: DNA ratio reduces the DNA binding at NTD for cleavage by the wild-type mycobacterial topoisomerase I. Therefore less cleavage product was produced when wild-type mycobacterial topoisomerase I is in excess. MtTOP1-704t and MsTOP1-701t exhibit higher cleavage activity than wild-type mycobacterial topoisomerase I with MT2 (Figure 1.12, Figure 1.13), because they do not have the CTD subdomains to compete with the NTD active site for DNA binding. It can be postulated that high CTD binding affinity prevents the interaction between $\mathrm{N}$-terminal domain of wild-type topoisomerase I with DNA, unless both strands of unwound duplex DNA are available in negatively supercoiled DNA.

In the religation activity assays, $\mathrm{NaCl}$ serves to dissociate oligos from DNA topoisomerases following religation. A previous study showed that $\mathrm{Mg}^{2+}$ is not required for DNA cleavage by wild-type MsTOP1, but $\mathrm{Mg}^{2+}$ is needed for religation (Bhat et al., 2009). In our cleavage assay of mycobacterial topoisomerase I with MT3 substrate wild-type MtTOP1 and each mutant enzyme responded differently to the presence of $\mathrm{Mg}^{2+}$. It indicates that $\mathrm{Mg}^{2+}$ may interact with the four C-terminal subdomains to affect DNA binding there. The change in CTD-DNA interaction may affect the DNA cleavage-religation at the NTD active site in turn. This may be a direction for future study to understand the role of the 
mycobacterial topoisomerase I CTD in the conformational change of the enzymeDNA complex that accompanies the relaxation of supercoiled DNA.

In the cleavage assay of MsTOP1-909t with MT3, the cleavage activity of MsTOP1-909t did not show the clear response to different amounts of enzyme being added. Besides, in the cleavage activity assay of MsTOP1-909t and MtTOP1-910t with STS32 substrate, 1 pmol and 2 pmol reactions of these two enzymes did not show less cleavage product than $0.5 \mathrm{pmol}$ reactions. This suggests that the C-terminal positively charged tail has a role for ssDNA binding in mycobacterial topoisomerase I. MsTOP1-909t had decreased relaxation activity without the C-terminal tail. The sequence of wild-type MsTOP1's Cterminal tail is "RGPVKKKAPAKKAAKKAPAKKAAAKKA". It contains 5 lysine repeats. A recent study indicated that the C-terminal lysine repeats found in bacterial DNA topoisomerase I stabilize the enzyme-DNA complex (Strzalka et al., 2017). Without the C-terminal positively charged tail to stabilize the enzymeDNA complex, the CTD may lose some of the DNA binding affinity. 


\section{CHAPTER 2: TYPE IA TOPOISOMERASE MECHANISM-ACTIVE SITE STRUCTURE AND INTERACTIONS}

\section{ABSTRACT}

Type IA topoisomerases are present in all organisms for multiple vital cellular processes that include maintaining optimal DNA supercoiling density, and resolution of recombination or replication intermediate. Their conserved catalytic domains form an active site that can cleave and rejoin a single DNA strand. $\mathrm{Mg}^{2+}$ is required for catalysis but not for DNA cleavage. We have obtained new structures of Mycobacterium tuberculosis topoisomerase I (MtTOP1). Crystal structure of MtTOP1-704t (amino acids A2-T704) was obtained. Structures with ssDNA substrate bound to the active site with and without $\mathrm{Mg}^{2+}$ ion present were also investigated. Significant enzyme conformational changes upon DNA binding place the catalytic tyrosine in a pre-transition position for cleavage of a specific phosphodiester linkage to form a covalent intermediate. Meanwhile, the enzyme/DNA complex with $\mathrm{Mg}^{2+}$ bound at the active site may present the posttransition state for religation in the enzyme's multiple-state DNA relaxation activity. The first observation a divalent metal ion coordinated with the TOPRIM residues in the active site of a type IA topoisomerase allows assignment of likely catalytic role for the individual divalent ion and draws a comparison to proposed mechanism for type IIA topoisomerases. The critical function of a strictly conserved glutamic acid in acid-base catalysis of the DNA cleavage step was clearly demonstrated by site-directed mutagenesis. The functions assigned to 
the $\mathrm{Mg}^{2+}$ ion can account for the requirement of metal ions for DNA rejoining but not DNA cleavage by type IA topoisomerases. This work provides new functional insights into the more stringent requirement for DNA rejoining versus cleavage by type IA topoisomerase and further establishes the potential for select interference of DNA rejoining by this validated TB drug target.

\section{INTRODUCTION}

Mycobacterium tuberculosis is the chief causative agent of tuberculosis, the leading cause of morbidity and mortality globally with an estimated 10.4 million cases and 1.8 million deaths annually as reported by WHO this year. $M$. tuberculosis topoisomerase I (MtTOP1) is a validated target for much needed new antibiotics that can be used against the MDR-TB cases that are difficult to treat (Ahmed et al., 2014; Nagaraja et al., 2017; Ravishankar et al., 2015). Topoisomerases control the topological state of the genome, thus affecting vital cellular processes including replication, transcription, recombination and repair (Chen et al., 2013; Wang, 2002). Type I topoisomerases catalyze DNA topological transformations by breaking and rejoining a single-strand of DNA at a time, and are divided into type IA and type IB subfamilies based on distinctively different protein sequences and catalytic mechanisms (Baker et al., 2008; Corbett and Berger, 2004; Vos et al., 2011). MtTOP1 and topoisomerase I present in all bacterial pathogens are type IA topoisomerases that are needed for resolving topological barriers that require the passage of DNA through the break 
created on single-stranded DNA (ssDNA)(Forterre and Gadelle, 2009). This can be exploited for bactericidal action with topoisomerase poison inhibitors that can stabilize the break by inhibiting DNA rejoining (Tse-Dinh, 2015). The bacterial type IIA topoisomerases have been targeted extensively for discovery of antibiotics that include the widely used fluoroquinolones (Aldred et al., 2014; Tomasic and Masic, 2014). The efforts to discover bacterial topoisomerase I inhibitors would be aided greatly by the knowledge of how DNA religation following the formation of the covalent intermediate can be inhibited.

Type IA topoisomerases share certain functional and structural elements of similarities with type IIA topoisomerases (Berger et al., 1998), even though these two classes of topoisomerases appear to have evolved independently as essential topoisomerase activities in living organisms (Forterre and Gadelle, 2009). Both type IA and type IIA topoisomerases form a 5'-phosphoryl tyrosine linkage with cleaved DNA in a covalent intermediate (Tse et al., 1980), and divalent metal ions are absolutely required for the change in topology catalyzed by these topoisomerases. However, there is a significant difference in the biochemical mechanism of these two classes of topoisomerases. Type IA topoisomerases can cleave DNA in the absence of divalent metal ions to form a covalent intermediate (Depew et al., 1978), while DNA cleavage by type IIA topoisomerases requires the addition of divalent metal ions (Sissi and Palumbo, 2009). The requirement of metal ions for DNA religation, but not for DNA cleavage by bacterial topoisomerase I may present an opportunity for selective inhibition of DNA religation by small molecule inhibitors. None of the previously 
determined structures of type IA topoisomerases have divalent metal ions and DNA both present at the active site. The role of metal ions in the catalytic mechanism of bacterial topoisomerase I needs to be clarified further by structural information.

In a recent study, the structure of full-length EcTOP I in complex with single-stranded DNA was observed (Tan et al., 2015) (PDB ID: 4RUL). The Cterminal region of EcTOP I comprises three 4-Cys zinc ribbon motifs and two zinc ribbon-like subdomains, and a modular ssDNA-binding mode was reported. This suggests that the C-terminal region of MtTOP1 may also contain multiple subdomains with repeated and conserved sequence motifs even though the sequences of EcTOP I and MtTOP1 C-terminal regions are very different with essentially no homologies. We analyzed the structural aspects of the C-terminal region of mycobacterial topoisomerase I. The structure organization and functional characterizations of subdomains in mycobacterial topoisomerase I CTD are described in Chapter 1. In collaboration with Dr. Kemin Tan at Argonne National Laboratory, we first determined the crystal structure of MtTOP1-704t with the NTDs (D1-D4) and the CTD D5 (amino acids A2-T704). Collaboration with Dr. Tan also produced additional new structures of $M$. tuberculosis topoisomerase I. For the first time, divalent metal ion can be observed to coordinate DNA, water molecules and the acidic functional groups in the active site of a type IA topoisomerase. We observed metal ion interactions with the aspartates in the DxD motif (D111 and D113), proposed previously based on genetic and biochemical data. The invariant glutamic acid (E24) in the TOPRIM 
domain is in a position for key roles in the catalysis of DNA cleavage-religation. The requirement of the carboxyl group on E24 for acid-base catalysis of DNA cleavage in the absence of divalent metal ions is further clarified by the study of the E24A and E24Q mutants. Based on the new structural results, we compare the active site of topoisomerase IA, IIA, and III; and draw their possible similarities and differences in their catalytic mechanisms, particularly between topoisomerase IA.

\section{MATERIALS AND METHODS}

\section{Cloning, expression and purification}

The cloning, expression and purification methods of MtTOP1-704t have been described in Chapter 1. QuickChange site-directed mutagenesis protocol and Phusion Hot Start II High-Fidelity DNA Polymerase (Thermo Scientific) were used to construct mutant clones $\left(30\right.$ cycles of $95^{\circ} \mathrm{C}$ for $30 \mathrm{sec}, 70^{\circ} \mathrm{C}$ for $30 \mathrm{sec}$, $72^{\circ} \mathrm{C}$ for $4.5 \mathrm{~min}$ ). Plasmids $2 \mathrm{O}-\mathrm{T} \mathrm{MtTOP} 1$ and $2 \mathrm{O}-\mathrm{T}$ MsTOP1 were used as templates. The primers for the PCR amplification are listed in table 2.1. After PCR reaction, the PCR products were purified by electrophoresis in $1 \%$ agarose gel with TAE buffer. The template plasmids were digested by treating with Dpn1 restriction enzyme (New England Biolabs). NEB turbo competent cells (New England Biolabs) were used for the transformation of mutant plasmids. The transformants were plated on the LB $+100 \mu \mathrm{g} / \mathrm{ml}$ carbenicillin $+2 \%$ glucose plates. Plasmids were purified by GeneJET Plasmid Miniprep Kit (Thermo 
Scientific). Nucleotide sequencing (Eurofins genomics) was used to verify the complete coding region of plasmids.

After verifying the sequence of mutant plasmids, mutant clones of MsTOP1 were overexpressed in E. coli BL21 star (DE3) strain (Invitrogen). Mutant clones of MtTOP1 were overexpressed in E. coli T7 Express crystal strain (New England Biolabs). Cells were grown at $37^{\circ} \mathrm{C}$ overnight. Overnight cell cultures were diluted 1:100 and incubated in LB medium with $100 \mu \mathrm{g} / \mathrm{ml}$ carbenicillin at $30^{\circ} \mathrm{C}$ to exponential phase $\left(\mathrm{OD}_{600}=0.4\right)$. BL21 star (DE3) cell culture was induced by $1 \mathrm{mM}$ IPTG. T7 express crystal cell culture was induced by $0.4 \mathrm{mM}$ IPTG. Induced cell culture was grown at $22^{\circ} \mathrm{C}$ overnight. Cell cultures were centrifuged at $4500 \mathrm{rpm}$ at $4^{\circ} \mathrm{C}$ for $30 \mathrm{~min}$. Cell pellets were suspended in lysis buffer $(50 \mathrm{mM}$ sodium phosphate, $0.3 \mathrm{M} \mathrm{NaCl}, 10 \mathrm{mM}$ imidazole, and $1 \mathrm{mg} / \mathrm{ml}$ lysozyme, $\mathrm{pH}$ 8.0). The resuspended cell lysate were left on ice for $1 \mathrm{hr}$. Four cycles of freeze-thawing were used to lyse cells. The cell lysate was centrifuge at $32000 \mathrm{rpm}$ at $4^{\circ} \mathrm{C}$ for $2 \mathrm{hr}$. Mutant proteins, MtTOP1E24A, MtTOP1-E24Q, MsTOP1-E21A and MsTOP1-E21Q, were purified by NiSepharose 6 Fast Flow chromatography from soluble cell lysate. The protein fractions were dialyzed against storage buffer $(0.1 \mathrm{M}$ potassium phosphate, 0.2 mM EDTA pH 8.0, 50\% glycerol). 


\begin{tabular}{|l|l|}
\hline Primer name & \multicolumn{1}{|c|}{ Primer sequence (5'-3') } \\
\hline MtTOP1-E24A forward & CTTGGTGGGCGACGCGACGATGACCAG \\
\hline MtTOP1-E24A reverse & CTGGTCATCGTCGCGTCGCCCACCAAG \\
\hline MtTOP1-E24Q forward & CTTGGTGGGCGACTGGACGATGACCAGTC \\
\hline MtTOP1-E24Q reverse & GACTGGTCATCGTCCAGTCGCCCACCAAG \\
\hline MsTOP1-E21A forward & CCTTCGTCGGCGACGCGACAATCACGAGT \\
\hline MsTOP1-E21A reverse & ACTCGTGATTGTCGCGTCGCCGACGAAGG \\
\hline MsTOP1-E21Q forward & CTTCGTCGGCGACTGGACAATCACGAGTCG \\
\hline MsTOP1-E21Q reverse & CGACTCGTGATTGTCCAGTCGCCGACGAAG \\
\hline
\end{tabular}

Table 2.1 Primers used for site-directed mutagenesis.

\section{Cleavage assay}

The oligonucleotide substrate STS32 and MTS2-13 were labeled with Y${ }^{32}$ P-ATP at the 5 ' end by T4 polynucleotide kinase (New England Biolabs) (Table 2.2). The labeling reactions were carried on $37^{\circ} \mathrm{C}$ for $30 \mathrm{~min}$ and terminated by heating at $75^{\circ} \mathrm{C}$ for $15 \mathrm{~min} .{ }^{32} \mathrm{P}$-labeled oligonucleotide substrates were purified after the labeling reaction using a Sephadex G-50 (STS32) or Sephadex G-25 spin column (MTS2-13). Purified substrates were eluted in 10 $\mathrm{mM}$ Tris- $\mathrm{HCl}, \mathrm{pH}$ 8.0. Serially diluted wild-type and mutant mycobacterial topoisomerase I were incubated with 0.5 pmol STS32 or MTS2-13 in $5 \mu \mathrm{l}$ of 10 $\mathrm{mM}$ Tris- $\mathrm{HCl}(\mathrm{pH} 8.0)$ at $37^{\circ} \mathrm{C}$ for $30 \mathrm{~min}$. To terminate the reactions, the equal volume of cleavage stop buffer $(79 \%$ formamide, $200 \mathrm{mM} \mathrm{NaOH}, 0.1 \mathrm{mM}$ EDTA, $0.04 \%$ bromophenol) was added to the reactions followed by heating at $95^{\circ} \mathrm{C}$ for 5 min. The STS32 cleavage product was separated from the substrate by electrophoresis in $15 \%$ sequencing gel. The MTS2-13 cleavage product was separated from the substrate by electrophoresis in $20 \%$ sequencing gel. The 
TBE buffer was used as running buffer. Gels were analyzed by PhosphorImager.

\begin{tabular}{|l|l|}
\hline Oligos name & Oligos sequence (5'-3') \\
\hline STS32 & 5'-CAGTGAGCGAGCTTCCGC $\downarrow$ TTGACATCCCAATA-3' \\
\hline MTS2-11 & 5'-TTCCGC $\downarrow T T G A C-3 '$ \\
\hline MTS2-13 & 5'-TTCCGC $\downarrow T T G A C T T-3 '$ \\
\hline MTS2-19 & 5'-CAGTGAGCGAGCTTCCGCT-3' \\
\hline MTS2-18 & 5'-CAGTGAGCGAGCTTCCGC-3' \\
\hline MT7 & 5'-TTCCGCT-3' \\
\hline MT6 & 5'-TTCCGC-3' \\
\hline
\end{tabular}

Table 2.2 Oligonucleotides used for mycobacterial activity assay. STS32, MTS11, MTS2-13 were used as cleavage reaction substrates. MTS2-19, MTS2-18, MT7 ad MT6 were used as standards in electrophoresis analysis of the cleavage products.

\section{Electrophoretic mobility shift assay (EMSA)}

The oligonucleotide substrate STS32 was labeled with $\mathrm{y}^{32}{ }^{32} \mathrm{P}-\mathrm{ATP}$ at the 5' end (Table 2.2). The electrophoretic mobility shift assay was carried on $10 \mu \mathrm{l}$ of $20 \mathrm{mM}$ Tris-HCl (pH 8.0), $100 \mu \mathrm{g} / \mathrm{ml} \mathrm{BSA}, 18 \%$ glycerol, $0.5 \mathrm{mM}$ EDTA. 1-4 pmol of wild-type MtTOP1, MtTOP1-E24A and MtTOP1-E24Q were incubated with 5 pmol STS 32 at $37^{\circ} \mathrm{C}$ for $5 \mathrm{~min}$. The reactions were placed on ice about 5 $\min$. The non-covalent protein-DNA complex and free substrate were separated with $8 \%$ polyacrylamide gel. $0.5 \times$ TBE buffer was used as running buffer. The gels were vacuum dried at $80^{\circ} \mathrm{C}$ for $2 \mathrm{hr}$. The dried gel was analyzed by Phosphor-Imager. 


\section{Identification of cleavage site}

The oligonucleotide substrate STS32, MTS2-11, MTS2-13, MTS2-19, MTS2-18, MT7, and MT6 were labeled with $\mathrm{y}^{32}{ }^{32}$ P-ATP at the 5 ' end (Table 2.2). ${ }^{32} \mathrm{P}$-labeled oligonucleotide substrates MTS2-19 and MTS2-18 were purified after the labeling reaction using Sephadex G-25 columns. ${ }^{32} \mathrm{P}$-labeled oligonucleotide substrates MT7 and MT6 were purified after the labeling reaction using Sephadex G-15 columns (GE Healthcare). Purified substrates were eluted in 10 $\mathrm{mM}$ Tris- $\mathrm{HCl}, \mathrm{pH}$ 8.0. $\quad 0.5 \mathrm{pmol}$ STS32, MTS2-11 and MTS2-13 were incubated with wild-type MtTOP1, wild-type MsTOP1, MtTOP1-704t and MsTOP1-701t in $10 \mathrm{mM}$ Tris- $\mathrm{HCl}(\mathrm{pH} 8.0)$ at $37^{\circ} \mathrm{C}$ for $15 \mathrm{~min}$. Oligonucleotide MTS2-13 (0.5 pmol) was incubated with wild-type MtTOP1 in $10 \mathrm{mM}$ Tris- $\mathrm{HCl}(\mathrm{pH}$ 8.0) and $0.25 \mathrm{mM} \mathrm{MgCl} 2$ at $37^{\circ} \mathrm{C}$ for $15 \mathrm{~min}$. The equal volume of cleavage stop buffer was added to terminate reactions. The reactions were heated at $95{ }^{\circ} \mathrm{C}$ for $5 \mathrm{~min}$. MTS2-19, MTS2-18, MT7, and MT6 were used as standards in gel electrophoresis to identify the cleavage site of mycobacterial topoisomerase I on these oligonucleotide substrates. The cleavage product and standards were electrophoresed in a sequencing gel (15\% for substrate STS32, $20 \%$ gel for MTS2-13 or other oligonucleotide substrates)

\section{Religation assay}

The oligonucleotide substrate MT3 and MTS2-13 were labeled with $\mathrm{y}^{3}{ }^{32} \mathrm{P}-$ ATP at the 5' end. Wild-type and mutant proteins $(1 \mathrm{pmol})$ were incubated with $0.5 \mathrm{pmol}$ oligonucleotide substrate in $5 \mu 10 \mathrm{mM}$ Tris- $\mathrm{HCl}(\mathrm{pH} 8.0)$ at $37^{\circ} \mathrm{C}$ for 15 
min. We added $0.25 \mathrm{mM}$ or $2.5 \mathrm{mM} \mathrm{MgCl} 2$ into the cleavage reaction respectively for 5 min further incubation at $37^{\circ} \mathrm{C}$. The reactions were terminated with equal volume of loading buffer $(79 \%$ formamide, $0.2 \mathrm{M} \mathrm{NaOH}, 0.04 \%$ bromophenol blue) and heated at $95^{\circ} \mathrm{C}$ for $5 \mathrm{~min}$. The reaction products were analyzed by electrophoresis in $15 \%$ sequencing gel. The TBE buffer was used as running buffer. Gels were analyzed by Phosphor-Imager.

\section{Relaxation assay}

Wild-type and mutant mycobacterial topoisomerase I were serially diluted. Diluted proteins were incubated with $250 \mathrm{ng}$ negatively supercoiled plasmid pBAD/thio (purified by $\mathrm{CsCl}$ density gradient centrifugation) in $20 \mu \mathrm{L}$ of $10 \mathrm{mM}$ Tris- $\mathrm{HCl}$ (pH 8.0), $150 \mathrm{mM} \mathrm{NaCl}, 0.1 \mathrm{mg} / \mathrm{ml}$ gelatin, and $5 \mathrm{mM} \mathrm{MgCl} 2$ at $37^{\circ} \mathrm{C}$ for $30 \mathrm{~min}$. The relaxation reactions were terminated by addition of $4 \mu \mathrm{L}$ of stop buffer (50 mM EDTA, 50\% glycerol and 0.5\% (v/v) bromophenol blue). The DNA was then electrophoresed in a $1 \%$ agarose gel with TAE buffer $(40 \mathrm{mM}$ Trisacetate, $\mathrm{pH}$ 8.0, $2 \mathrm{mM}$ EDTA). The gels were stained with $1 \mu \mathrm{g} / \mathrm{mL}$ ethidium bromide for $1 \mathrm{hr}$ and photographed over UV light. 


\section{RESULTS}

\section{Cleavage and religation activity assay of MtTOP1-704t with oligonucleotide MTS2-13}

The MtTOP1-704t is used here for determination of the enzyme structure by X-ray crystallography in collaboration with Dr. Kemin Tan at Argonne National Laboratory. The biochemical catalytic activity of MtTOP1-704t has been described in Chapter 1. MtTOP1-704t lacks relaxation activity with negatively supercoiled DNA. It retains catenation and decatenation activity with singlestranded circular or catenated kDNA. It can cleave and religate long oligonucleotides STS32, MT2, and short oligonucleotide MT3. In Figure 2.1, it exhibits the cleavage activity with oligonucleotide MTS2-13. Wild-type MtTOP1 shows little cleavage activity with MTS2-13 because the oligonucleotide is binding to the CTD under these reaction conditions. With the addition of $\mathrm{Mg}^{2+}$, MtTOP1-704t religated cleaved MTS2-13 (Figure 2.2). These results indicates that $\mathrm{Mg}^{2+}$ is required for catalysis but not for DNA cleavage. 


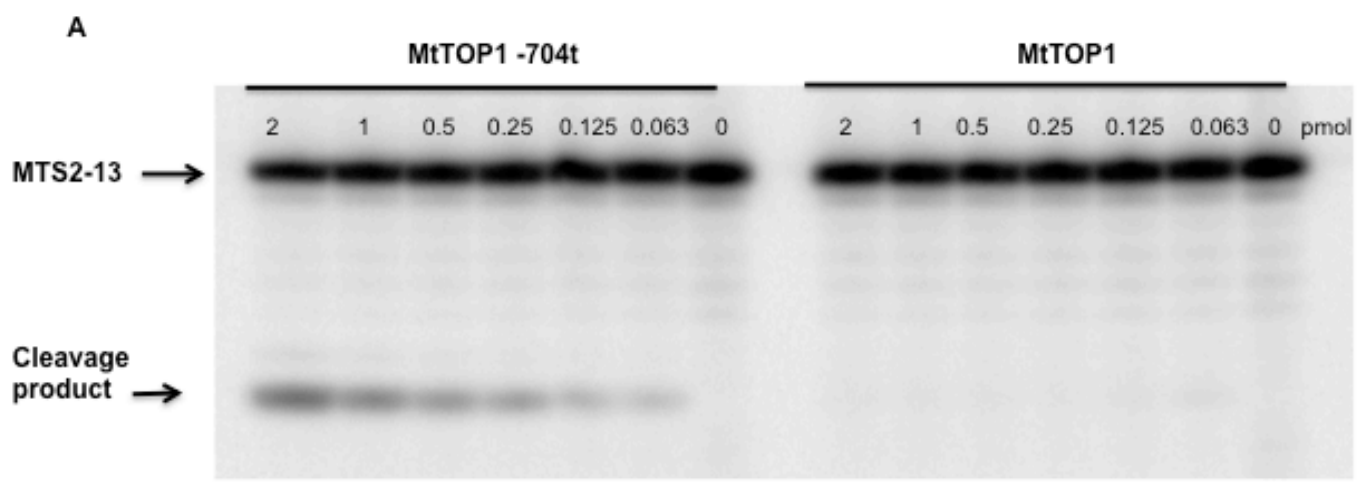

B

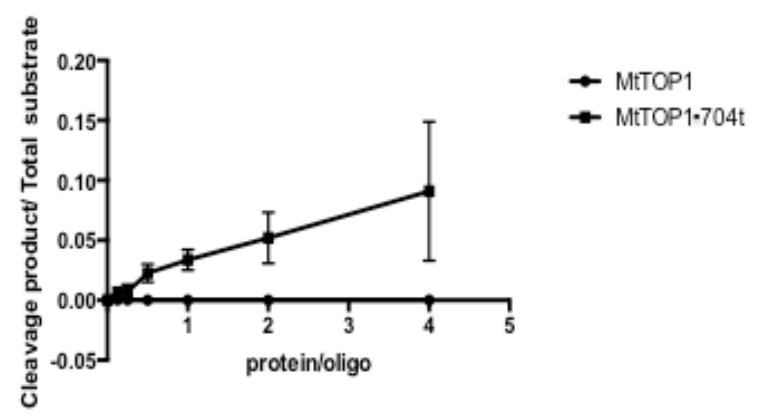

Figure 2.1 Assay of MTS2-13 cleavage by wild-type MtTOP1 and MtTOP1-704t. (A) Assay of ${ }^{32} \mathrm{P}$-labeled MTS2-13 cleavage by wild-type MtTOP1 and MtTOP1-704t. (B) Analysis of cleavage product from MT2-13 with wild-type MtTOP1 and MtTOP1-704t. The average and standard deviation from two separate experiments is shown. 


\begin{tabular}{|l|c|c|c|c|}
\hline $1 \mathrm{pmol} \mathrm{MtTOP1-704t}$ & - & + & + & + \\
\hline $0.25 \mathrm{mM} \mathrm{MgCl}_{2}$ & - & - & + & - \\
\hline $2.5 \mathrm{mM} \mathrm{MgCl}_{2}$ & - & - & - & + \\
\hline
\end{tabular}

MTS2-13 $\longrightarrow$

product $\longrightarrow$

Figure 2.2 Religaton assay of MtTOP1-704t with MTS2-13. Wild-type MtTOP1-704t reacted with $0.5 \mathrm{pmol} \mathrm{MTS} 2-13$ oligosubstrate $37^{\circ} \mathrm{C}$ for $15 \mathrm{~min} . \mathrm{MgCl}_{2}$ were added into the cleavage reaction respectively for $5 \mathrm{~min}$ further incubation at $37^{\circ} \mathrm{C}$. 


\section{The crystal structure of MtTOP1-704t}

MtTOP1 contains four GxxGPY sequence motifs in its C-terminal region. Based on the locations of the four GxxGPY repeats, we divided the region into four repeat domains (Figure 1.1, Figure 1.2). MtTOP1-704t is one of the constructs that have been made based on the CTD prediction mentioned above. It spans from amino acid A2 to amino acid T704 and includes the N-terminal subdomains, D1-D4 along with C-terminal subdomain D5. The crystal structure of MtTOP1-704t is showed in Figure 2.3 (PDB ID: 5D5H). The $15 \mathrm{~N}$-terminal residues (A2-S16) are not visible in the structure. The NTD (G17-A638) of MtTOP1-704t has a similar toroid assembly as EcTOP I (G2-N590) NTD (Tan et al., 2016). The D1 subdomain contains the region from $\mathrm{G} 17$ to $\mathrm{G} 50$, and region from $P 87$ to $D 157$. It is observed to have five $\beta$-turns and a short $\beta$-hairpin. The hinge subdomain D2 comprises two sequentially separated regions: from F213 to R302 ( $\beta 1-\beta 2-\alpha 1-\beta 3)$ and from D434 to R516 ( $\beta 4-\beta 5-\alpha 2-\beta 6)$. D3 is an all- $\alpha$-helical subdomain (from P303 to A433), including the catalytic residue Y342. The two regions of D4 subdomain link to D1 and D5 subdomains.

The D5 subdomain is the first C-terminal subdomain of MtTOP1. It extends from residue R638 to P705. It contains a four-stranded antiparallel $\beta$ sheet with a C-terminal helix packed against the $\beta$-sheet on one side (Figure 2.3). Hydrophobic interaction dominates the interaction between the $\beta$-sheet and the helix. The helix apparently plays an important role in stabilizing the $\beta$-sheet and the small subdomain. The conserved tyrosine $Y 665$, the third residue of the 
B3 strand, is predicted to be a key residue in the interaction of D5 with DNA by forming $\pi$-stackings with the bases.

A

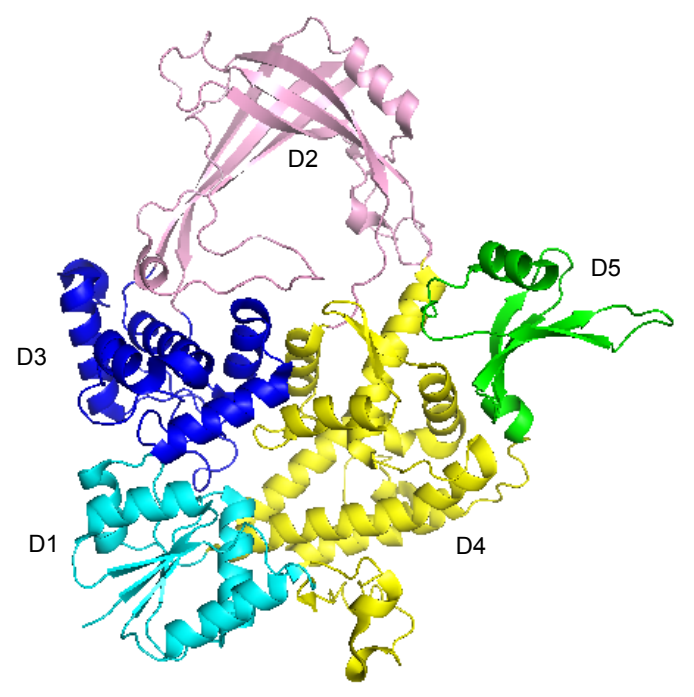

B

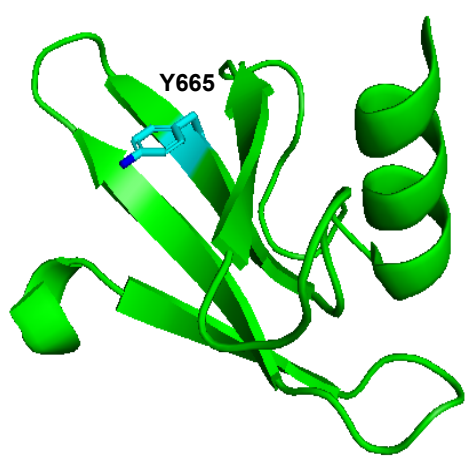

Figure 2.3 The crystal structure of MtTOP1-704t. (A) A ribbon diagram of the structure of MtTOP1-704t. The N-terminal D1, D2, D3 and D4 subdomains, are colored cyan, pink, blue and yellow. The C-terminal D5 subdomain is colored green. (B) Structure of MtTOP1 first C-terminal subdomain D5. Conserved Y665 are highlighted. The program Pymol was used for the preparation. 


\section{Co-crystals of MtTOP1-704t with short ssDNA substrates}

Co-crystallization trials of MtbTOPI-704t were set up with MTS (Mycobacterial Topoisomerase Substrate) oligonucleotides of various lengths with sequences derived from a 32 nucleotide long substrate (STS32) previously identified as having a strong topoisomerase site (STS)(Bhat et al., 2009). Multiple crystal forms were harvested, and their X-ray diffraction data were collected. The highest resolution data set $(2.42 \AA)$ was obtained from a cocrystal with a short, 11-mer oligonucleotide (MTS2-11, 5'-TTCCGCTTGAC-3'). This crystal structure (MtTOP1-704t/MTS2-11) (PDB: 6CQI) represents a topoisomerase I/ssDNA complex in the absence of metal ions at the active site (Figure 2.4). 


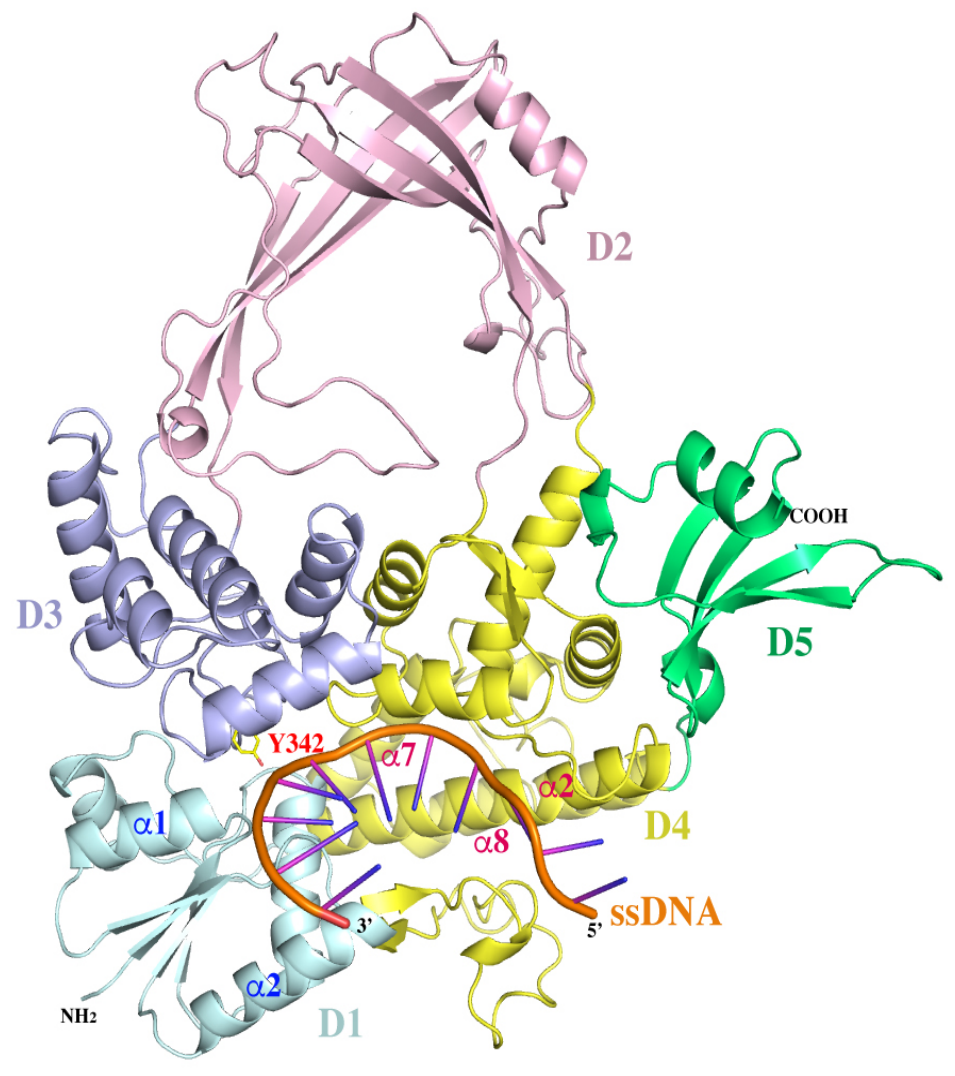

Figure 2.4 Structure of MtTOP1-704t/ssDNA complex. The ribbon diagram of one structure of MtTOP1-704t in complex with MTS2-11. The five individual subdomains, D1-D5 are colored in cyan, pink, blue, yellow and green, respectively. The phosphate backbone of oligonucleotide is in orange with its polarity labeled. The catalytic residue, Y342 is drawn for highlighting its position. The program Pymol was used for the preparation. 


\section{Conformation of ssDNA substrate and its kink}

The ssDNA MTS2-11 is intact in the structure (Figure 2.4). Its sugarphosphate backbone is mostly buried along the bottom of the DNA-binding groove from D4 to the edge of the D1-D3 interface in a 5' to 3' direction (Figure 2.4, Figure $2.5 \mathrm{~A}$ ). The bases of the seven nucleotides from positions -4 to +3 resemble the stacking conformation of one B-DNA strand as described earlier for DNA bound to E. coli topoisomerase III (EcTOP III) (Changela et al., 2001) and topoisomerase I (EcTOP I)(Perry and Mondragón, 2003). This conformation is interrupted between the -4 and -5 positions with a backbone kink and insertion of a tyrosine side chain from the enzyme (Y176) between the two bases (Figure 2.5B). The kink contributes to the recognition of cytosine at the -4 position relative to the scissile phosphate for all preferred bacterial topoisomerase I cleavage sites (Annamalai et al., 2009; Narula and Tse-Dinh, 2012; Zhang et al., 2011). Aside from the interactions with the -4 cytosine base involving $R 168$, R172 and Y176, there are additional enzyme-ssDNA interactions, including a series of arginine-phosphate salt bridges mediated by R194, R344 and R547 (Figure 2.5B and Figure 2.6). 

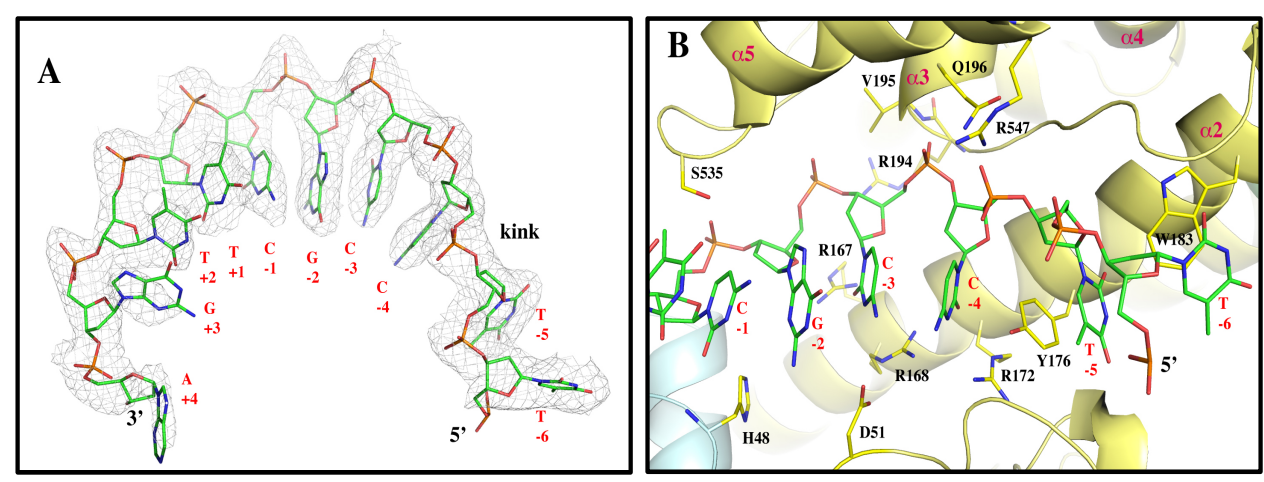

Figure 2.5 Conformation of ssDNA substrate and its interaction to MtTOP1-704t. (A) The ssDNA bound to MtTOP1-704t resembles a B-DNA conformation, which is interrupted between -4 and -5 positions. The 2FoFc electron density map is drawn in grey mesh and contoured at $1 \sigma$ level and within $2.1 \AA$ of the ssDNA, which is drawn in stick format. (B) Part of interaction between ssDNA and MtTOP1-704t. Several arginine residues involved in the interaction to either phosphate backbone (R194 and R547) or bases (R167, R168 and R172) are presented. One anchoring site of ssDNA to MtTOP1$704 \mathrm{t}$ is located at the phosphate group between -3 and -4 positions. The phosphate group is positioned below the N-terminus of the $\alpha 3$ helix of $D 4$, which has an equivalent charge about +0.5 unit. In the apo structures of MtTOP1-704t, a phosphate group or a sulfide group from crystallization buffer is commonly found at this position. The tyrosine Y176 inserts between the bases at -4 and -5 positions, helping create a kink on the base packing of ssDNA. The residue $\mathrm{Y} 176$ forms $\pi-\pi$ stacking with bases at both -4 and -5 positions. Both Fig.2A and 2B were prepared based on the MtTOP1-704t/MTS2-11 structure (PDB code: 6CQI). 


\section{Active-site conformation in the absence of $\mathrm{Mg}^{2+}$-binding}

The conformational change upon ssDNA binding not only helps create the gate for the passing of the T-strand, it also brings catalytic residues together to form an active site. The active site configuration of MtTOP1-704t/ MTS2-11, in the absence of $\mathrm{Mg}^{2+}$ ion, is similar to that of the covalent complex of EcTOP I and EcTOP III/ssDNA complexes, but with new features (Figure 2.6A). The catalytic tyrosine Y342 makes two hydrogen bonds from top to the scissile phosphate, including one to its bridging 5'-oxygen atom and one to a nonbridging $\mathrm{O}$ atom (Figure 2.6 A). The distance between the hydroxyl groups of Y342 to the phosphorous of the scissile phosphate is $2.96 \AA$. The scissile phosphate is being positioned on one side by R344 through an argininephosphate salt bridge, and on the other side by E24 through a hydrogen bond from its bridging 3'-oxygen atom (Figure 2.6A). E24 also forms a hydrogen bond with the amide group of D111, bridging the catalytic residue to the scissile phosphate.

The MtTOP1-704t/MTS2-11 structure does not have any positively charged lysine side chain interacting with the DNA at the active site while in the EcTOP III/ssDNA complex, lysine K8 interacts with the putative scissile phosphate. The positively charged K8 was believed to help stabilize the negative charge on non-bridging oxygens of the pentavalent transition state (Changela et al., 2001). However, in MtTOP1 as well as in EcTOP I, this lysine residue is not conserved, being replaced by a serine in the bacterial topoisomerase I sequences (Strahs et al., 2006). A nearby lysine K28 in MtTOP1 (equivalent to 
K13 in EcTOP I) is more than $6.5 \AA$ away from the scissile phosphate by measuring the distances between $\mathrm{K} 28 \mathrm{~N} \xi$ atom to the oxygen atoms of the phosphate (Figure 2.6 A). The absence of EcTOP III K8 equivalent in MtTOP1 and EcTOP I active site structures implies some difference in the catalytic mechanisms of bacterial topoisomerase I and topoisomerase III, as suggested earlier (Terekhova et al., 2012; Zhang et al., 2011). The side chain of D111 is quite mobile without well-defined electron density in electron density maps. D111 can potentially make a hydrogen bond with an invariant $\mathrm{H} 389$ on the long loop between $\alpha 3$ and $\alpha 4$ helices of D3. H389 also forms a displaced and tilted $\pi$ $\mathrm{H}$ (hydrogen) interaction with Y342 in this MtTOP1-704t/MTS2-11 complex. It is noted that the $\alpha 3$ _ 44 loop of D3 is very flexible, allowing the position and conformation of the strictly conserved histidine to be highly variable from structure to structure. Similar observations were made for the covalent EcTOP I complex as well as in the open and the mutant forms of EcTOP III, in which the histidine forms a nearly parallel displaced $\pi-\pi$ stacking with catalytic tyrosine. However, in the closed and the intermediate forms of EcTOP III, there is no interaction between these two residues. This flexible $\alpha 3$ _ $\alpha 4$ loop of D3 and the conserved histidine could play a potential role in charge relay in the DNA cleavage and religation steps (Perry and Mondragon, 2002). The direct $\pi-\pi$ interaction with the catalytic tyrosine may also allow this invariant histidine to assist in stabilization of the transition state for DNA cleavage in the absence of $\mathrm{Mg}^{2+}$. 


\section{Structure of active site with bound $\mathrm{Mg}^{2+}$ ion}

Magnesium plays an essential role in DNA religation by type IA topoisomerase (Tse-Dinh, 1986). However, divalent ion has never been observed in any co-crystal structures of topoisomerase IA-DNA complex. After the extensive screening of MtTOP1-704t/ssDNA crystals grown under different conditions, one crystal structure of MtTOP1-704t in complex with a 13-mer oligonucleotide, MTS2-13 reveals a mode of metal binding at the enzyme active site (Figure 2.6B). Compared to the structure of MtTOP1-704t/ssDNA in the absence of metal ion (Figure 2.6A), the extra electron densities in an approximately globular shape between the scissile phosphate and the carboxyl groups of E24 and D111 strongly indicate a metal binding site, $\mathrm{Mg}^{2+}(1)$ in Figure 2.6B. One water molecule, W (1), was assigned to completes the coordination of the metal ion, forming a trigonal bipyramid genometr, in which E24, OP1 and W1 are equatorial ligands while D111 and O3 are axial. It is worthwhile to mention that the position of the sidechain of D111 is not well-defined in electron density maps. After applying only Mg-O bond distance restrain $(2.10 \pm 0.10 \AA)$ to the metal binding site in the subsequent structural refinements, the trigional pyramid geometry is quite stable and the model fits the electron densities well. Interestingly, the water W1 forms a hydrogen bond with another TOPRIM acidic residue D113 (Figure 2.6B) proposed previously (Aravind et al., 1998; Bhat et al., 2009) to interact with divalent $\mathrm{Mg}^{2+}$. After obtaining this MtTOP1-704t/MTS2$13 / \mathrm{Mg}$ complex structure, a second structure with a metal ion bound at the same site was determined after extensive screening of crystals formed in different 
conditions, particularly in conditions with added $\mathrm{MgCl}_{2}$ in the crystallization buffers. The addition of $\mathrm{Mg}^{2+}$ in the crystallization buffer did not simply increase $\mathrm{Mg}^{2+}$ binding, at least under the buffer condition used.
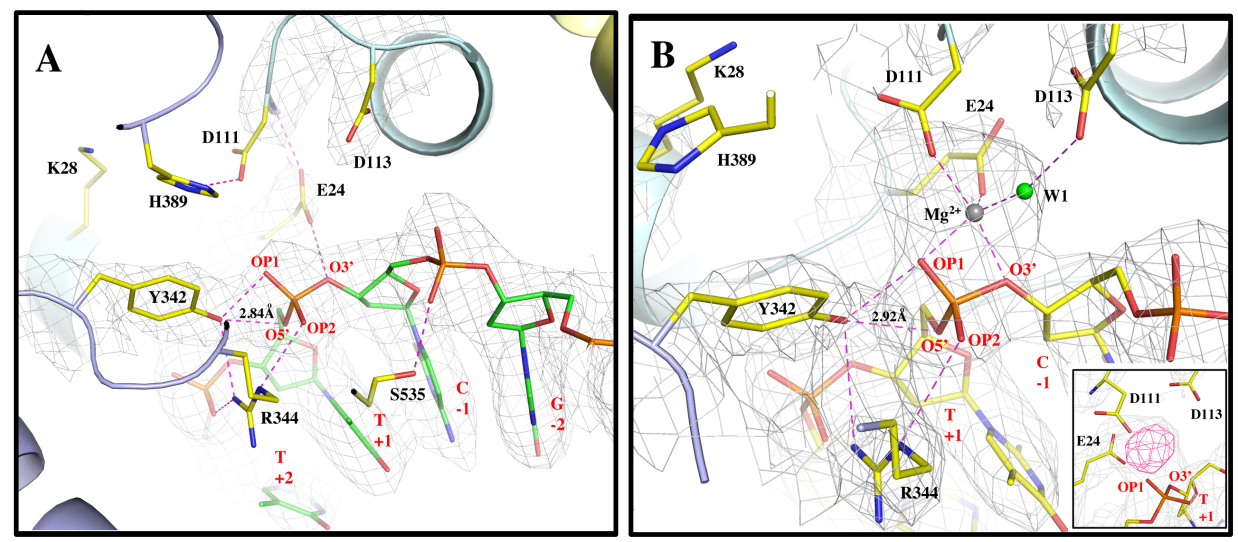

Figure 2.6 Active sites in the absence and in the presence of Mg2+. (A) The active site interaction pattern between MtTOP1-704t and ssDNA (MTS2-11) in the absence of $\mathrm{Mg}^{2+}$. The key residues from MtTOP1-704t and ssDNA are drawn in stick format. All hydrogen bonds and salt bridges are drawn in magenta dash lines. The residue K28, as discussed in text, is too far away from scissile phosphate. The 2FoFc electron density map is drawn in grey mesh and contoured at $1 \mathrm{~s}$ level and within $2.1 \AA$ of the ssDNA, the residues of E24, D111, D113 and Y342. (B) The active site interaction pattern between MtTOP1-704t and ssDNA (MTS2-13) in the presence of $\mathrm{Mg}^{2+}$. The MtTOP1-704t complex shown in this figure is slightly rotated along the horizontal axis in respect to that shown in Figure 2.6A for better view of $\mathrm{Mg}^{2}$ binding site. Besides hydrogen bonds and salt bridges, all $\mathrm{Mg}-\mathrm{O}$ bonds are also drawn in magenta dash lines. The 2FoFc electron density map is drawn in grey mesh and contoured at $1 \sigma$ level and within $2.1 \AA$ of the ssDNA, the residues of E24, D111, D113 and Y342, and the meal ion and water molecules. The insert figure displays simulated annealing omit maps of metal-binding site, 2Fo-Fc map in grey at contour level of $1 \sigma$, and Fo-Fc map in pink at contour level of $5 \sigma$. The simulated annealing refinement with a starting temperature of $5000 \mathrm{~K}$ was performed with $\mathrm{Mg}^{2+}$ and $\mathrm{W} 1$ being omitted. 


\section{Mapping of exact cleavage site on single-stranded oligonucleotide substrates}

In each of the crystal structures of the enzyme-DNA complex reported here, there is a DNA phosphate positioned at a distance from Tyr342 expected for the scissile phosphate. We confirmed that this is indeed the scissile phosphate for the cleavage of oligonucleotides MTS2-11 and MTS2-13 by PAGE analysis of the cleavage product, using shorter 5'-end labeled oligonucleotides for comparison (Figure 2.7 A, B). We also confirmed that both MtTOP1 and M. smegmatis topoisomerase I (MsTOP1) cleave at the same site in oligonucleotide STS32, a 32-base long ssDNA oligonucleotide from which the sequence of these shorter oligonucleotide substrates has been derived (Figure 2.7C). This cleavage position is shifted by one nucleotide towards the 5'-end from the position expected from the previous report (Bhat et al., 2009). This could be due to differences in enzyme preparation, cleavage reaction conditions, and cleavage site mapping protocols (Sikder and Nagaraja, 2000). 


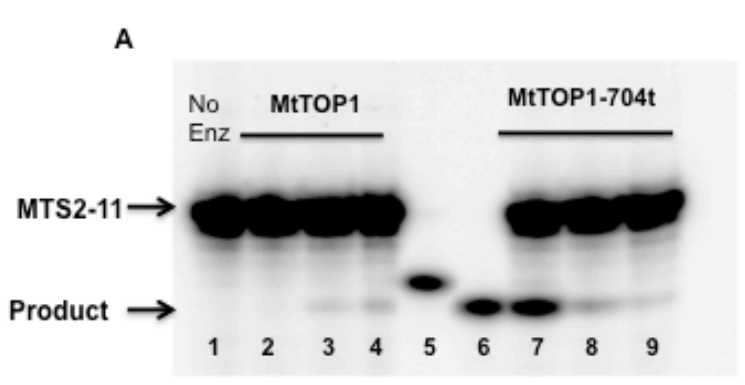

B

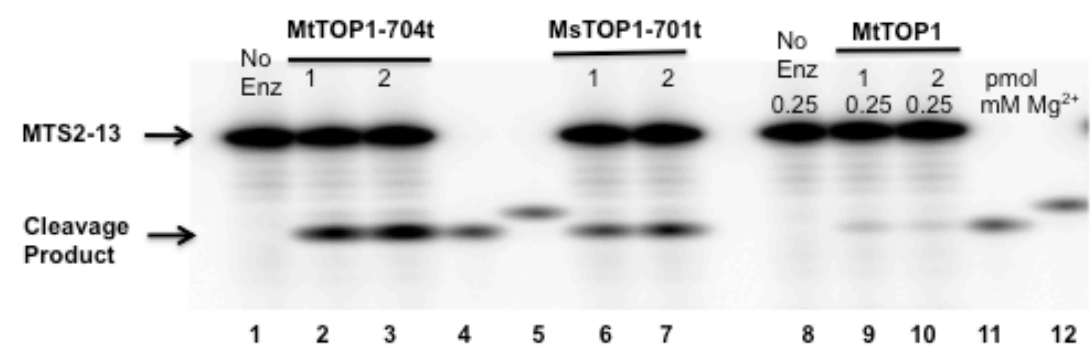

Figure 2.7 Identification of cleavage site with MTS2-11, MTS2-13 and STS32 oligonucleotide substrate. (A) Identification of cleavage site with MTS2-11. Lane 1: No enzyme. Lane 2: 1 pmol MtTOP1 cleavage product with oligo. Lane 3: 1 pmol MtTOP1 cleavage product with $0.5 \mathrm{mM} \mathrm{Mg}^{2+}$ added. Lane4: 1 pmol MtTOP1 cleavage product with $0.5 \mathrm{mM} \mathrm{Mg}^{2+}$ and $1 \mathrm{M} \mathrm{NaCl}$ added. Lane5: Oligo standard MT7. Lene6: Oligo standard MT6. Lane 7: 1 pmol MtTOP1-704t cleavage product. Lane 8: 1 pmol MtTOP1-704t cleavage product with $0.5 \mathrm{mM} \mathrm{Mg}^{2+}$ added. Lane9: 1 pmol MtTOP1-704t cleavage product with $0.5 \mathrm{mM} \mathrm{Mg}^{2+}$ and $1 \mathrm{M} \mathrm{NaCl}$ added. (B) Identification of cleavage site with MTS2-13. Lane 4 and Lane 11: Oligo standard MT6. Lane 5 and Lane 12: Oligo standard MT7. Lane 9 and lane 10 is cleavage product with $0.25 \mathrm{mM} \mathrm{Mg}^{2+}$ added. (C) Identification of cleavage site with STS32. 1 pmol MtTOP1-704t, MtTOP1 and MsTOP1 were used in Lane 2,3 and 6. Lane 4: Oligo standard MTS2-18. Lane 5, Oligo standard MTS2-19. 


\section{Requirement of the strictly conserved Glu24 carboxyl side chain for DNA cleavage}

The $\sim 100$ amino acid long TOPRIM domains found in type IA and type IIA topoisomerases have two strictly conserved sequence motifs of acidic residues that play important roles in the catalysis of these topoisomerases, as well as other nucleotidyl transfer enzymes that require $\mathrm{Mg}^{2+}$ for their activities (Aravind et al., 1998). The first motif is centered around a conserved glutamate that corresponds to residue E24 in MtTOP1 and E9 in EcTOP I respectively. The second motif is at the two conserved aspartates present as DxD (D111 and D113 in MtTOP1). Site-directed mutagenesis of EcTOP I has shown that alanine substitution at E9 abolishes DNA relaxation activity, and the E9A mutant could not cleave DNA (1998; Zhu et al., 1998). A role for this conserved glutamate in acid-base catalysis of DNA cleavage and rejoining has been proposed, with the glutamate side chain providing the proton for the 3'-OH leaving group during DNA cleavage, and enhancing the nucleophilic properties of the $3^{\prime}-\mathrm{OH}$ during DNA religation. E24 of MtTOP1 is well positioned for these roles as seen in the structure with MTS2-11 in the absence of divalent ions as the likely structure prior to the DNA cleavage step, and in the structure with MTS2-13 in the presence of $\mathrm{Mg}^{2+}$ as the probable structure post DNA religation. The critical functions of the strictly conserved glutamate E24 may be assisted by charge relay involving D111 and $\mathrm{H} 389$, with water molecules in the hydrogen-bonding network at the active site being potential participants in the acid-base catalysis. 
D111 and H365 in EcTOP I are well positioned for the proposed charge relay (Perry and Mondragon, 2002). The sequence of charge relay during DNA cleavage would involve donation of a proton from the invariant histidine to the nearby aspartate, which then relays the charge to the strictly conserved glutamate so that it can be protonated at physiological $\mathrm{pH}$ to act as a general acid for neutralizing the negative charge on the 3'-hydroxyl leaving group. The bell-shaped pH dependence of EcTOP I catalysis is modified by H365 mutations (Perry and Mondragon, 2002) is consistent with the role of this conserved histidine in optimal catalysis at physiological pH (Perry and Mondragon, 2002). A nearby water molecule can potentially replace the role of the histidine for donating a proton if the histidine is mutated to another residue. However, the role of EcTOP I glutamate E9 as a general acid during DNA cleavage is inconsistent with the reported retention of DNA cleavage activity for the EcTOP I E9Q mutant (Chen and Wang, 1998). In order to clarify the catalytic role of this critical conserved glutamic acid residue, we mutated E24 of MtTOP1 to alanine or glutamine. Both the MtTOP1-E24A and MtTOP1-E24Q mutants had null relaxation activity as well as no observable DNA cleavage activity (Figure 2.8 A, B). Similar results were obtained for the MsTOP1 E21A and E21Q mutants (Figure 2.9). Gel shift assay of non-covalent binding to the oligonucleotide substrate showed that the activities of the MtTOP1-E24A and MtTOP1-E24Q mutant proteins are unaffected prior to the DNA cleavage step (Figure 2.8C). 


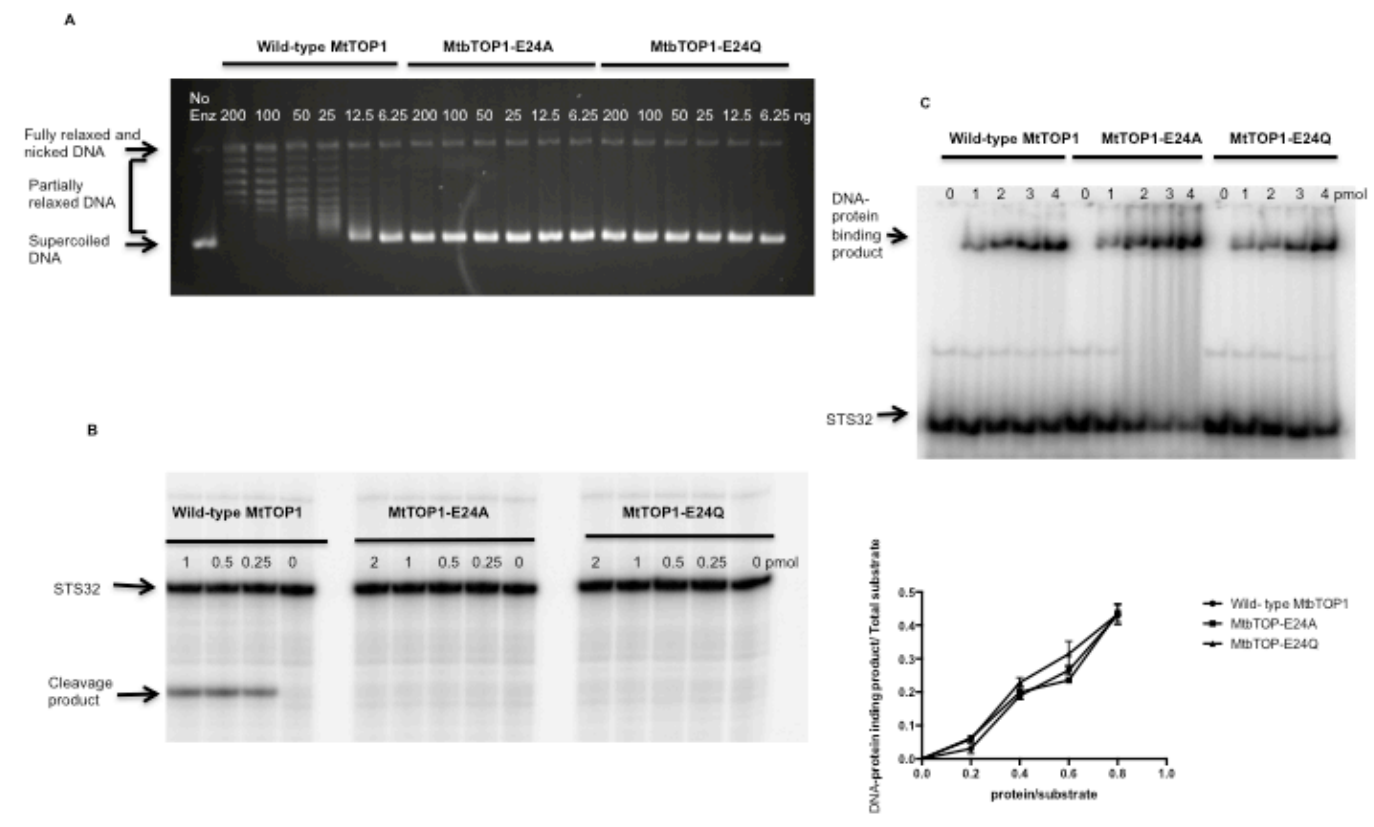

Figure 2.8 Substitutions in MtTOP1 E24 prevent relaxation of supercoiled DNA and ssDNA cleavage by the enzyme without affecting non-covalent DNA binding. (A) Relaxation assay: Agarose gel electrophoresis of products from incubation of supercoiled $\mathrm{pBAD} /$ Thio plasmid DNA with wild-type MtTOP1 and E24A, E24Q mutant enzymes at $37^{\circ} \mathrm{C}$ for $30 \mathrm{~min}$. (B) ssDNA cleavage assay: STS32 oligonucleotide labeled with ${ }^{32} \mathrm{P}$ at the $5^{\prime}$-end was incubated with enzymes at $37^{\circ} \mathrm{C}$ for $15 \mathrm{~min}$. The substrate and product were separated by electrophoresis in a $15 \%$ sequencing gel. (C) ssDNA binding assay of wild-type and mutant MtTOP1: Electrophoretic mobility shift assay for formation of non-covalent complex between labeled STS32 oligonucleotide and enzyme. The graph shows average and means from results of three experiments. 

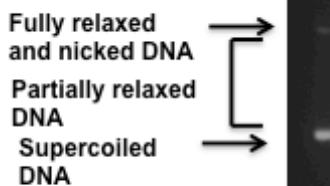

DNA

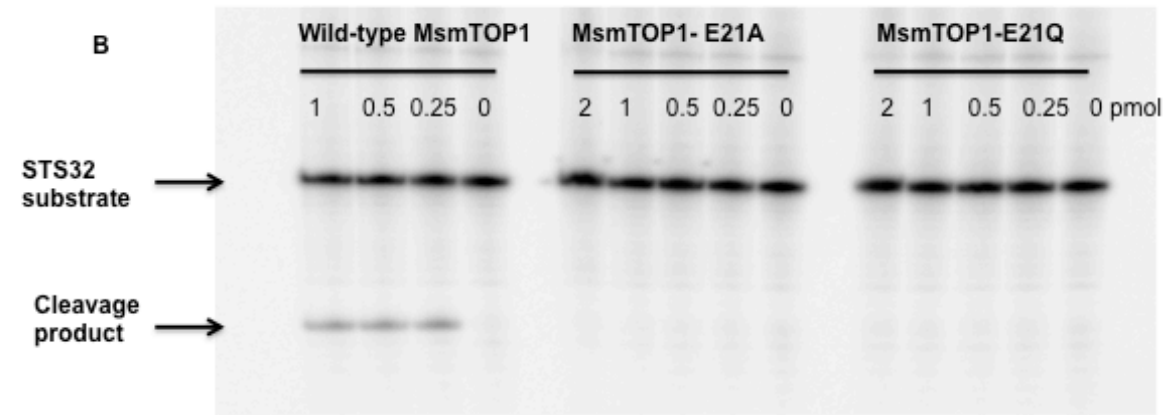

Figure 2.9 Substitutions in MsTOP1-E21 prevent ssDNA cleavage by the enzyme. (A) Relaxation assay. Serial diluted MsTOP1, MsTOP1-E21A and MsTOP1-E21Q were incubated with $250 \mathrm{ng} \mathrm{pBAD} /$ Thio plasmid DNA $37^{\circ} \mathrm{C}$ for $30 \mathrm{~min}$. (B) ssDNA cleavage assay. SsDNA cleavage assay: STS32 oligonucleotide labeled with ${ }^{32} \mathrm{P}$ at the $5^{\prime}$-end was incubated with enzymes at $37^{\circ} \mathrm{C}$ for $15 \mathrm{~min}$. The substrate and product were separated by electrophoresis in a $15 \%$ sequencing gel. 


\section{DISSCUSSION}

In the model of DNA cleavage proposed for type IIA topoisomerases (Schmidt et al., 2010), a divalent metal ion and a conserved arginine interact with the scissile phosphate to stabilize the transition state while a second metal ion interacts with the -1 phosphate to position the scissile phosphate in the active site for cleavage by the tyrosine nucleophile. We propose that for bacterial topoisomerase I, the strictly conserved arginine (R344 in MtTOP1) is mainly responsible for an electrostatic interaction with the scissile phosphate to allow DNA cleavage to take place in the absence of metals (Figure 2.10A). A water molecule may act as a general base (B:) to extract a proton from the active site tyrosine Y342, facilitating nucleophilic attack. The positively charged side chain of R344 interacts with both the tyrosine oxygen and the transition state to stabilize the negative charges. E24 acts as general acid to protonate the 3'-O leaving group. D111 and H389 are in place for charge relay to assist E24. This proposed scheme is supported by the previously observed requirement of $\mathrm{Mg}^{2+}$ for DNA cleavage by EcTOP I mutants with the conserved arginine (R321) altered to an aromatic residue that can interact with the active site tyrosine through hydrophobic interaction, but cannot provide any electrostatic interaction (Narula et al., 2011; Narula and Tse-Dinh, 2012). The stacking interaction between the invariant histidine (H389 in MtTOP1) and the catalytic tyrosine may also help to stabilize the DNA cleavage transition state in the absence of $\mathrm{Mg}^{2+}$. 
A

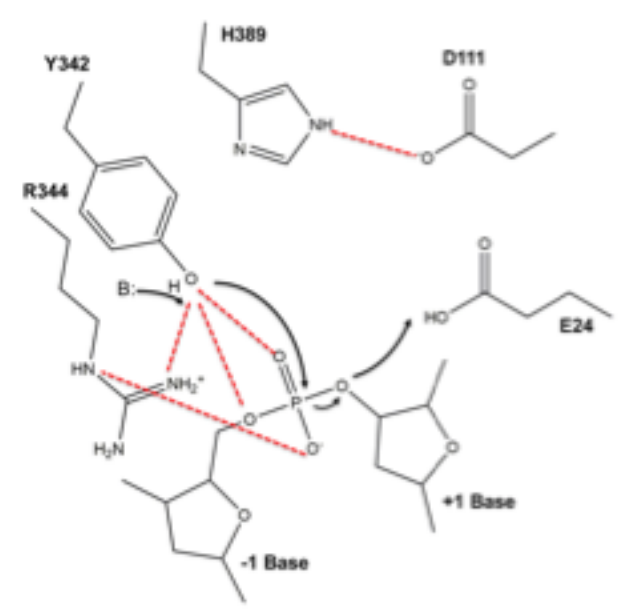

B

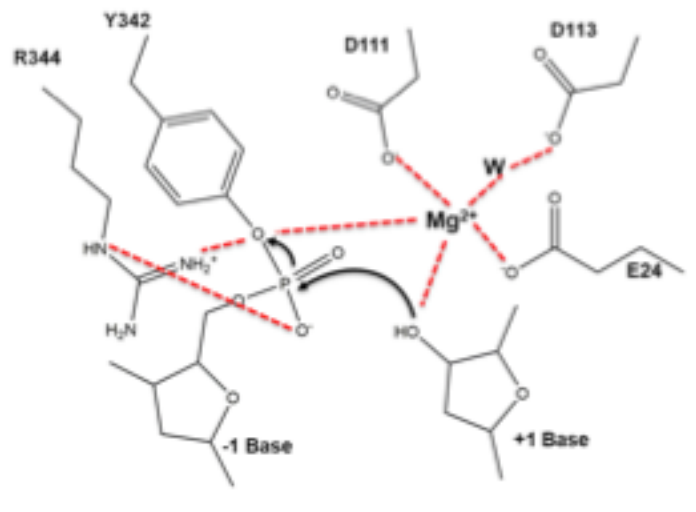

Figure 2.10 Proposed schemes for DNA cleavage and religation. (A) Proposed schemes for DNA cleavage in the absence of divalent ions. (B) Proposed schemes for DNA reliagtion in the presence of divalent ion.

The preferred DNA cleavage sites of MtTOP1 have a cytosine base at the -4 position upstream of the scissile phosphate (Annamalai et al., 2009). This cleavage site preference holds true for all bacterial topoisomerase I, but not for topoisomerase III. We propose that the interactions of R168, R172, Y176 (Figure 2.5) with the cytosine base in the -4 position serve the role of the second metal ion proposed for type IIA topoisomerase for positioning the DNA substrate (Schmidt et al., 2010), ensuring that the tyrosine hydroxyl is at the required distance from the scissile phosphate in the active site for DNA cleavage to take place. Analysis of the site-directed alanine substitution mutations of the EcTOP I residues required for interaction with the cytosine in the -4 position showed that the mutants have significantly decreased DNA cleavage activity, and that the preference of the cytosine in the -4 position can be altered to an adenine base 
instead (Narula and Tse-Dinh, 2012). Topoisomerase III enzymes do not have the requirement of a cytosine base in the -4 position for preferred cleavage sites to utilize this mechanism for aligning the active site tyrosine with the scissile phosphate. A lysine conserved in topoisomerase III enzymes (K8 in EcTOP III) has been proposed to replace the role of a metal ion required by type IIA topoisomerase in the active site (Schmidt et al., 2010). A lysine is conserved in bacterial topoisomerase I in a nearby, but non-equivalent position (K13 in EcTOP I, K28 in MtTOP1). Site-directed mutagenesis of EcTOP I K13 showed that this lysine is required for DNA cleavage (Strahs et al., 2006), but its positively charged side chain is not in the vicinity of the scissile phosphate in all the EcTOP I crystal structures available to date. We also find that K28 is not near the DNA phosphates in the active site of MtTOP1-704t bound to DNA in the absence or presence of metal ions (Figure 2.6). We cannot dismiss the possibility that K28 of MtTOP1 and its equivalent lysine in other bacterial topoisomerase I can move into the active site to interact with the transition state in a reaction intermediate that has not been captured by crystallography. It is also possible that the role of $\mathrm{K} 13$ in EcTOP I and K28 in MtTOP1 in catalysis is different from K8 in EcTOP III, as their positions are not equivalent. The lysine conserved in this specific position of bacterial topoisomerase I may be required for the assembly of the active site. It may also have a polarizing effect on the nearby acidic residues, as previously proposed (Strahs et al., 2006).

Because type IA topoisomerases break and rejoin a single-strand of DNA that is not base-paired to its complementary strand, Watson-Crick base pairing is not 
available to help align the 3'-OH and 5'-phosohoryl group linked to the tyrosine in the covalent intermediate for rejoining. Therefore, we propose that there is a stringent requirement for the presence of the metal ion to be present for these DNA ends to be joined into a phosphodiester linkage in the DNA religation step. Metal ion is required to position the 3 '-hydroxyl group as the nucleophile at a required distance from the phosphotyrosine linkage. The metal ion could be involved in positioning the 5'-phosphoryl tyrosine, and in the stabilization of the transition state for DNA rejoining (Figure 2.10B). Such roles for the divalent ion would differ from the classic two-metal ion mechanism, with both metal ions interacting with the transition state, and one metal assisting in the activation of the nucleophile while the other metal stabilizes the leaving group (Strahs et al., 2006). There are also significant differences from the mechanism proposed for type IIA topoisomerase (Schmidt et al., 2010), with both metal ions assisting the acid-base catalysis by interacting with the transition state and the second metal ion interacting with an adjacent phosphate to anchor the substrate DNA. We cannot disregard any movement of the metal ion in type IA and type IIA topoisomerases during catalysis to facilitate nucleophile formation and stabilize both transition state and leaving group as expected for the canonical two-metal ion mechanism (Schmidt et al., 2010; Strahs et al., 2006). Nevertheless, bacterial topoisomerase I may have evolved to have a metal ion involved in forming and stabilizing the transition state for DNA rejoining because of the single-stranded state of the DNA strand during cleavage-religation, and the utilization of a cytosine binding pocket for positioning the DNA substrate for 
cleavage instead of using a metal ion for such purpose. The 3'-OH nucleophile is activated by $\mathrm{Mg}^{2+}$ in DNA rejoining (Figure 2.10B). The positive charge of the conserved arginine (R344 in MtTOP1) interacting with the active site tyrosineleaving group is essential for DNA rejoining. DNA cleavage intermediate accumulates in vivo when this arginine in EcTOP I (R321) is mutated to a hydrophobic amino acid (Narula et al., 2011). The presence of $\mathrm{Mg}^{2+}$ cannot compensate for the absence of the arginine positive charge for DNA rejoining. Therefore even though a metal may be in a position to stabilize the negative charge of the tyrosine hydroxyl leaving group as expected for the canonical twometal ion mechanism, the positive charge of this arginine is still required for interacting with the tyrosine hydroxyl negative charge during DNA rejoining.

Certain mutants of EcTOP I and MsTOP1 with specific substitutions at the conserved arginine and aspartates in the active site have been demonstrated to be dominant lethal (Bhat et al., 2009; Tse-Dinh, 2009). These mutant enzymes can still cleave DNA while DNA rejoining in the presence of $\mathrm{Mg}^{2+}$ became less efficient, resulting in accumulation of covalent intermediates and bacterial cell death (Cheng et al., 2009; Narula et al., 2011; Tse-Dinh, 2009). MtTOP1 is essential for the viability of the TB pathogen, and can be exploited as a novel target for discovery of new therapies (Godbole et al., 2015; Nagaraja et al., 2017; Ravishankar et al., 2015; Sandhaus et al., 2016) in the treatment of MDR-TB. Genetic manipulation to deplete MtTOP1 and inhibition of MtTOP1 activity by small molecules have been shown to inhibit growth (Godbole et al., 2015; Ravishankar et al., 2015). Significant bactericidal activity may require only a 
small number of the trapped covalent topoisomerase-DNA intermediates (Aedo and Tse-Dinh, 2012) through the action of topoisomerase poison inhibitors (Pommier, 2013; Pommier et al., 2010). Small molecules that can selectively perturb the MtTOP1 active site interactions in the presence of $\mathrm{Mg}^{2+}$ observed in the structure of enzyme/DNA/Mg complex reported here may be candidates for topoisomerase poison inhibitors against MtTOP1. 


\section{REFERENCES}

Abubakar, I., Pimpin, L., Ariti, C., Beynon, R., Mangtani, P., Sterne, J. A., et al. (2013). Systematic review and meta-analysis of the current evidence on the duration of protection by bacillus Calmette-Guerin vaccination against tuberculosis. Health Technol Assess, 17(37), 1-372, v-vi.

Aedo, S., and Tse-Dinh, Y. C. (2012). Isolation and quantitation of topoisomerase complexes accumulated on Escherichia coli chromosomal DNA. Antimicrob Agents Chemother, 56(11), 5458-5464.

Ahmed, W., Bhat, A. G., Leelaram, M. N., Menon, S., and Nagaraja, V. (2013). Carboxyl terminal domain basic amino acids of mycobacterial topoisomerase I bind DNA to promote strand passage. Nucleic Acids Res, 41(15), 7462-7471.

Ahmed, W., Menon, S., Godbole, A. A., Karthik, P. V., and Nagaraja, V. (2014). Conditional silencing of topoisomerase I gene of Mycobacterium tuberculosis validates its essentiality for cell survival. FEMS Microbiol Lett, 353(2), 116-123.

Ahmed, W., Menon, S., Karthik, P. V., and Nagaraja, V. (2015). Reduction in DNA topoisomerase I level affects growth, phenotype and nucleoid architecture of Mycobacterium smegmatis. Microbiology, 161(Pt 2), 341-353.

Ahumada, A., and Tse-Dinh, Y. C. (2002). The role of the $\mathrm{Zn}$ (II) binding domain in the mechanism of E. coli DNA topoisomerase I. BMC Biochem, 3, 13.

Aldred, K. J., Kerns, R. J., and Osheroff, N. (2014). Mechanism of quinolone action and resistance. Biochemistry, 53(10), 1565-1574.

Alsdurf, H., Hill, P. C., Matteelli, A., Getahun, H., and Menzies, D. (2016). The cascade of care in diagnosis and treatment of latent tuberculosis infection: a systematic review and meta-analysis. Lancet Infect Dis, 16(11), 1269-1278.

Ameeruddin, N. U., and Luke Elizabeth, H. (2014). Impact of isoniazid resistance on virulence of global and south Indian clinical isolates of Mycobacterium tuberculosis. Tuberculosis (Edinb), 94(6), 557-563. 
Annamalai, T., Dani, N., Cheng, B., and Tse-Dinh, Y. C. (2009). Analysis of DNA relaxation and cleavage activities of recombinant Mycobacterium tuberculosis DNA topoisomerase I from a new expression and purification protocol. BMC Biochem, 10, 18.

Aravind, L., Leipe, D. D., and Koonin2, E. V. (1998). Toprim-a conserved catalytic domain in type IA and II topoisomerases, DnaG-type primases, OLD family nucleases and RecR proteins. Nucleic Acids Research, 26(28), 9.

Bailey, R., Priego Moreno, S., and Gambus, A. (2015). Termination of DNA replication forks: "Breaking up is hard to do". Nucleus, 6(3), 187-196.

Baker, N. M., Rajan, R., and Mondragon, A. (2008). Structural studies of type I topoisomerases. Nucleic Acids Research, 37(3), 693-701.

Banda, S., Cao, N., and Tse-Dinh, Y. C. (2017). Distinct Mechanism Evolved for Mycobacterial RNA Polymerase and Topoisomerase I Protein-Protein Interaction. J Mol Biol, 429(19), 2931-2942.

Baranello, L., Levens, D., Gupta, A., and Kouzine, F. (2012). The importance of being supercoiled: How DNA mechanics regulate dynamic processes. Biochimica Biophy Acta (BBA) - Gene Regulatory Mechanisms, 1819(7), 632-638.

Basu, A., Parente, A. C., and Bryant, Z. (2016). Structural Dynamics and Mechanochemical Coupling in DNA Gyrase. J Mol Biol, 428(9 Pt B), 1833-1845.

Berger, J. M., Fass, D., Wang, J. C., and Harrison, S. C. (1998). Structural similarities between topoisomerases that cleave one or both DNA strands. Proc. Natl. Acad. Sci. U. S. A., 95, 7876-7881.

Berger, J. M., and Wang, J. C. (1996). Recent developments in DNA topoisomerase II structure and mechanism. Current Opinion in Structure Biology, $6(1), 84-90$.

Bhaduri, T., Bagui, T. K., Sikder, D., and Nagaraja, V. (1998). DNA Topoisomerase I from Mycobacterium smegmatis. Journal of Biological Chemistry, 273(22), 13925-13932. 
Bhat, A. G., Leelaram, M. N., Hegde, S. M., and Nagaraja, V. (2009).

Deciphering the distinct role for the metal coordination motif in the catalytic activity of Mycobacterium smegmatis topoisomerase I. J Mol Biol, 393(4), 788802.

Bhat, Z. S., Rather, M. A., Maqbool, M., Lah, H. U., Yousuf, S. K., and Ahmad, Z. (2017). Cell wall: A versatile fountain of drug targets in Mycobacterium tuberculosis. Biomed Pharmacother, 95, 1520-1534.

Bugreev, D. V., and Nevinsky, G. A. (2010). Structure and mechanism of action of type IA DNA topoisomerases. Biochemistry (Moscow), 74(13), 1467-1481.

Bush, N. G., Evans-Roberts, K., and Maxwell, A. (2015). DNA Topoisomerases. EcoSal Plus, 6(2).

Capranico, G., Marinello, J., and Chillemi, G. (2017). Type I DNA Topoisomerases. J Med Chem, 60(6), 2169-2192.

Changela, A., DiGate, R. J., and Mondragon, A. (2001). Crystal structure of a complex of a type IA DNA topoisomerase with a single-stranded DNA molecule. Nature, 411, 1077-1081.

Chawla, S., Garg, D., Jain, R. B., Khanna, P., Choudhary, S., Sahoo, S., et al. (2014). Tuberculosis vaccine: time to look into future. Hum Vaccin Immunother, 10(2), 420-422.

Chen, S. H., Chan, N. L., and Hsieh, T. S. (2013). New mechanistic and functional insights into DNA topoisomerases. Annu Rev Biochem, 82, 139-170.

Chen, S. J., and Wang, J. C. (1998). Identification of active site residues in Escherichia coli DNA topoisomerase I. J. Biol. Chem., 273, 6050-6056.

Cheng, B., Annamalai, T., Sorokin, E., Abrenica, M., Aedo, S., and Tse-Dinh, Y. C. (2009). Asp-to-Asn substitution at the first position of the DxD TOPRIM motif

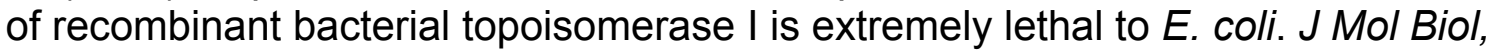
385(2), 558-567. 
Cheng, B., Zhu, C. X., Ji, C., Ahumada, A., and Tse-Dinh, Y. C. (2003). Direct interaction between Escherichia coli RNA polymerase and the zinc ribbon domains of DNA topoisomerase I. J Biol Chem, 278(33), 30705-30710.

Chong, S., Chen, C., Ge, H., and Xie, X. S. (2014). Mechanism of transcriptional bursting in bacteria. Cell, 158(2), 314-326.

Connell, D. W., Berry, M., Cooke, G., and Kon, O. M. (2011). Update on tuberculosis: TB in the early 21st century. Eur Respir Rev, 20(120), 71-84.

Corbett, K. D., and Berger, J. M. (2004). Structure, molecular mechanisms, and evolutionary relationships in DNA topoisomerases. Annu Rev Biophys Biomol Struct, 33, 95-118.

Dai, X., and Rothma-Denes, L. B. (1999). DNA structure and replication. Current Opinion in Microbiology, 2, 126-130.

Delogu, G., Sali, M., and Fadda, G. (2013). The biology of mycobacterium tuberculosis infection. Mediterr J Hematol Infect Dis, 5(1), e2013070.

Depew, R. E., Liu, L. F., and Wang, J. C. (1978). Interaction between DNA and Escherichia-Coli Protein-Omega - Formation of a Complex between SingleStranded-DNA and Omega-Protein. Journal of Biological Chemistry, 253(2), 511518.

Dinardo, S., Voelkel, K., and Stenglanz, R. (1984). DNA topoisomerase II mutant of Saccharomy cescerevisiae: Topoisomerase II is required for segregation of daughter molecules at the termination of DNA replication. Proc. Natl. Acad. Sci. USA, 81, 2016-2020.

Fachinetti, D., Bermejo, R., Cocito, A., Minardi, S., Katou, Y., Kanoh, Y., et al. (2010). Replication termination at eukaryotic chromosomes is mediated by Top2 and occurs at genomic loci containing pausing elements. Mol Cell, 39(4), 595605.

Finzi, L., and Dunlap, D. (2016). Supercoiling biases the formation of loops involved in gene regulation. Biophys Rev, 8(Suppl 1), 65-74. 
Fogel, N. (2015). Tuberculosis: a disease without boundaries. Tuberculosis (Edinb), 95(5), 527-531.

Forterre, P., and Gadelle, D. (2009). Phylogenomics of DNA topoisomerases: their origin and putative roles in the emergence of modern organisms. Nucleic Acids Res, 37(3), 679-692.

Forterre, P., Gribaldo, S., Gadelle, D., and Serre, M. C. (2007). Origin and evolution of DNA topoisomerases. Biochimie, 89(4), 427-446.

Fu, L. M., and Fu-Liu, C. S. (2002). Is Mycobacterium tuberculosis a closer relative to Gram-positive or Gram-negative bacterial pathogens? Tuberculosis, 82(2-3), 85-90.

Gentry, A. C., and Osheroff, N. (2013). DNA Topoisomerases: Type II Encyclopedia of Biological Chemistry (pp. 163-168).

Glickman, M., and Jr., W. J. (2001). Microbial Pathogenesis of Mycobacterium tuberculosis:Dawn of a Discipline. Cell, 104, 477-485,.

Godbole, A. A., Ahmed, W., Bhat, R. S., Bradley, E. K., Ekins, S., and Nagaraja, V. (2015). Targeting Mycobacterium tuberculosis topoisomerase I by smallmolecule inhibitors. Antimicrob Agents Chemother, 59(3), 1549-1557.

Harmon, F. G., Brockman, J. P., and Kowalczykowski, S. C. (2003). RecQ helicase stimulates both DNA catenation and changes in DNA topology by topoisomerase III. J Biol Chem, 278(43), 42668-42678.

Harmon, F. G., DiGate, R. J., and Kowalczykowski, S. C. (1999). RecQ Helicase and Topoisomerase III Comprise a Novel DNA Strand Passage Function: A Conserved Mechanism for Control of DNA Recombination. Molecular Cell, 3, 611-620.

Hiasaand, H., and Marians, K. J. (1994). Topoisomerase III, but Not Topoisomerase I, Can Support Nascent Chain Elongation during Theta-type DNA Replication. J. Biol. Chem., 269(51), 32655-32659. 
Higgins, N. P., and Vologodskii, A. V. (2015). Topological Behavior of Plasmid DNA. Microbiol Spectr, 3(2), 1-25.

Jacobs, A. J., Mongkolsapaya, J., Screaton, G. R., McShane, H., and Wilkinson, R. J. (2016). Antibodies and tuberculosis. Tuberculosis (Edinb), 101, 102-113.

Jain, P., and Nagaraja, V. (2006). Indispensable, functionally complementing N and C-terminal domains constitute site-specific topoisomerase I. J Mol Biol, 357(5), 1409-1421.

Janin, Y. L. (2007). Antituberculosis drugs: ten years of research. Bioorg Med Chem, 15(7), 2479-2513.

Jankute, M., Cox, J. A., Harrison, J., and Besra, G. S. (2015). Assembly of the Mycobacterial Cell Wall. Annu Rev Microbiol, 69, 405-423.

Jassal, M., and Bishai, W. R. (2009). Extensively-drug-resistant-tuberculosis. The Lancet Infectious Diseases, 9, 19-30.

Kapust, R. B., Tozser, J., Copeland, T. D., and Waugh, D. S. (2002). The P1' specificity of tobacco etch virus protease. Biochem Biophys Res Commun, 294(5), 949-955.

Kaufmann, S. H. (2013). Tuberculosis vaccines: time to think about the next generation. Semin Immunol, 25(2), 172-181.

Keszthelyi, A., Minchell, N. E., and Baxter, J. (2016). The Causes and Consequences of Topological Stress during DNA Replication. Genes (Basel), 7(12), 134-146.

Koster, D. A., Crut, A., Shuman, S., Bjornsti, M. A., and Dekker, N. H. (2010). Cellular strategies for regulating DNA supercoiling: a single-molecule perspective. Cell, 142(4), 519-530.

Kouzine, F., Levens, D., and Baranello, L. (2014). DNA topology and transcription. Nucleus, 5(3), 195-202. 
Lee, S., Jung, S. R., Heo, K., Byl, J. A., Deweese, J. E., Osheroff, N., et al. (2012). DNA cleavage and opening reactions of human topoisomerase llalpha are regulated via Mg2+-mediated dynamic bending of gate-DNA. Proc Natl Acad Sci U S A, 109(8), 2925-2930.

Lipworth, S., Hammond, R. J., Baron, V. O., Hu, Y., Coates, A., and Gillespie, S. H. (2016). Defining dormancy in mycobacterial disease. Tuberculosis (Edinb), 99, 131-142.

Lu, J., Wang, W., Tan, G., Landry, A. P., Yi, P., Si, F., et al. (2011). Escherichia coli topoisomerase I is an iron and zinc binding protein. Biometals, 24(4), 729736.

Magnan, D., and Bates, D. (2015). Regulation of DNA Replication Initiation by Chromosome Structure. J Bacteriol, 197(21), 3370-3377.

Mishra, R., Shukla, P., Huang, W., and Hu, N. (2015). Gene mutations in Mycobacterium tuberculosis: multidrug-resistant TB as an emerging global public health crisis. Tuberculosis (Edinb), 95(1), 1-5.

Nagaraja, V., Godbole, A. A., Henderson, S. R., and Maxwell, A. (2017). DNA topoisomerase I and DNA gyrase as targets for TB therapy. Drug Discov Today, 22(3), 510-518.

Narula, G., Annamalai, T., Aedo, S., Cheng, B., Sorokin, E., Wong, A., et al. (2011). The strictly conserved Arg-321 residue in the active site of Escherichia coli topoisomerase I plays a critical role in DNA rejoining. $J$ Biol Chem, 286(21), 18673-18680.

Narula, G., Becker, J., Cheng, B., Dani, N., Abrenica, M. V., and Tse-Dinh, Y. C. (2010). The DNA relaxation activity and covalent complex accumulation of Mycobacterium tuberculosis topoisomerase I can be assayed in Escherichia coli: application for identification of potential FRET-dye labeling sites. BMC Biochem, $11,41$.

Narula, G., and Tse-Dinh, Y. C. (2012). Residues of E. coli topoisomerase I conserved for interaction with a specific cytosine base to facilitate DNA cleavage. Nucleic Acids Res, 40(18), 9233-9243. 
Nath, H., and Ryoo, S. (2013). First- and Second-Line Drugs and Drug Resistance Tuberculosis - Current Issues in Diagnosis and Management (pp. 163-180).

Nitiss, J. L. (2009). Targeting DNA topoisomerase II in cancer chemotherapy. Nat Rev Cancer, 9(5), 338-350.

Nurse, P., Levine, C., Hassing, H., and Marians, K. J. (2003). Topoisomerase III can serve as the cellular decatenase in Escherichia coli. J Biol Chem, 278(10), 8653-8660.

Pai, M., Behr, M. A., Dowdy, D., Dheda, K., Divangahi, M., Boehme, C. C., et al. (2016). Tuberculosis. Nat Rev Dis Primers, 2, 16076.

Parker, M. W., Botchan, M. R., and Berger, J. M. (2017). Mechanisms and regulation of DNA replication initiation in eukaryotes. Crit Rev Biochem Mol Biol, 52(2), 107-144.

Patel, A., Yakovleva, L., Shuman, S., and Mondragon, A. (2010). Crystal structure of a bacterial topoisomerase IB in complex with DNA reveals a secondary DNA binding site. Structure, 18(6), 725-733.

Perry, K., and Mondragon, A. (2002). Biochemical characterization of an invariant histidine involved in Escherichia coli DNA topoisomerase I catalysis. $J$ Biol Chem, 277(15), 13237-13245.

Perry, K., and Mondragón, A. (2003). Structure of a Complex between E. coli DNA Topoisomerase I and Single-Stranded DNA. Structure, 11(11), 1349-1358.

Piccini, P., Chiappini, E., Tortoli, E., de Martino, M., and Galli, L. (2014). Clinical peculiarities of tuberculosis. BMC Infect Dis, 14 Suppl 1, S4.

Pieters, J. (2008). Mycobacterium tuberculosis and the macrophage: maintaining a balance. Cell Host Microbe, 3(6), 399-407.

Podany, A. T., and Swindells, S. (2016). Current strategies to treat tuberculosis. F1000Res, 5. 
Pommier, Y. (2013). Drugging topoisomerases: lessons and challenges. ACS Chem Biol, 8(1), 82-95.

Pommier, Y., Leo, E., Zhang, H., and Marchand, C. (2010). DNA topoisomerases and their poisoning by anticancer and antibacterial drugs. Chem Biol, 17(5), 421433.

Rampakakis, E., Gkogkas, C., Di Paola, D., and Zannis-Hadjopoulos, M. (2010). Replication initiation and DNA topology: The twisted life of the origin. $J$ Cell Biochem, 110(1), 35-43.

Ravishankar, S., Ambady, A., Awasthy, D., Mudugal, N. V., Menasinakai, S., Jatheendranath, S., et al. (2015). Genetic and chemical validation identifies Mycobacterium tuberculosis topoisomerase I as an attractive anti-tubercular target. Tuberculosis (Edinb), 95(5), 589-598.

Rosenbaum, G., Alkire, R. W., Evans, G., Rotella, F. J., Lazarski, K., Zhang, R. G., et al. (2006). The Structural Biology Center 19ID undulator beamline: facility specifications and protein crystallographic results. J Synchrotron Radiat, 13(Pt 1), 30-45.

Sandhaus, S., Annamalai, T., Welmaker, G., Houghten, R. A., Paz, C., Garcia, P. K., et al. (2016). Small-Molecule Inhibitors Targeting Topoisomerase I as Novel Antituberculosis Agents. Antimicrob Agents Chemother, 60(7), 4028-4036.

Schmidt, B. H., Burgin, A. B., Deweese, J. E., Osheroff, N., and Berger, J. M. (2010). A novel and unified two-metal mechanism for DNA cleavage by type II and IA topoisomerases. Nature, 465(7298), 641-644.

Schmidt, B. H., Osheroff, N., and Berger, J. M. (2012). Structure of a topoisomerase II-DNA-nucleotide complex reveals a new control mechanism for ATPase activity. Nat Struct Mol Biol, 19(11), 1147-1154.

Schoeffler, A. J., and Berger, J. M. (2008). DNA topoisomerases: harnessing and constraining energy to govern chromosome topology. Q Rev Biophys, 41(1), 41101.

Seol, Y., and Neuman, K. C. (2016). The dynamic interplay between DNA topoisomerases and DNA topology. Biophys Rev, 8(Suppl 1), 101-111. 
Sikder, D., and Nagaraja, V. (2000). Determination of the recognition sequence of Mycobacterium smegmatis topoisomerase I on mycobacterial genomic sequences. Nucleic Acids Research, 28, 1830-1837.

Sissi, C., and Palumbo, M. (2009). Effects of magnesium and related divalent metal ions in topoisomerase structure and function. Nucleic Acids Res, 37(3), 702-711.

Smith, J. P. (2017). Nanoparticle Delivery of Anti-Tuberculosis Chemotherapy as a Potential Mediator Against Drug-Resistant Tuberculosis. YALE JOURNAL OF BIOLOGY AND MEDICINE, 84, 9.

Sridevi, J. P., Suryadevara, P., Janupally, R., Sridhar, J., Soni, V., Anantaraju, H. $S$., et al. (2015). Identification of potential Mycobacterium tuberculosis topoisomerase I inhibitors: a study against active, dormant and resistant tuberculosis. Eur J Pharm Sci, 72, 81-92.

Strahs, D., Zhu, C. X., Cheng, B., Chen, J., and Tse-Dinh, Y. C. (2006). Experimental and computational investigations of Ser10 and Lys13 in the binding and cleavage of DNA substrates by Escherichia coli DNA topoisomerase I. Nucleic Acids Res, 34(6), 1785-1797.

Strzalka, A., Szafran, M. J., Strick, T., and Jakimowicz, D. (2017). C-terminal lysine repeats in Streptomyces topoisomerase I stabilize the enzyme-DNA complex and confer high enzyme processivity. Nucleic Acids Res, 45(20), 1190811924.

Sulis, G., Roggi, A., Matteelli, A., and Raviglione, M. C. (2014). Tuberculosis: epidemiology and control. Mediterr J Hematol Infect Dis, 6(1), e2014070.

Suski, C., and Marians, K. J. (2008). Resolution of converging replication forks by RecQ and topoisomerase III. Mol Cell, 30(6), 779-789.

Takiff, H., and Guerrero, E. (2011). Current prospects for the fluoroquinolones as first-line tuberculosis therapy. Antimicrob Agents Chemother, 55(12), 5421-5429.

Tan, K., Cao, N., Cheng, B., Joachimiak, A., and Tse-Dinh, Y. C. (2016). Insights from the Structure of Mycobacterium tuberculosis Topoisomerase I with a Novel Protein Fold. J Mol Biol, 428(1), 182-193. 
Tan, K., Zhou, Q., Cheng, B., Zhang, Z., Joachimiak, A., and Tse-Dinh, Y. C. (2015). Structural basis for suppression of hypernegative DNA supercoiling by $E$. coli topoisomerase I. Nucleic Acids Res, 43(22), 11031-11046.

Tang, J., Yam, W. C., and Chen, Z. (2016). Mycobacterium tuberculosis infection and vaccine development. Tuberculosis (Edinb), 98, 30-41.

Terekhova, K., Gunn, K. H., Marko, J. F., and Mondragon, A. (2012). Bacterial topoisomerase I and topoisomerase III relax supercoiled DNA via distinct pathways. Nucleic Acids Res, 40(20), 10432-10440.

Terekhova, K., Marko, J. F., and Mondragon, A. (2013). Studies of bacterial topoisomerases I and III at the single-molecule level. Biochem Soc Trans, 41(2), 571-575.

Terekhova, K., Marko, J. F., and Mondragon, A. (2014). Single-molecule analysis uncovers the difference between the kinetics of DNA decatenation by bacterial topoisomerases I and III. Nucleic Acids Res, 42(18), 11657-11667.

Tomasic, T., and Masic, L. P. (2014). Prospects for developing new antibacterials targeting bacterial type IIA topoisomerases. Curr. Top. Med. Chem, 14, 130-151.

Travers, A., and Muskhelishvili, G. (2015). DNA structure and function. FEBS J, 282(12), 2279-2295.

Tse, Y. C., Kirkegaard, K., and Wang, J. C. (1980). Covalent bonds between protein and DNA. formation of phosphotyrosine linkage between certain DNA topoisomerases and DNA. J. Biol. Chem., 255, 15.

Tse-Dinh, Y.-C. (1998). Bacterial and archeal type I topoisomerases. Biochimica et Biophysica Acta, 1400, 19-27

Tse-Dinh, Y.-C., and Beran-Steed, R. K. (1988). Escherichia coli DNA Topoisomerase I Is a Zinc Metalloprotein with Three Repetitive Zinc-binding Domain. J. Biol. Chem., 263(31), 15857-15869. 
Tse-Dinh, Y. C. (1986). Uncoupling of the DNA breaking and rejoining steps of Escherichia coli type I DNA topoisomerase. Demonstration of an active covalent protein-DNA complex. J. Biol. Chem., 261, 5.

Tse-Dinh, Y. C. (2009). Bacterial topoisomerase I as a target for discovery of antibacterial compounds. Nucleic Acids Res, 37(3), 731-737.

Tse-Dinh, Y. C. (2015). Targeting bacterial topoisomerase I to meet the challenge of finding new antibiotics. Future Med Chem, 7(4), 459-471.

Veatch, A. V., and Kaushal, D. (2017). Opening Pandora's Box: Mechanisms of Mycobacterium tuberculosis Resuscitation. Trends Microbiol, 26(2).

Venketaraman, V., Kaushal, D., and Saviola, B. (2015). Mycobacterium tuberculosis. J Immunol Res, 2015, 857598.

Venturini, E., Turkova, A., Chiappini, E., Galli, L., de Martino, M., and Thorne, C. (2014). Tuberculosis and HIV co-infection in children. BMC Infect Dis, 14 Suppl $1, \mathrm{~S} 5$.

Viard, T., and de la Tour, C. B. (2007). Type IA topoisomerases: a simple puzzle? Biochimie, 89(4), 456-467.

Vologodskii, A. (2010). DNA supercoiling helps to unlink sister duplexes after replication. Bioessays, 32(1), 9-12.

Vos, S. M., Tretter, E. M., Schmidt, B. H., and Berger, J. M. (2011). All tangled up: how cells direct, manage and exploit topoisomerase function. Nat Rev Mol Cell Biol, 12(12), 827-841.

Wang, J. C. (1979). Helical repeat of DNA insolution. Proc Natl Acad Sci U S A, 76 (1), 200-203.

Wang, J. C. (2002). Cellular roles of DNA topoisomerases: a molecular perspective. Nat Rev Mol Cell Biol, 3(6), 430-440. 
WHO. (2017). Global Tuberculosis Report 2017. [GLOBAL TUBERCULOSIS REPORT 2017].

Wilby, K. J., Ensom, M. H., and Marra, F. (2014). Review of evidence for measuring drug concentrations of first-line antitubercular agents in adults. Clin Pharmacokinet, 53(10), 873-890.

Wu, L., Liu, Y., and Kong, D. (2014). Mechanism of chromosomal DNA replication initiation and replication fork stabilization in eukaryotes. Sci China Life Sci, 57(5), 482-487.

Zhang, Z., Cheng, B., and Tse-Dinh, Y. C. (2011). Crystal structure of a covalent intermediate in DNA cleavage and rejoining by Escherichia coli DNA topoisomerase I. Proc Natl Acad Sci U S A, 108(17), 6939-6944.

Zhu, C. X., Roche, C. J., Papanicolaou, N., DiPietrantonio, A., and Tse-Dinh, Y. C. (1998). Site-directed mutagenesis of conserved aspartates, glutamates and arginines in the active site region of Escherichia coli DNA topoisomerase I. J. Biol. Chem., 273(15), 8783-8789. 
VITA

\section{NAN CAO}

2003-2007

B.S., Bioengineering China Pharmaceutical University

Nanjing, Jiangsu, China

2007-2009

Research associate, Biomedicine department

Shanghai Institute of Pharmaceutical Industry

Shanghai, China

2011-2012

M.A., Biological science

Mississippi college

Clinton, MS

2012-2013 Teaching Assistant

Florida International University

Miami, FL

2013-2016 Research Assistant

Florida International University

Miami, FL

2017-2018 Research Assistant

Florida International University

Miami, FL

\section{PUBLICATIONS}

Dong, Y., Cao, N., Zhu, Y., Zhang, X., Feng, J. (2010) Study on Preparation of Pramlintide, Chinese Journal of Pharmaceuticals, 41(11), 82-84.

Tan, K., Cao, N., Cheng, B., Joachimiak, A., and Tse-Dinh, Y. C. (2016). Insights from the Structure of Mycobacterium tuberculosis Topoisomerase I with a Novel Protein Fold. J Mol Biol, 428(1), 182-193.

Banda, S., Cao, N., and Tse-Dinh, Y. C. (2017). Distinct Mechanism Evolved for Mycobacterial RNA Polymerase and Topoisomerase I Protein-Protein Interaction. J Mol Biol, 429(19), 2931-2942. 
Cao, N., Tan, K., Annamalai, T., Joachimiak, A., and Tse-Dinh, Y. C. (2018). Investigating mycobacterial topoisomerase I mechanism from the analysis of metal and DNA substrate interactions at the active site. Nucleic Acids Res.

Cao $\mathrm{N}$ and Tse-Dinh YC. Mechanism and Function of Subdomains in Mycobacterial Topoisomerase I C-terminal Domain. (In preparation)

Cao, N., and Tse-Dinh, Y.C. Targeting Topoisomerase III in protozoan parasite Trypansoma brucei. Gordon research conferences-DNA Topoisomerases in Biology \& Medicine, August 10-15, 2014, Newry, Maine.

Cao, N., and Tse-Dinh, Y.C. Targeting Topoisomerase III in protozoan parasite Trypansoma brucei. FIU Chemistry Department Annual Visitation Day, March 7, 2014, Miami, Florida.

Cao, N., and Tse-Dinh, Y.C. Functional Characterization of Mycobacterial Topoisomerase I C-terminal Domain. FIU Graduate Student Appreciation Week, April 6 2015, Miami, Florida.

Cao, N., and Tse-Dinh, Y.C. Functional Characterization of Mycobacterial Topoisomerase I C-terminal Domain. Florida Annual Meeting and Exposition (FAME), May 8, 2015, Tampa, Florida.

Cao, N., and Tse-Dinh, Y.C. Functional Characterization of Mycobacterial Topoisomerase I C-terminal Domain. Gordon research conferences-DNA Topoisomerases in Biology \& Medicine, August 7-12, 2016, Newry, Maine. 